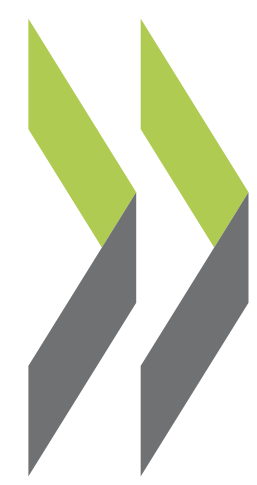

OECD Local Economic and Employment Development (LEED) Papers 2011/16

Leveraging Training Skills Development in SMEs: An \title{
Analysis of OSTIM
} Sirin Elci

Organised Industrial Zone, Turkey 

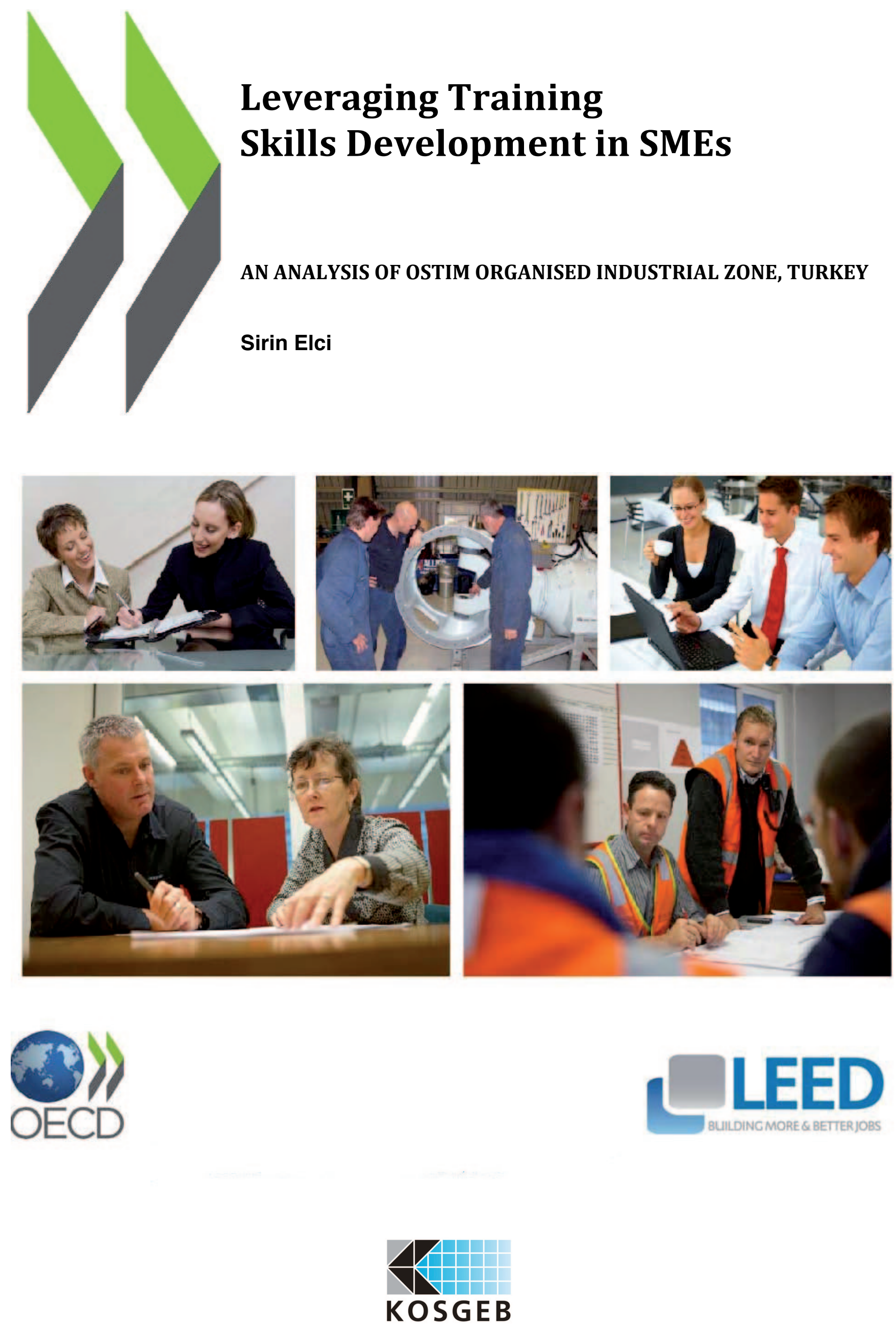



\section{LEVERAGING TRAINING}

\section{SKILLS DEVELOPMENT IN SMES}

AN ANALYSIS OF OSTIM ORGANISED INDUSTRIAL ZONE, TURKEY

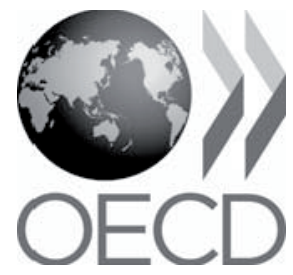




\title{
ABOUT THE OECD
}

The Organisation for Economic Co-operation and Development (OECD) is a unique forum where the governments of 30 market democracies work together to address the economic, social and governance challenges of globalisation as well as to exploit its opportunities. The OECD's way of working consists of a highly effective process that begins with data collection and analysis and moves on to collective discussion of policy, then decision-making and implementation. Mutual examination by governments, multilateral surveillance and peer pressure to conform or reform are at the heart of OECD effectiveness.

Much of the material collected and analysed at the OECD is published on paper or online; from press releases and regular compilations of data and projections to one-time publications or monographs on particular issues; from economic surveys of each member country to regular reviews of education systems, science and technology policies or environmental performance. For more information on the OECD, please visit www.oecd.org/about.

\begin{abstract}
About LEED
The OECD Programme on Local Economic and Employment Development (LEED) has advised government and communities since 1982 on how to respond to economic change and tackle complex problems in a fast-changing world. It draws on a comparative analysis of experience from some 50 countries in the Americas, Asia, Australasia and Europe in fostering economic growth, employment and inclusion. For more information on the LEED Programme, please visit www.oecd.org/cfe/leed.
\end{abstract}

\section{Note on the author}

This country report was prepared by Sirin Elci, who is the founder and director of Technopolis Group Turkey. She has a professional experience of 20 years, around 16 in S\&T and innovation policies; enterprise, entrepreneurship, and innovation development actions. She is also teaching Innovation Policy to the MS and PhD students at the S\&T Policy Studies Programme of the Middle East Technical University in Ankara. During her career, she has provided advice and support to the international organisations (EC, World Bank, OECD, UNESCO, UNDP, etc.), and a variety of government departments, regional authorities and organisations in Turkey and abroad. She also participates in a number of international and national associations and networks on entrepreneurship and innovation, provides mentoring to youngsters and entrepreneurs all over the world, and sits on the board of several SMEs and NGOs.

The views contained in this report are those of the author and do not necessarily represent those of the OECD or its member governments.

\section{ISSN 2079-4797 (PDF)}

OECD Local Economic and Employment Development (LEED) Working Paper Series.

This report is part of a series of working papers from the OECD Local Economic and Employment Development (LEED) Programme. The LEED Programme identifies, analyses and disseminates innovative ideas for local development, governance and the social economy. Governments from OECD member and non-member economies look to LEED and work through it to generate innovative guidance on policies to support employment creation and economic development through locally based initiatives. 


\title{
PREFACE
}

The qualified labor force is one of the critical and indispensable components of the Turkish industrial sector, which has a tendency to expand in recent years with an impetus. In line with the rapid growth of Turkey, human resources are crucially needed for a productive economy. On the other hand, studies indicate the lack of a qualified labor force, which is critically important for the developing economies, in Turkish private sector. The vocational education and training system in Turkey has to be improved, especially since Turkey is now a candidate to be a full-fledged member of the European Union.

Small and Medium Enterprises (SMEs), contrary to big enterprises, could not solve unqualified labor problems within their organizational system. Therefore, KOSGEB has played a significant role by organizing various training and support programs for SMEs. While delivering training facilities to SMEs, assessing the needs and ensuring the SMEs' participation have been detected as critical issues, both the employer and employees perceptions on the importance of the training need to be improved.

Turkey has decided to participate in the Leveraging Training and Skills Development in SMEs Project, which is implemented by the OECD along with another five countries in order to develop new strategies and support mechanisms for public policy makers and to also identify the behaviours of SMEs on vocational and technical training.

During the survey process of the project, a case study region, OSTIM OIZ (Organised Industrial Zone) one of Turkey's largest small and medium sized industrial zones located in Ankara, is selected along with five other countries which are participating in this project. With approximately 40-years of production experience, five thousand enterprises operating in eight main sectors, 118 business segments and 50 thousand employees, OSTIM OIZ is an exemplary role model of its kind in Turkey. The Turkey Country Report for the project is prepared with fruitful and valuable cooperation and contribution from the OSTIM OIZ Management.

Awareness of SMEs to training is one of the main factors that directly affect their business life. Moreover, well-trained staffs always carry the responsibility of the job, are able to use initiative and have the capacity to lead the business forward.

Undoubtedly, the findings and recommendations in the report will bring new perspectives to SME-related policies of Turkey about training and also contribute to the targets for the year 2023, Turkey's 100th anniversary year of establishment.

\author{
Mustafa KAPLAN \\ President \\ Small and Medium Size Enterprises Development and Support Organisation \\ Ministry of Industry and Trade
}





\section{ACKNOWLEDGEMENTS}

The author is grateful to the many people who have helped with the research for this report. Sylvain Giguère and Dr. Cristina Martinez-Fernandez at the OECD LEED Programme designed the methods used in the research as part of a wider international project. Dr. Martinez-Fernandez, the co-ordinator of the entire "Training and Skills development in SMEs" (TSME) project supervised the international project and all the phases of its Turkish part (including preparation of this final report). Also to Mr. Damian Garnys who managed the survey platform process and prepared the report for publication. The project has been supported by the European Commission.

The project was implemented in partnership with the SME Development and Support Organisation (KOSGEB). Mr. Murat Demirez and Mr. Fatih Buyukfidan from the Regional and Local Development Department of KOSGEB were directly responsible for the project and they greatly contributed towards its results. KOSGEB's OSTIM branch (KOSGEB Ankara OSTIM Service Centre) provided valuable support during the course of the field research.

Extensive support of OSTIM and ODEM management teams, in particular, Ms. Burcu Ozturk, Mr. Hakan Unsal and Ms. Gulnaz Karaosmanoglu during the surveys, field visits and the regional workshop was highly appreciated.

The whole research team is very grateful to those people who participated in the surveys, to all the participants in the skills ecosystem workshop and to the managers of SMEs who made themselves available to be interviewed. Finally, the team is very grateful to the researchers who conducted the survey interviews; Ms. Ozge Eyigun, Ms. Gozde Kose and Mr. Serkan Atmaca from Technopolis Group Turkey. 



\section{TABLE OF CONTENTS}

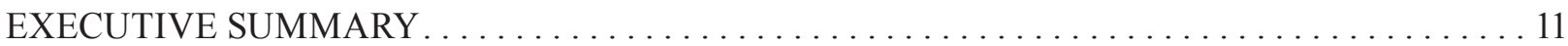

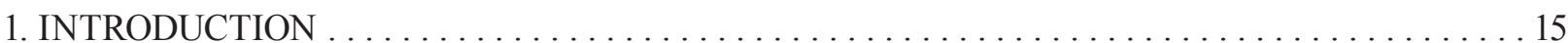

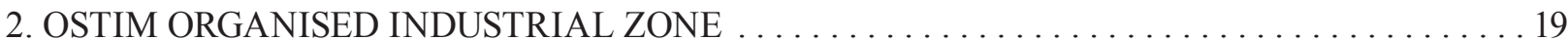

3. RESULTS OF THE FIELD RESEARCH $\ldots \ldots \ldots \ldots \ldots \ldots \ldots \ldots \ldots \ldots \ldots \ldots \ldots \ldots \ldots \ldots$

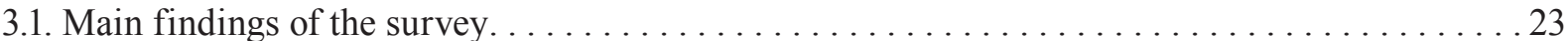

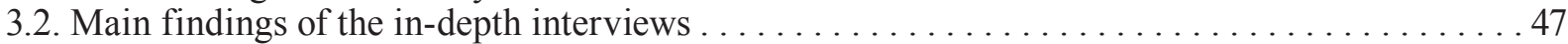

3.3. Findings of the workshop: the regional skills and training ecosystem in OSTIM . . . . . . . . 54

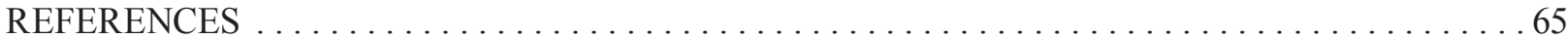

ANNEX A. BRIEF INFORMATION ABOUT SME DEVELOPMENT AND SUPPORT

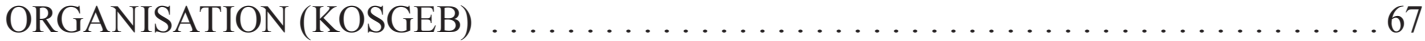

ANNEX B. TECHNICAL AND VOCATIONAL EDUCATION SYSTEM, AND GENERAL STRUCTURE OF HIGHER EDUCATION IN TURKEY . . . . . . . . . . . . . . . 69

ANNEX C. PARTICIPANTS OF ECOSYSTEM WORKSHOP $\ldots \ldots \ldots \ldots \ldots \ldots \ldots \ldots \ldots \ldots \ldots \ldots 71$

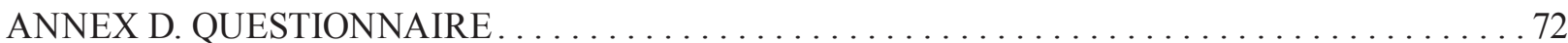

Figures

Figure $1 \quad$ Respondent enterprises by age. . . . . . . . . . . . . . . . . . . . . . . . . . . . . 24

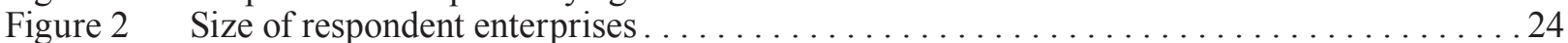

Figure 3 Responding enterprises by number of apprentices/trainees $\ldots \ldots \ldots \ldots \ldots \ldots \ldots \ldots 25$

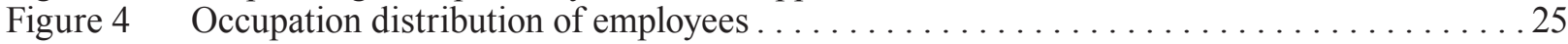

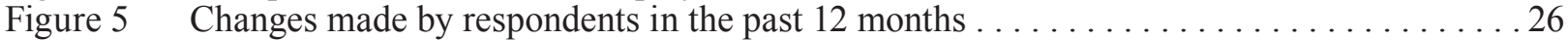

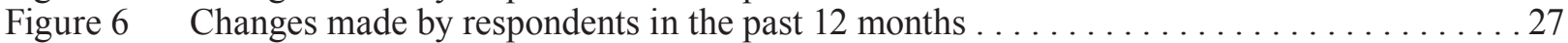

Figure 7 Areas where additional training is needed over the next twelve months . . . . . . . . . 27

Figure $8 \quad$ VET activities participated by SMEs over the past twelve months. . . . . . . . . . . . . . 29

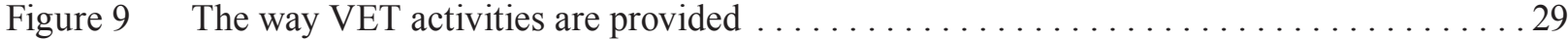

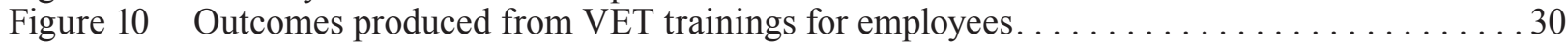

Figure 11 Outcomes produced from outcomes produced from VET for business, local area and

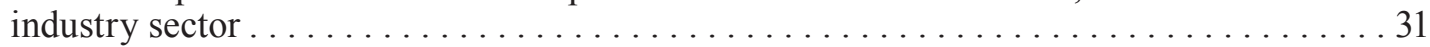


Figure 12 The main reasons for not carrying out VET in the past 12 months $\ldots \ldots \ldots \ldots \ldots 32$

Figure 13 KISA carried out by firms in the past 12 months $\ldots \ldots \ldots \ldots \ldots \ldots \ldots \ldots \ldots \ldots \ldots \ldots$

Figure 14 Importance of the groups in KISA of firms during the past 12 months . . . . . . . . 34

Figure 15 Outcomes produced for employees as a result of KISA $\ldots \ldots \ldots \ldots \ldots \ldots \ldots \ldots . \ldots 34$

Figure 16 Outcomes produced for businesses, industry sector and local area as a result of KISA. . . 35

Figure 17 Comparison of KISA with VET courses as sources of learning for staff . . . . . . . . . 36

Figure 18 The reasons for respondent SMEs to undertake training and skills development activities

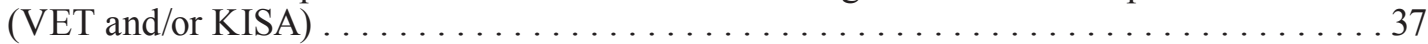

Figure 19 The organisations with whom respondent SMEs associate for VET and KISA . . . . . . . 38

Figure 20 The organisations named by respondent SMEs as counterparts for VET and KISA . . . . 39

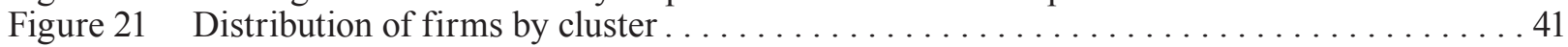

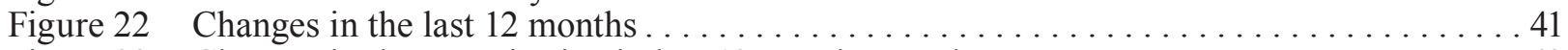

Figure 23 Changes in the organisation in last 12 months per cluster $\ldots \ldots \ldots \ldots \ldots \ldots \ldots \ldots 43$

Figure 24 VET activities VET activities participated by SMEs over the past twelve months . . . . .44

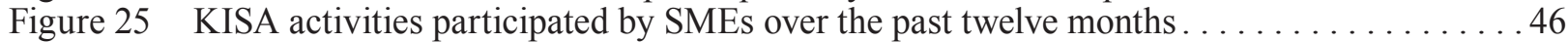

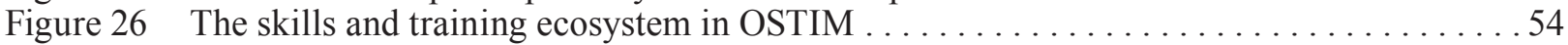

\section{Tables}

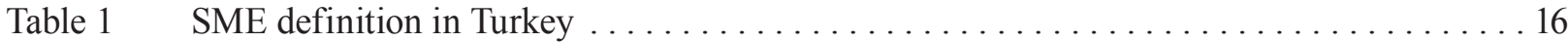

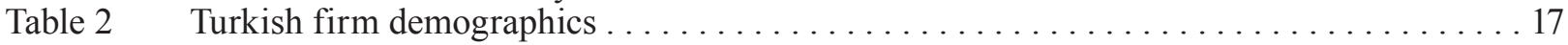

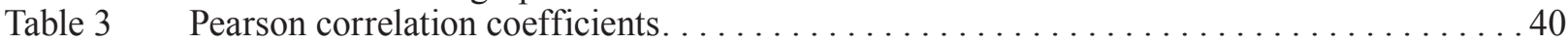

Table $4 \quad$ Institutionalisation of training activities in clusters $\ldots \ldots \ldots \ldots \ldots \ldots \ldots \ldots \ldots \ldots 42$

Table $5 \quad$ A summary of findings from in-depth interviews $\ldots \ldots \ldots \ldots \ldots \ldots \ldots \ldots \ldots \ldots \ldots \ldots \ldots \ldots$

\section{Box}

Box 1 The role of regional universities in the development of OSTIM clusters: the case of Cankaya University . . . . . . . . . . . . . . . . . . . 20 


\section{EXECUTIVE SUMMARY}

This report presents the findings and analysis of the research conducted in Turkey as part of the international project on Leveraging Training and Skills in SMEs. The project has been implemented by the Local Employment and Economic Development (LEED) Programme at the Organisation for Economic Co-operation and Development (OECD) in collaboration with the Small and Medium Entreprise Development and Support Organisation (KOSGEB) in Turkey. The study in Turkey focused on the OSTIM Organised Industrial Zone in Ankara, which, similar to the other industrial zones, provides necessary infrastructure dedicated to manufacturing companies.

The project mainly investigated both the formal/vocational education and training (VET), and informal learning resulting from daily activities of firms related to work that is not organised in terms of objectives, time or learning support (the so-called "Knowledge Intensive Service Activities" or KISA). The research conducted for this purpose consisted of the questionnaire surveys (which were responded to by 108 SMEs in OSTIM), the indepth interviews with five randomly selected firms, and the workshop organised with the stakeholders of trainings and skills development ecosystem. Since OSTIM has four industrial clusters (namely, construction and engineering machines cluster, medical industry cluster, defence industry cluster and renewable energy cluster), developed since 2007, the research also included a comparative analysis of these clusters.

The survey findings indicated that the majority of SMEs do not attach importance to training and skills development (only $28 \%$ of SMEs declared that they received VET and $25 \%$ stated that they participated in KISA over the last 12 months). As for the fields of training, companies mainly focus on organisational health \& safety and job-specific technical training, while green skills receive the least attention from SMEs. The majority of firms neither have a department nor a staff responsible for human resources. It also found that training (both VET and KISA) opportunities are not equally distributed among staff at firms. They are mainly offered to high-medium skilled employees rather than low skilled staff. Another finding is that the majority of SMEs cannot provide an assessment on the outcomes of training (both VET and KISA) for business, local area and industry sectors, which, in turn, may have a negative effect on the level of interest in training activities. While SMEs state that the costs involved in training as well as the lack of public finance are the main reasons for not carrying out training, a relatively large number of low-cost VET and KISA providers and public finance providers are accessible and active in the zone (perhaps more than any other organised industrial zone in Turkey). The correlation analysis confirmed the benefit of investment in training and skills development on innovation activities of SMEs: the existence of a formal training plan and training budget positively affects the innovation activities of SMEs. Investment in green skills development (particularly through KISA) has a positive impact on green innovations. Furthermore, KISA on entrepreneurship positively affects management innovations and operation innovations (which is not observed in the case of VET). 
Since the clusters in OSTIM are still in the embryonic stage of development, positive outcomes and impacts of clusters on firm behaviour, including those on training and skills development, are not yet observed. For example, a relatively large number of SMEs state that they do not need to develop social skills of their employees. In general, the results of cluster level analysis revealed that clusters in OSTIM show varying levels of innovation performance and training and skills development investments. Similar to all other SMEs, which responded to the questionnaire, cluster firms also attach greater importance to organisational health \& safety and job-specific technical training than any other training topic.

The in-depth interviews showed SMEs, in general, attach importance to technical training and for this purpose they usually consider masters degree programmes for highskilled workers and free-of-charge training organised by local and regional non-profit organisations for low-tech staff. SMEs consider government R\&D support programmes as the key sources of KISA which help them develop their staff, giving them the skills and competences required for product development and production improvements. The interviews also highlighted low levels of collaboration and interaction between organisations in OSTIM.

The training and skills ecosystem workshop verified the results of the field research and provided explanations about the reasons for the key findings: for example, the workshop participants explained that the majority of the SMEs are family-owned enterprises which, in general, are not institutionalised. It depends on the vision and/or willingness of the owner of the company to invest in training. Most of the time, SME owners think that investment in training equals a waste of money but at the same time never consider the cost of continuing to employ staff without proper training/skills. There is the fear that trained personnel would leave the company when their skill levels increase after training. The workshop revealed the need for collaboration and communication between the public organisations and NGOs responsible for training/skills development in SMEs, as well as the need for enhancing the governance system at local, regional and national level in order to eliminate overlaps and fill the gaps in the system.

In light of the research results, the following recommendations are suggested under two main categories:

\section{Investing in training and skills development in SMEs}

- Raise awareness among SMEs on the need for training and skills development through various means, for example by

- giving right messages on wrong perceptions, such as "Training has little impact on job mobility, despite employer fear about trained staff being poached by rivals and so losing their investment" and "It is much more expensive not to train the people";

- identifying and disseminating success stories of SMEs from different sectors which continuously invest in training and skills development;

- particularly targeting cultural change among SME owners/managers.

- Design and implement policy measures

- to stimulate training and skills development for low-skilled workers;

- $\quad$ specific to micro enterprises' needs on training and skills development; 
- to encourage institutionalisation of SMEs;

- $\quad$ to provide on-the-job coaching/mentoring to micro and small enterprises;

- $\quad$ to stimulate development of green skills, and innovation, entrepreneurship and social skills in SMEs;

- to encourage inter-firm collaboration and collaboration between SMEs and other actors in the system for training and skills development (also through effective cluster development programmes);

- Pay attention to developing a balanced policy mix on trainings and skills development. For this purpose, focus on segmentation of target groups to successfully address their needs in the area.

\section{Improving the ecosystem}

- Improve governance by assigning an oversight body for SME training \& skills development which carefully orchestrates co-operation among major players at national/regional/sectoral levels - KOSGEB can play this role effectively.

- Develop a balanced, effective and complementary set of training and skills development programmes by evaluating existing measures (in terms of their complementarities, effectiveness, efficiency, impact, relevance, coherence and sustainability), and by eliminating overlaps and multiplicities.

- Make sure that the main stakeholders in the system communicate and interact regularly and effectively (through meetings/workshops, etc). Regional level coordination can be achieved by the regional development agencies.

- Develop and implement tools to monitor and measure the impact of training and skills development at different levels.

- Modernise VET education and develop mechanisms to ensure that vocational schools \& universities collaborate with SMEs to keep their curricula relevant and current to the changing needs of companies.

- Conduct a skills gap analysis to identify critical work-force skills, analyse shortfalls, and develop strategies resolving these shortfalls.

- Provide regular training to the staff of the organisations providing SME services, including the public bodies implementing SME support programmes.

- Develop an accreditation system for the organisations providing training to SMEs. Also help them to continuously upgrade their services and improve their skills and capabilities through training-the-trainers schemes. 



\section{INTRODUCTION}

This report is an output of the research project on "Leveraging Training and Skills Development in SMEs" carried out by the Local Employment and Economic Development (LEED) Programme at the Organisation for Economic Co-operation and Development (OECD).

The project explores the participation of small and medium enterprises (SMEs) in training and skills developments at regional level. A number of regions from countries including Belgium, Canada, New Zealand, Poland, United Kingdom and Turkey have been selected to provide an understanding of how SMEs' approach to skills and training activities varies and to also provide insight into the best practices at the firm and local skills ecosystem level. The study is supported by the European Commission, DG Employment, Social Affairs and Equal Opportunities.

The project tackles the following questions:

- What is the impact of knowledge intensive/productivity enhancement activities on skills development in SMEs? What is the impact of these activities on employability of the labour force, specially the low qualified and older workers?

- How can SMEs increase the participation of the low-skilled and low-qualified, older workers in their knowledge intensive service/productivity enhancement activities? Which incentives can be provided to employers to increase this participation?

- How can the skills developed through informal activities be recognised in generating formal qualifications? What is the impact and returns of these activities for the firm?

- How can the different elements of the networking of SMEs with their supply chain and organisations from the local skills ecosystem where they are embedded, contribute to a greater participation of the labour force in training and skills development activities? What examples of best practices are available in OECD countries? What are the lessons for both productivity enhancement and workforce development?

The project mainly investigated both the formal/vocational education and training, and informal learning resulting from daily activities related to work that are not organised in terms of objectives, time or learning support (Knowledge Intensive Service Activities - KISA).

Vocational education and training (VET) includes education and training programmes designed for, and typically leading to, a particular job or type of job. It normally involves practical training as well as the learning of relevant theory. Initial VET includes programmes mainly designed for and used by young people (aged 30 and under) at the beginning of their careers and commonly before entering the labour market. It includes many upper secondary and tertiary programmes. Continuing VET is made up of all the other kinds of VET, including enterprise training of employees and training provided specifically for those who have lost their jobs (OECD 2009). 
Knowledge Intensive Service Activities (KISA) are defined as the activities originating from the production and integration of knowledge-intensive services and are crucial for the innovation process of the firm. They may be undertaken by firms in manufacturing or service sectors, and in combination with manufactured outputs or as stand-alone services (OECD, 2003). Typical examples of KISA include R\&D services, management consulting, IT services, human resource management services, legal services (such as those on IP-related issues), accounting and financing, and marketing services. Activities oriented towards the use and integration of knowledge are instrumental for building and maintaining a firm's innovation capability. In practice, KISA in a firm are achieved by the use of in-house, or the combination of in-house and external, expertise. The firm's capacity to perform these KISA more effectively may indeed be what differentiates a firm from its competitors (Martinez-Fernandez, 2006).

The project on "Leveraging Training and Skills Development in SMEs" is supported by the SME Development and Support Organisation (KOSGEB) in Turkey. The Turkish government established KOSGEB in 1990 in order to increase the value added and productivity of SMEs, and to enhance the competitiveness of SMEs in national and international markets. Reporting to the Ministry of Industry and Trade, KOSGEB plays a leadership role in supporting SMEs in all stages of their development.

The OSTIM Organised Industrial Zone in Ankara has been selected as the Turkish contribution to the study. Due to the characteristics of the zone, as explained in Section 1, SMEs investigated in this study were mainly manufacturing industry companies.

Similar to other developed and developing economies in the world, SMEs play a predominant role in Turkey. Turkey adopted the EU's SME definition in 2005. Accordingly, the SME definition in Turkey is as follows:

Table 1. SME definition in Turkey

\begin{tabular}{lccc}
\hline Scale & Headcount & $\begin{array}{c}\text { Annual turnover } \\
\text { (million TL) }\end{array}$ & $\begin{array}{c}\text { Annual Balance Sheet } \\
\text { (million TL) }\end{array}$ \\
\hline Micro & $1-9$ & $\leq 1(\sim 0.8$ USD) & $\leq 1$ \\
Small & $10-49$ & $\leq 5(\sim 4$ USD) & $\leq 5$ \\
Medium & $50-249$ & $\leq 25(\sim 20$ USD) & $\leq 25$ \\
\hline
\end{tabular}

Source: KOSGEB.

SMEs form $99.9 \%$ of all companies in the country. They account for $81.3 \%$ of total employment and but only $57 \%$ of value added. The share of micro enterprises in SMEs is remarkably high (98.1\%). The share of employment created by SMEs in the industry sector is lower than that of the services sector, and industry sector generate less value added than services (Table 2.).

The first section of this report gives brief information about the region (OSTIM) which is under study. The second section presents an analysis of the findings from the field research; namely, the questionnaire surveys responded to by 108 SMEs in OSTIM, the indepth interviews with five randomly selected firms, and the workshop organised with the stakeholders of training and skills development ecosystem. Conclusions and recommendations are presented in the last section. 
Table 2. Turkish firm demographics

Structural indicators on enterprise population, 2006

\begin{tabular}{|c|c|c|c|c|c|c|c|c|c|c|c|c|c|}
\hline & \multicolumn{5}{|c|}{ Number of enterprises } & \multicolumn{5}{|c|}{ Total employment } & \multicolumn{3}{|c|}{ Value added (factor costs) } \\
\hline & \multicolumn{2}{|c|}{ Industry } & \multicolumn{2}{|c|}{ Services } & \multirow{2}{*}{$\begin{array}{c}\text { Total } \\
\% \\
\end{array}$} & \multicolumn{2}{|c|}{ Industry } & \multicolumn{2}{|l|}{ Services } & \multirow{2}{*}{$\begin{array}{c}\text { Total } \\
\% \\
\end{array}$} & Industry & Services & Total \\
\hline & No. firms & $\%$ & No. firms & $\%$ & & No. engaged & $\%$ & No. engaged & $\%$ & & & $\%$ & \\
\hline Micro & 383577 & 93.8 & 1889647 & 99.1 & 98.1 & 1113081 & 32.5 & 3512942 & 75.9 & 57.4 & 12.2 & 44.4 & 28.2 \\
\hline Small & 16149 & 3.9 & 12190 & 0.6 & 1.2 & 521934 & 15.2 & 314797 & 6.8 & 10.4 & 11.1 & 11.5 & 11.3 \\
\hline Medium & 7795 & 1.9 & 4362 & 0.2 & 0.5 & 799763 & 23.3 & 286359 & 6.2 & 13.5 & 21.7 & 13.2 & 17.5 \\
\hline SMEs & 407521 & 99.6 & 1906199 & 100.0 & 99.9 & 2434778 & 71.1 & 4114098 & 88.9 & 81.3 & 45.0 & 69.1 & 57.0 \\
\hline Large & 1537 & 0.4 & 938 & 0.0 & 0.1 & 991465 & 28.9 & 514680 & 11.1 & 18.7 & 55.0 & 30.9 & 43.0 \\
\hline
\end{tabular}

Source: OECD (2010) SMEs, Entrepreneurship and Innovation (OECD, Structural and Demographic Business Statistics). 



\section{OSTIM ORGANISED INDUSTRIAL ZONE}

Established in 1967 in Ankara, Turkey, the Middle East Industry and Trade Centre (OSTIM) was granted the status of "organised industrial zone" by the Ministry of Industry and Trade in 1997.

An "organised industrial zone" is an area with a necessary infrastructure dedicated to the manufacturing industry. These zones aim to ensure that industrial activities are carried out in appropriate places enabling the manufacturing sector to locate and develop according to a pre-defined plan while preventing environmental problems.

The zones are governed under the Law No. 4562 of 12 April 2000, and the regulatory oversight is undertaken by the Ministry of Industry and Trade. The managing companies of the zones are in charge of the provision of the following services: permanent and secure supply of electricity, water and gas; construction and maintenance of roads; security; access to internet and web-hosting; fire brigade, fire training, first aid and fully equipped ambulance services; establishment of environmental administration, follow up to environmental permissions, waste management, etc; provision of information on permission for construction and development, maps and controls, permissions, licenses for new buildings, expansions, renovations; sale of food for employees, catering and conference rooms.

As of 2010, there are 120 OIZs in Turkey hosting 37,000 firms, which employ 820,000 people.

OSTIM is one of the leading zones in the country. It is located over 500 hectares and hosts around 5,000 companies (mainly manufacturing SMEs) which generate approximately 50,000 jobs. The main sectors in the region are machine construction, metal processing, machine and machine parts, plastics and rubber, electric and electronics, medical equipment, automotive and defence. $20 \%$ of firms in OSTIM are exporters and a majority of them are suppliers to the big manufacturers in Turkey.

The management company of OSTIM is very active in terms of providing a broad range of services and facilities to the firms operating in the zone: it operates a number of subsidiaries from an employment office to a trade fair organisation firm, and from an energy company to a TV and radio station.

One of the key subsidiaries of OSTIM in the area of training and skills development is its consultancy and training company called ODEM. ODEM conducts training and consultancy needs assessment, matches SMEs with consultants in its database, organises low cost training courses and assists with technology transfer and networking. One of the strengths of ODEM is that its experts carry out continuous firm level assessment and monitoring for keeping up-to-date with the changing needs of individual SMEs and providing them with the required training and consultancies. It also acts as an intermediary between SMEs and those providing training and public support for training and consultancy. Another activity of ODEM is to train and educate human resources to be employed by local SMEs as intermediate workers through the employment office of OSTIM. 
In addition to ODEM, OSTIM hosts a number of training and education facilities: an apprenticeship school, a vocational training centre, vocational high schools of two regional universities (Fatih and Hacettepe), a technical and industrial education school, a vocational training and technology centre.

KOSGEB has a local branch (the so-called "KOSGEB Ankara OSTIM Service Centre") located in the zone to provide SMEs with necessary supports for growth and competitiveness. Other important infrastructures in OSTIM include an extension of the technopark of the Middle East Technical University (METU) hosting 60 R\&D intensive companies and a joint research centre established with the same university.

OSTIM is also active in developing clusters in various sectors. There are four clusters being developed since 2007 together with regional universities:

- Construction and engineering machines cluster was initiated by the OSTIM management company in 2007 together with Cankaya University and other national/ regional/sectoral stakeholders. Number of member firms in the cluster is 80 .

- Medical industry cluster was created by the OSTIM management company with KOSGEB, METU, Baskent University, Fatih University and other national/ regional/sectoral stakeholders. The number of member firms is 44 .

- Defence industry cluster was initiated in 2007 by the OSTIM management company in partnership with KOSGEB, METU and other national/regional/sectoral stakeholders. Number of member firms in the cluster as of 2010 is 69.

- Renewable energy cluster was developed by the OSTIM management company together with KOSGEB, Hacettepe University, METU, Baskent University, Cankaya University and other national/regional/sectoral stakeholders since 2008. The cluster has 68 members.

\section{Box 1. The role of regional universities in the development of OSTIM clusters: the case of Cankaya University}

The regional universities in Ankara have been the driving force in the development of four clusters in OSTIM. Particularly, Cankaya University contributed to the idea of developing clusters in the region for enhanced competitiveness and greater market share.

The preparation studies started in 2007 under the leadership of OSTIM Chairman of the Board and the Rector of Cankaya University. They agreed to focus on the construction and engineering machines sector which is one of the leading sectors in the zone. A strategic plan setting the path the cluster will take was developed with the involvement of 40 firms operating in the sector and other regional stakeholders.

In order to institutionalise the efforts, a non-profit association was created by the end of 2008 . So far, the activities of clusters mainly focus on building trust between member companies through various events such as regular breakfast meetings.

At the same time, the cluster management took steps to develop partnerships and link the cluster with various regional and national networks. One example includes the partnership created between the cluster and the joint procurement company (OSO Corp-www.osoline. com) established with the support of the Undersecretariat of Foreign Trade in 2005 to facilitate a competitive procurement process for the machinery producers. The construction and engineering machines cluster in OSTIM signed a protocol with OSO from which member companies are now benefiting. 


\section{Box 1. The role of regional universities in the development of OSTIM clusters: the case of Cankaya University (continued)}

The university also initiated a number of programmes for its faculties to create linkages with the cluster companies. The students of Cankaya University and their academic advisors are encouraged to collaborate with SMEs in conducting their graduation projects by providing advice and/or carrying out research at cluster members. By end-2010, some 70 projects from engineering fields to finance and accountancy were completed by students. The students and academics are also making efforts to disseminate the results of these projects by organising seminars with the cluster members.

Cankaya University, together with OSTIM management, is implementing two projects with the funding from the Leonardo da Vinci programme of the European Union in partnership with European countries. Under these projects they organised two sets of trainings for SMEs in the cluster in 2009 and 2010 on various topics including strategic management, R\&D management and human resources management. Cankaya University is planning to increase and diversify training courses to develop skills and capabilities in cluster member companies. 



\section{RESULTS OF THE FIELD RESEARCH}

The field research for the study included a survey questionnaire sent to the OSTIM SMEs, interviews with randomly selected enterprises, company visits and a workshop organised with the participation of the stakeholders of the skills and training ecosystem.

The key findings from these studies are presented in the following sections.

\subsection{Main findings of the survey}

An on-line survey was conducted with the SMEs in the OSTIM organised industrial zone. The survey is divided into four sections: the first section asks for some details about the business and its employees. Section two asks about the business' use of industry and skills development training/vocational education and training (VET) activities. Section three asks about other ways of building the employees' skills, knowledge and competencies beyond training (KISA). Section four refers to the business collaborative activities and reasons for training and skills development.

The survey, prepared by the OECD, was implemented in two waves. The first wave was co-ordinated by KOSGEB and implemented in co-operation with OSTIM management unit. The SMEs in the OSTIM database were contacted through e-mail and invited to complete the on-line questionnaire. In addition, OSTIM management organised face-to-face interviews with the companies in defence clusters to collect the responses for the survey questions. Since the respond rate was lower than expected (58 firms replied to the questionnaire), a second wave of surveys, which was implemented through telephone interviews, was conducted by Technopolis Group. A total number of 108 SMEs were reached at the end of the two waves. The second wave of surveys particularly sought to cover all four clusters in OSTIM in order to allow a cluster level analysis. The findings from cluster level analysis are presented in Section 2.1.7 after the presentation of aggregate results.

\subsubsection{A brief profile of respondent enterprises}

Since the majority of the enterprises in OSTIM operate in manufacturing industry, $95 \%$ of respondents were from manufacturing sector (see below).

Responding enterprises by industry sector

\begin{tabular}{lc}
\hline Sector & Number of respondents \\
\hline Manufacturing & 103 \\
Fishing & 1 \\
Education & 1 \\
Construction & 1 \\
Real estate and rental & 1 \\
Transport, storage and communications & 1 \\
\hline
\end{tabular}


Nearly two-thirds of the respondent SMEs were older than 10 years. $15 \%$ of the enterprises were younger than 4 years (Figure 1).

Figure 1. Respondent enterprises by age

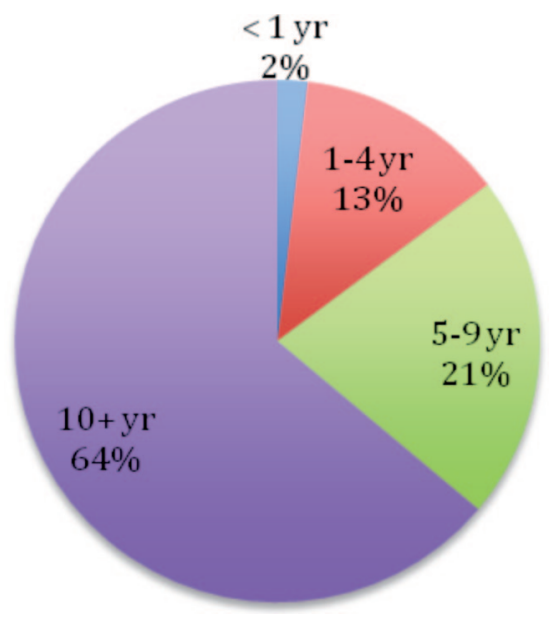

The majority of the respondents were small firms employing $10-49$ people (65\%). $24 \%$ of the enterprises were of micro size and the rest were medium enterprises (Figure 2).

\section{Figure 2. Size of respondent enterprises}

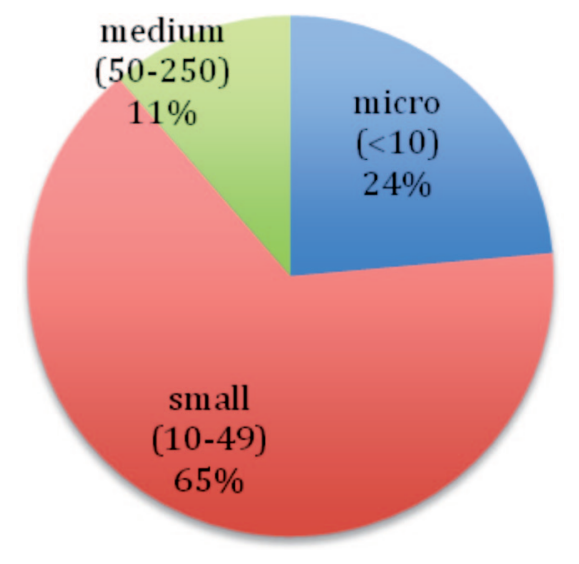

Majority of respondent SMEs (68\%) primarily sell their products to the national market. The rest sell their products locally $(16 \%)$ and internationally $(16 \%)$. Of a total of 3,224 employees working for the companies surveyed, $91 \%$ of the work force was identified as full-time by the respondents. The total number of employees reported as part-time was 22 . The number of casual workers was specified as 14 by the companies. $63 \%$ of respondents reported that they employ apprentices/trainees. A total number of 204 apprentices/ trainees are employed by all respondent enterprises (Figure 3). 
Figure 3. Responding enterprises by number of apprentices/trainees

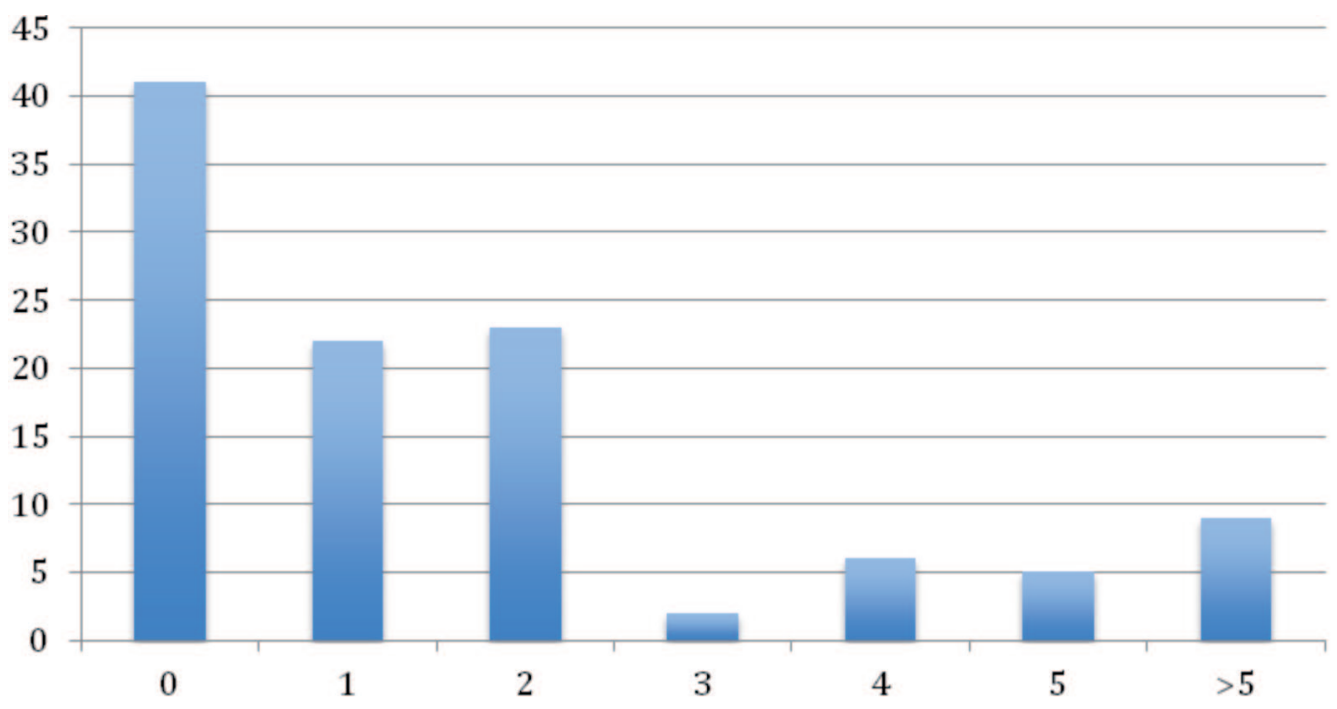

The majority of occupations of the staff were reported to be high-skilled (45\%), formed by manager and senior officials, professionals, and associate professional and technical occupations in the enterprises. Medium-skilled occupations (skilled trades, personal service, and sales and customer service occupations) constituted 30\% of occupations by respondents. $25 \%$ were reported as low skilled workers who are process, plant and machine operatives and elementary workers (Figure 4).

Figure 4. Occupation distribution of employees

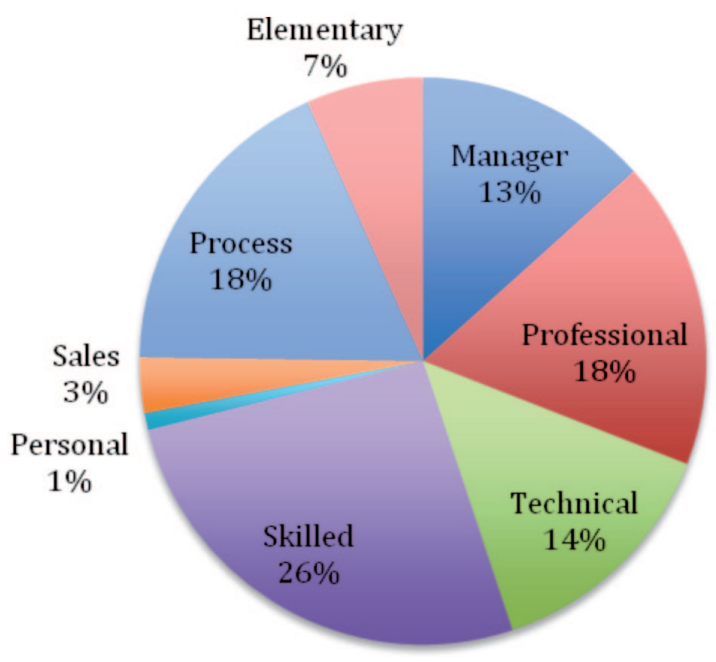

The majority of the workforce in respondent SMEs is younger than 50 years of age. $79 \%$ was identified as being between $25-49$ years old and $17 \%$ younger than 25 years old. Only 4\% of employees of all companies are between 50-64 years of age. 


\subsubsection{Changes in the last 12 months}

The respondents were asked whether they have conducted the following types of innovations in the previous year:

- A new product/service (or a substantially changed product/service)

- A new way of producing an existing product/service (e.g. a new operational process)

- Changes to the way your firm does things such as a new or substantially changed accounting system or human resource management system (e.g. a new management process)

- A new technology or equipment

- A new product/service/operation due to climate change adaptation/regulation

SMEs reported that they mainly implemented product, operation/process and technology changes (Figure 5). As also shown in below figure, a large portion of innovations made by respondents are incremental changes. Only 25 SMEs reported radical innovations.

Figure 5. Changes made by respondents in the past 12 months

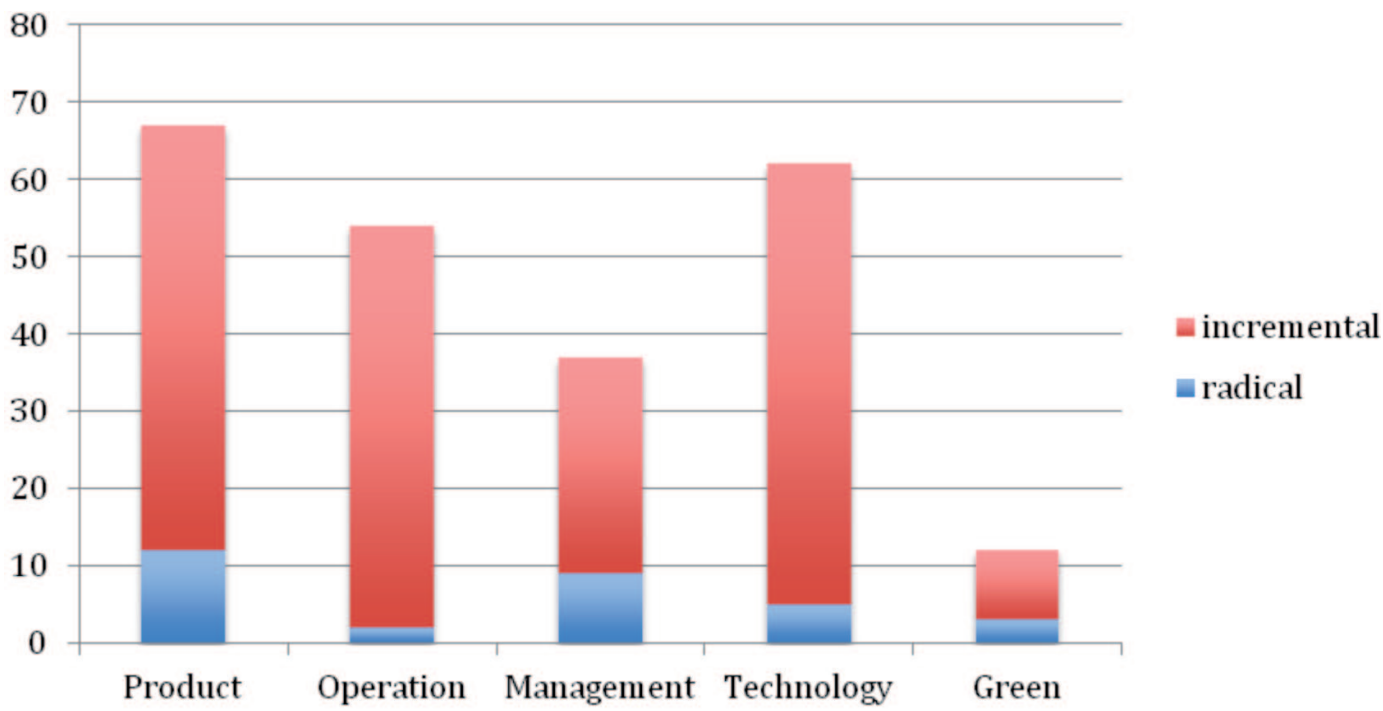

It is remarkable that the changes in the businesses in terms of introducing a new product/service/operation due to climate change adaptation/regulation were quite low: only 12 firms reported such changes. There were 11 "Don't know" replies on green innovations, which may be related to a low level of awareness and importance attached by SMEs to the subject.

Majority of the respondents declared that they increased the number of staff employed over the last 12 months (Figure 6). In addition, more than one-third of respondents also reported an increase in the number of employees provided with training, expenditures on training per employee and young employment.

The amount of formal training, leading to recognised qualifications, the number of apprentices and new trainees recruited, the proportion of total training delivered by external providers, the emphasis placed on informal learning instead of formal learning, 
employees with training and expenditures on training per employee stayed about the same in most of the enterprises that responded to the survey.

A relatively high number of SMEs marked the "Don't know/not answered" option in the questions about the amount of total training from external providers, formal training and the emphasis placed on informal learning is remarkable. Also, 16 enterprises did not respond to these questions.

Figure 6. Changes made by respondents in the past 12 months

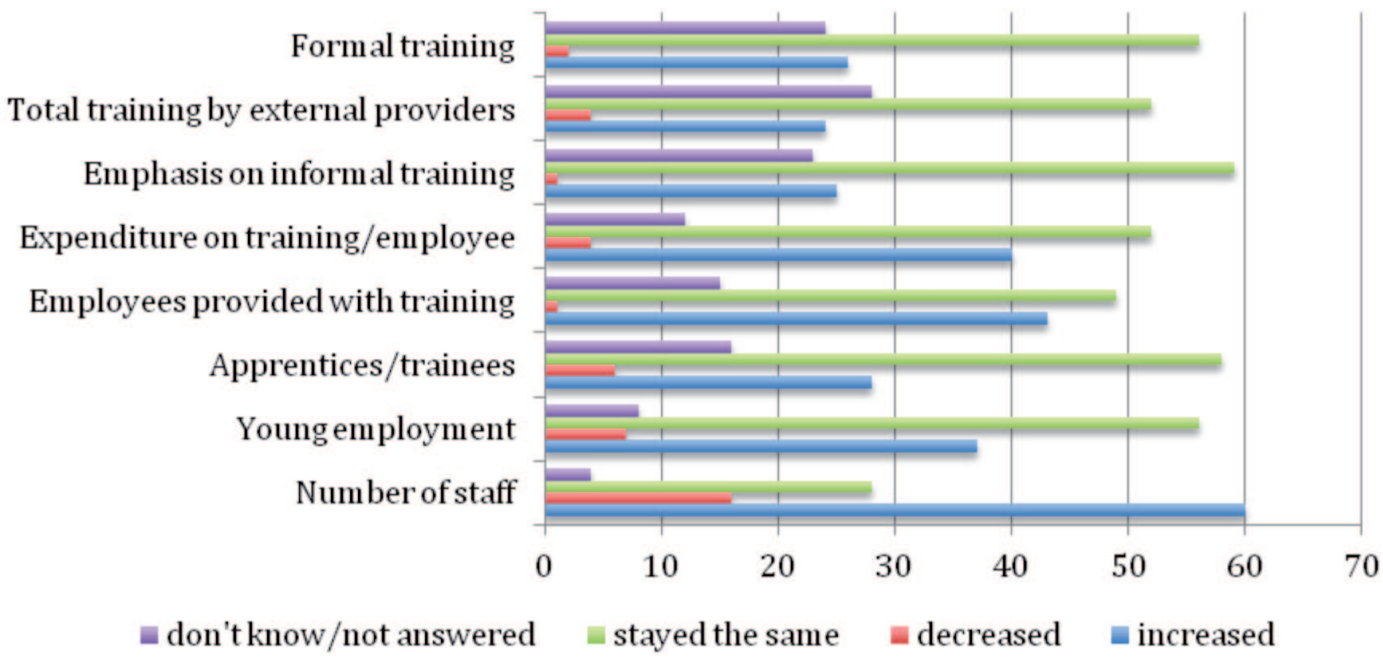

$47 \%$ of SMEs declared that, over the next 12 months, there is a strong need for additional trainings to develop technical/advanced skills, i.e. skills required for problem solving; design, operation, rethinking and maintenance of machinery or technological structures; IT professional skills (Figure 7). This can be explained by the fact that manufacturing SMEs in OSTIM, the majority of which are at the same time suppliers of highmedium tech producers, seek to excel in technical competence and skills. It should also be

Figure 7. Areas where additional training is needed over the next twelve months

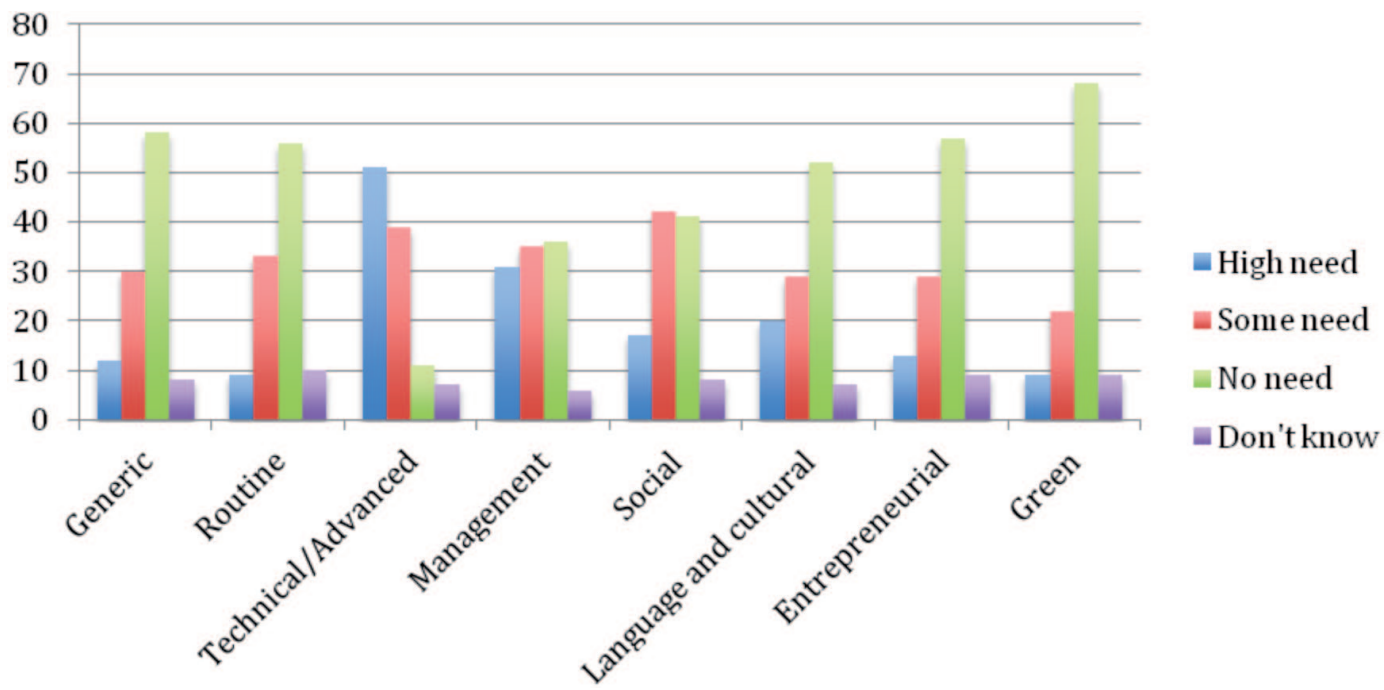


noted here that, based on the site visits, trainings which are most frequently organised and attract the highest number of attendees in OSTIM are those on technical fields.

The second most important area where respondents reported a need for additional training is in the development of management skills (skills for business planning, regulations and quality control, human resources planning (recruitment, training and skills development) and allocation of resources) (29\%).

The high share of "no need" replies is remarkable in almost all areas except technical/ advanced skills. The highest number of respondents $(63 \%)$ claims that they do not need specific skills required to adjust products, services or operations due to climate change adjustments, requirements or regulations. Green skills also have the lowest share of "high need" and "some need" replies.

What is also interesting is the relatively high share of "no need" responses to social skills (motivation and appreciation of people's characteristics for individual and team working purposes, customer handling; appreciation of networks and value-chain partners, etc.) which are required for clustering. 37\% of respondents who are a member of one of the clusters in OSTIM selected either "no need" or "don't know" replies. This may be because the clusters in OSTIM are still in the embryonic stage of development, and it requires time and high investment in cluster development activities for member SMEs recognise the advantages of operating within a cluster.

\subsubsection{Industry training/Vocational Education and Training (VET) activities in firms}

The majority of respondents declared that their employees did not participate in VET trainings in the areas listed in Figure 8 over the past 12 months. The only two areas where they received VET were for job-specific technical training and organizational health and safety (mainly due to legal requirements) where $37 \%$ and $33 \%$ of respondents participated in one-off trainings, respectively.

The VET fields with the lowest share of participation include green skills development, entrepreneurship related trainings, social skills development and e-commerce trainings.

SMEs usually receive in-house training (within the firm) (59\%) and on-the-job (53\%) (Figure 9). The high number of "Don't know" answers for providing formal (nationally recognised) qualifications (52\%) is remarkable. VET was always provided by accredited trainers according to $32 \%$ of respondents.

30 out of 108 respondents reported that their employees participated in VET during the past 12 months. 26 respondents declared that the VET was received by high-medium skilled employees and 14 stated that they trained low skilled employees*.

As for the age breakdown of employees, the majority of those who participated in training were between $25-49$ years of age (77\%). $22 \%$ of the staff who received training were younger than 25 years old.

* "High-skilled occupations" are defined in the survey as professionals, associate professionals and technical occupations. "Medium-skilled" is defined as administrative, secretarial, skilled trades, personal services, sales and customer services. The definition of "Low-skilled" is routine process, plant and machine operators, elementary occupations such as garbage collectors and food processing workers. 
Figure 8. VET activities participated by SMEs over the past twelve months

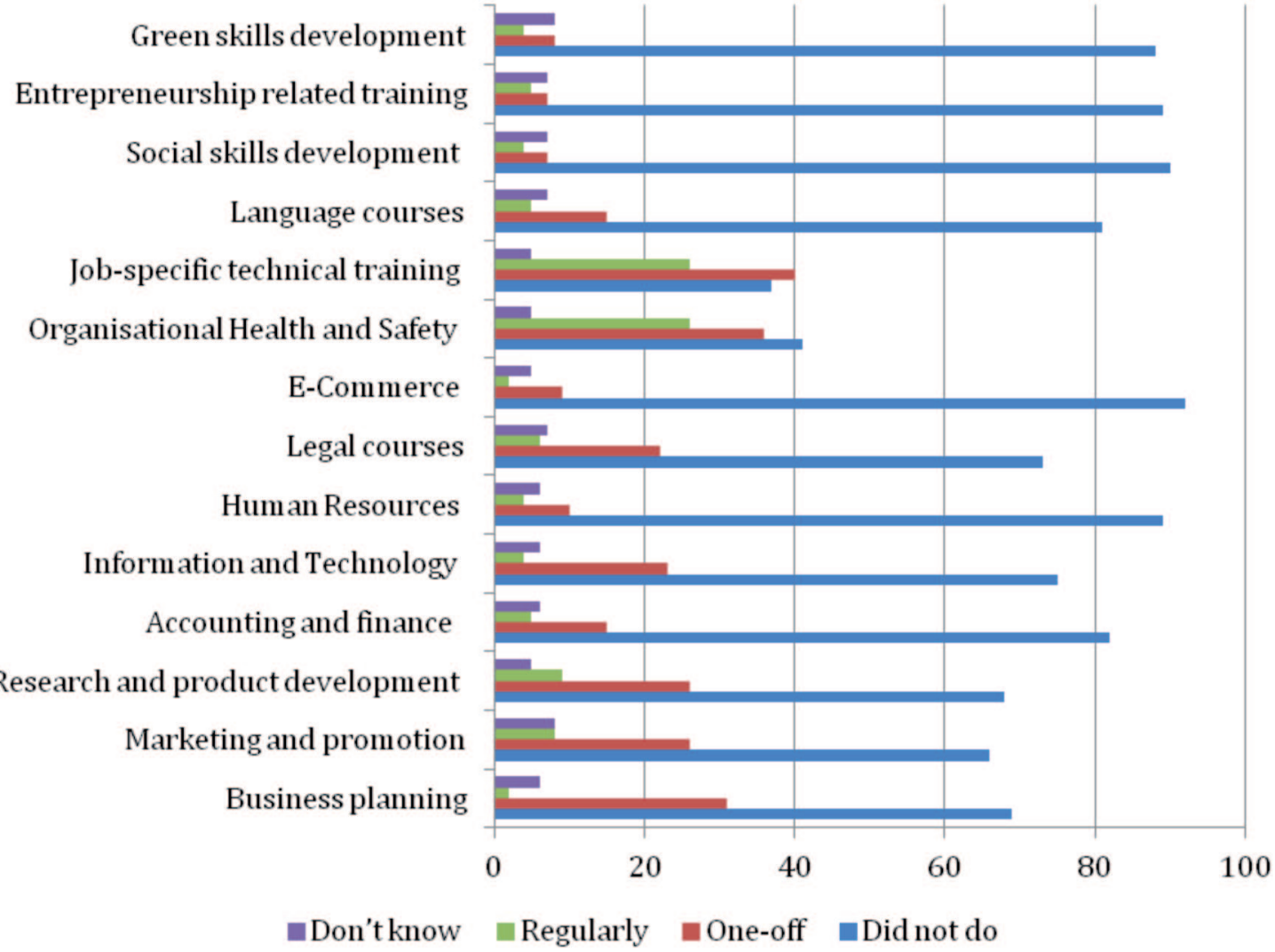

Figure 9. The way VET activities are provided

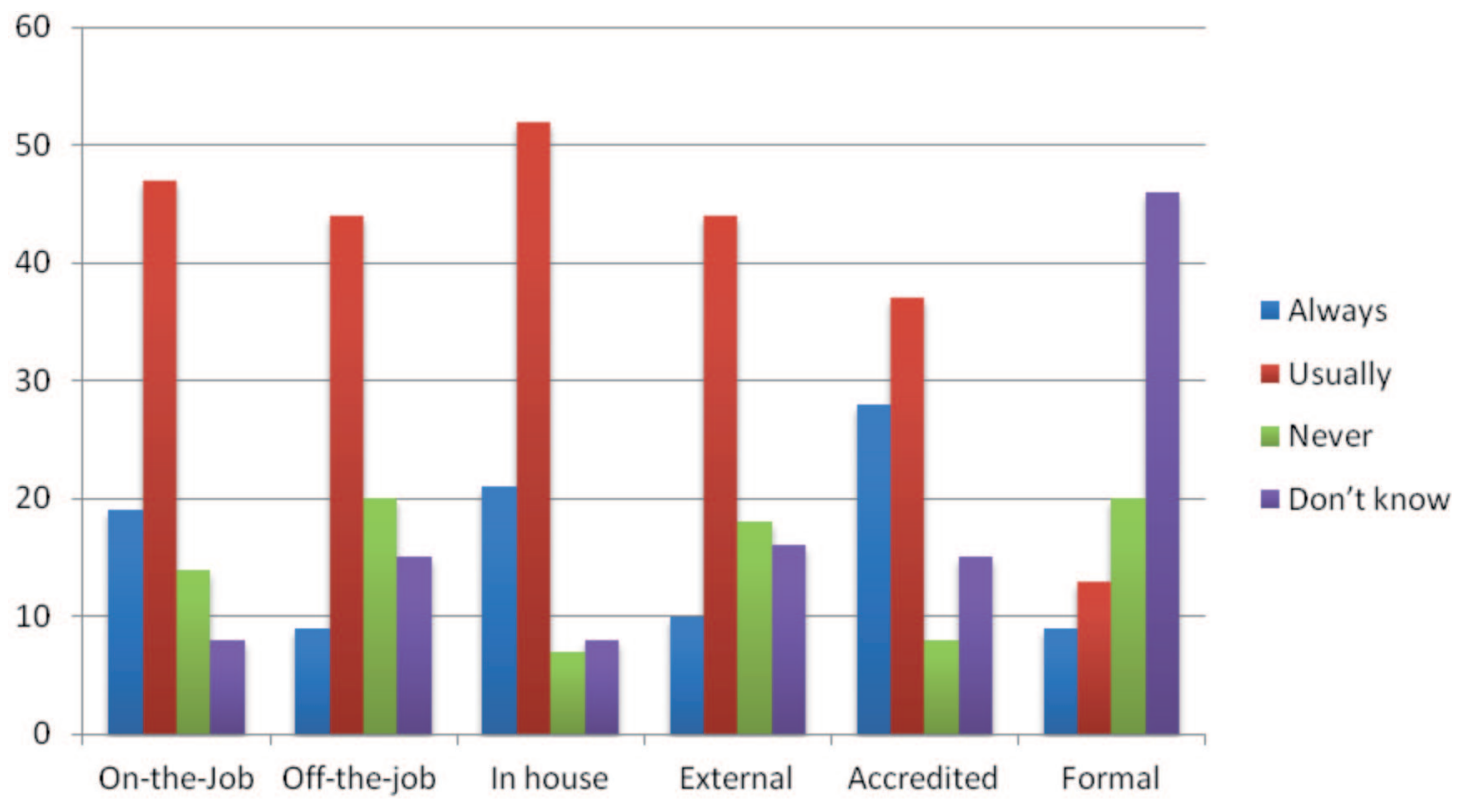


The most important outcome generated from VET for high-medium skilled employees is developed management skills (e.g. business planning, human resources planning) (39\%) whereas technical/advanced (problem solving) is the most important outcome produced for low-skilled workers (38\%) (Figure 10). Job change is one of the lowest observable outcomes of trainings both for high- and low-skilled workers. Positive impact of VET on social skills of employees is notable.

Figure 10. Outcomes produced from VET trainings for employees

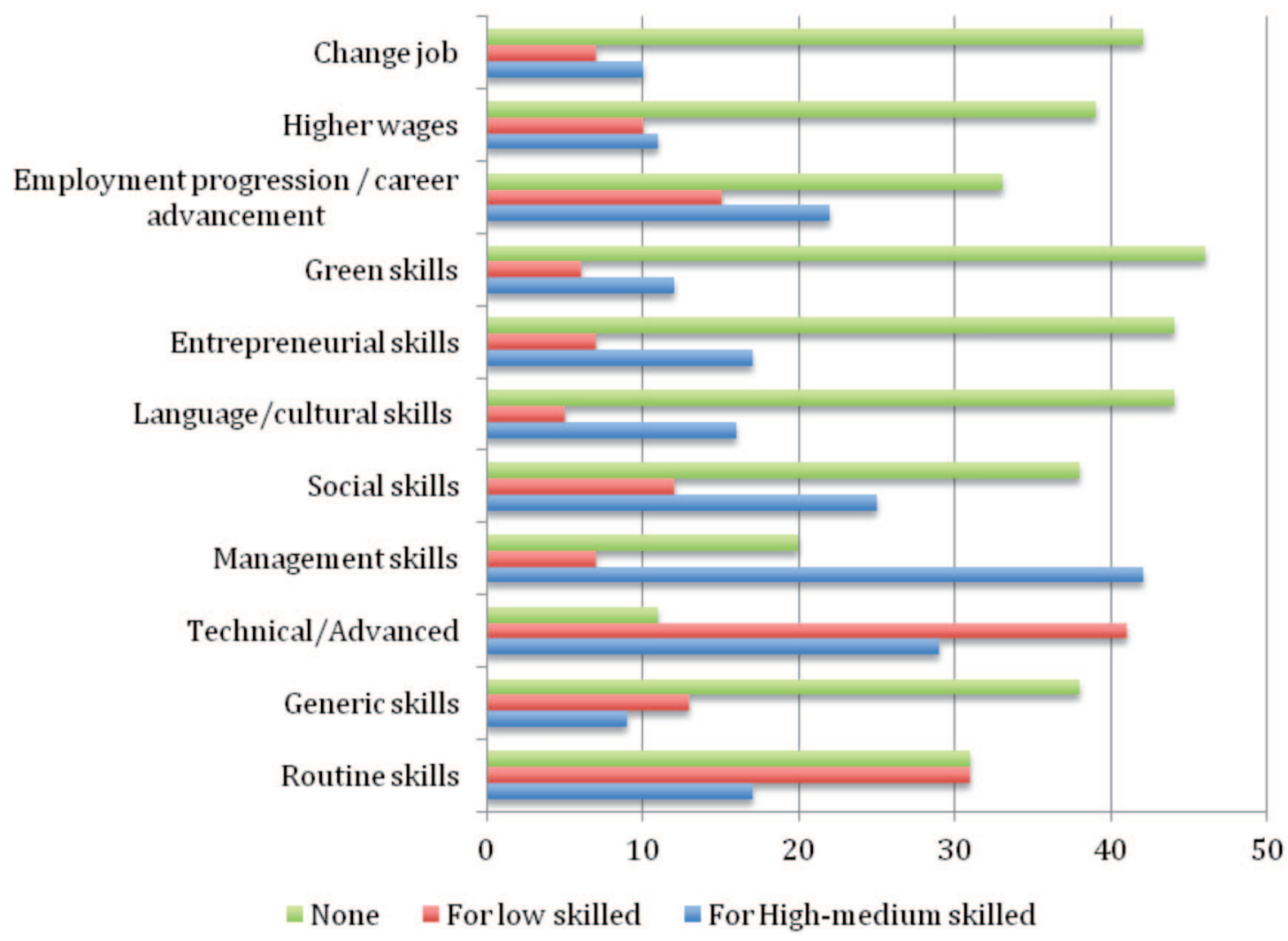

Green skills are those which received least attention by firms and as a result generated the lowest outcome from VET.

When the respondents were asked about the outcomes generated by VET for their businesses, the majority of them stated that they did not know whether or not trainings had produced positive outcomes in terms of:

- Increased productivity

- Increased innovation (new/improved products or services or new/improved management processes)

- Market positioning (local, national, international)

- Increased competitiveness

- Increased levels of education attainment

- Increased levels of trainers' expertise in designated areas

- Mitigation of climate change/contributing to the greening of the economy 
The only remarkable outcome reported by the majority of respondents is upgraded skills levels for the firm (37\%) (Figure 11). A relatively high number of SMEs surveyed also cited increased productivity, increased innovation, market positioning, increased levels of education attainment and increased competitiveness as outcomes produced for business. Outcomes produced by VET for local area are, in general, less notable than those produced for industry sector. Because of the limited importance attached to the green skills, as is also evident from the other findings, mitigation of climate change/contributing to the greening of the economy is an area which was not identified as one of the outcomes produced from VET for all levels (i.e. for business, local area and industry sector). The other outcome, which was cited as one of the least important for all three levels, is increased levels of trainer's expertise in designated areas.

Figure 11. Outcomes produced from outcomes produced from VET for business, local area and industry sector

\title{
Mitigation of climate change/contributing to the greening of the economy \\ Increased levels of trainers' expertise in designated areas
}

Increased levels of education attainment

\author{
Upgraded skill levels \\ Increased competitiveness \\ Market positioning
}

Increased innovation

Increased productivity

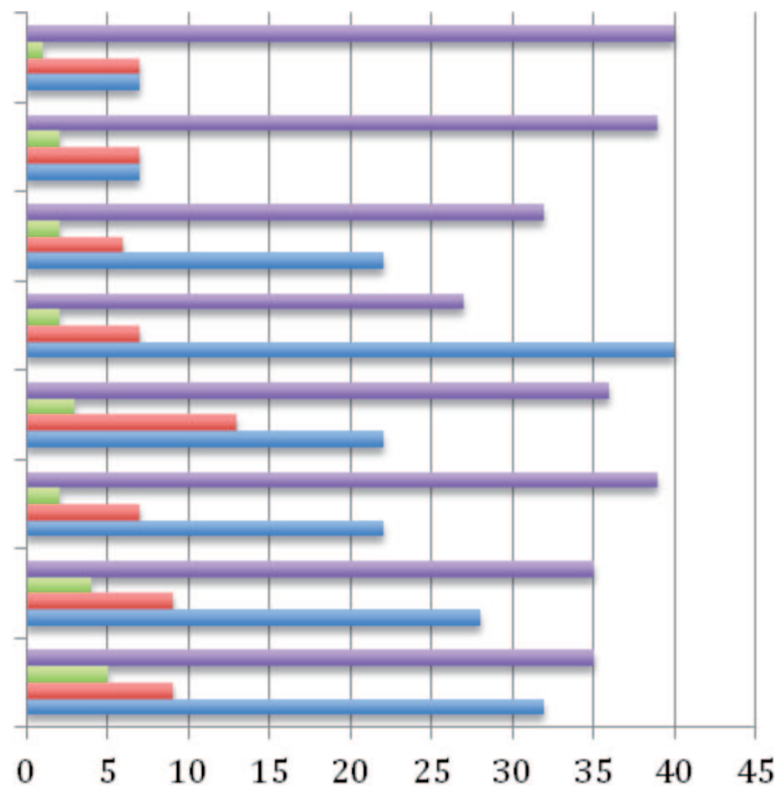

= Don't know $\quad$ Forlocal area

= For industry sector $\equiv$ For business

The majority of respondent enterprises (59\%) declared that there were not any VET activities they had wanted to carry out but did not during the last 12 months. 33\% stated that there were areas of trainings they would like to have received and the rest replied "don't know".

The main reasons for not carrying out VET in the past 12 months for high-medium skilled workers were the high costs involved in the trainings $(61 \%)$ and the lack of public financing (39\%). For low-skilled workers, the main reasons were not being able to interrupt production (not having time) (42\%) and the lack of public financing (36\%). The former is also the third important reason for high-medium skilled workers not to receive training. Interestingly, the reason articulated as "staff not willing to participate in training" for low-skilled workers was given a relatively high score by the SMEs surveyed. Mainly since there is an abundant number of VET opportunities which exist in OSTIM, the option "too difficult to access training" was one of the least cited reasons. (Figure 12). 
Figure 12. The main reasons for not carrying out VET in the past 12 months

Too difficult to access training

Too difficult to identify suitable training..

Risk of poaching after training

Training is too difficult to implement

Staff not willing to participate in training

Difficult to assess enterprise needs

Impossible to interrupt production/no time

Lack of public financing

People recruited with skills needed

High costs/too expensive

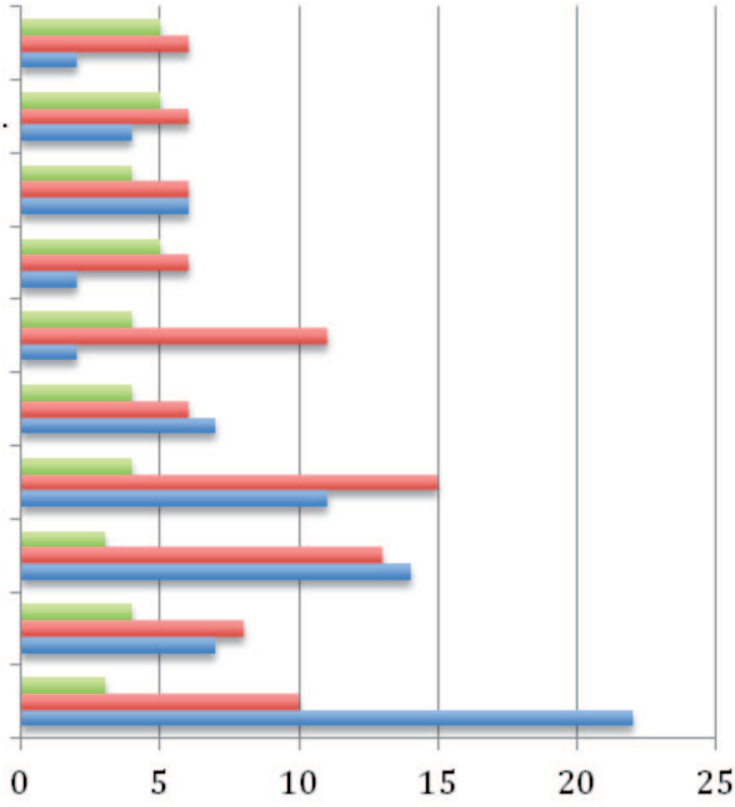

Don't Know a For low skilled $\quad$ For High-medium skilled

\subsubsection{Knowledge Intensive Skills Activities in firms}

Knowledge Intensive Skills Activities (KISA) are not at the focus of attention of SMEs surveyed in OSTIM. As shown in Figure 13, the majority of the respondents stated that they did not carry out KISA in the following areas over the past 12 months, which significantly increased the skills, competencies or knowledge of their employees.

- Business planning (including management and leadership services, consultancy and advice)

- Marketing and promotion services

- Research (including market research) and product development

- Accounting and finance services

- Information and Technology services

- Human Resource services

- Legal advice and services (IP, patents etc)

- E-Commerce (e.g. on-line work with clients and suppliers; access to web-based information)

- Organisational Health and Safety advice

- Job-specific technical activities (e.g. advice on utilisation of new plant or equipment)

- Language or communication coaching

- Social skills development 
- Entrepreneurship related activities (e.g. brainstorming about opening new markets or new range of products and services)

- Green skills development (e.g. cooperation with other organisations to find ways to adjust production to minimise climate change)

Similar to VET activities, KISA on organisational health and safety advice, and jobspecific technical activities (e.g. advice on utilisation of new plant or equipment) were those with the highest shares, as seen in the figure below.

Figure 13. KISA carried out by firms in the past 12 months

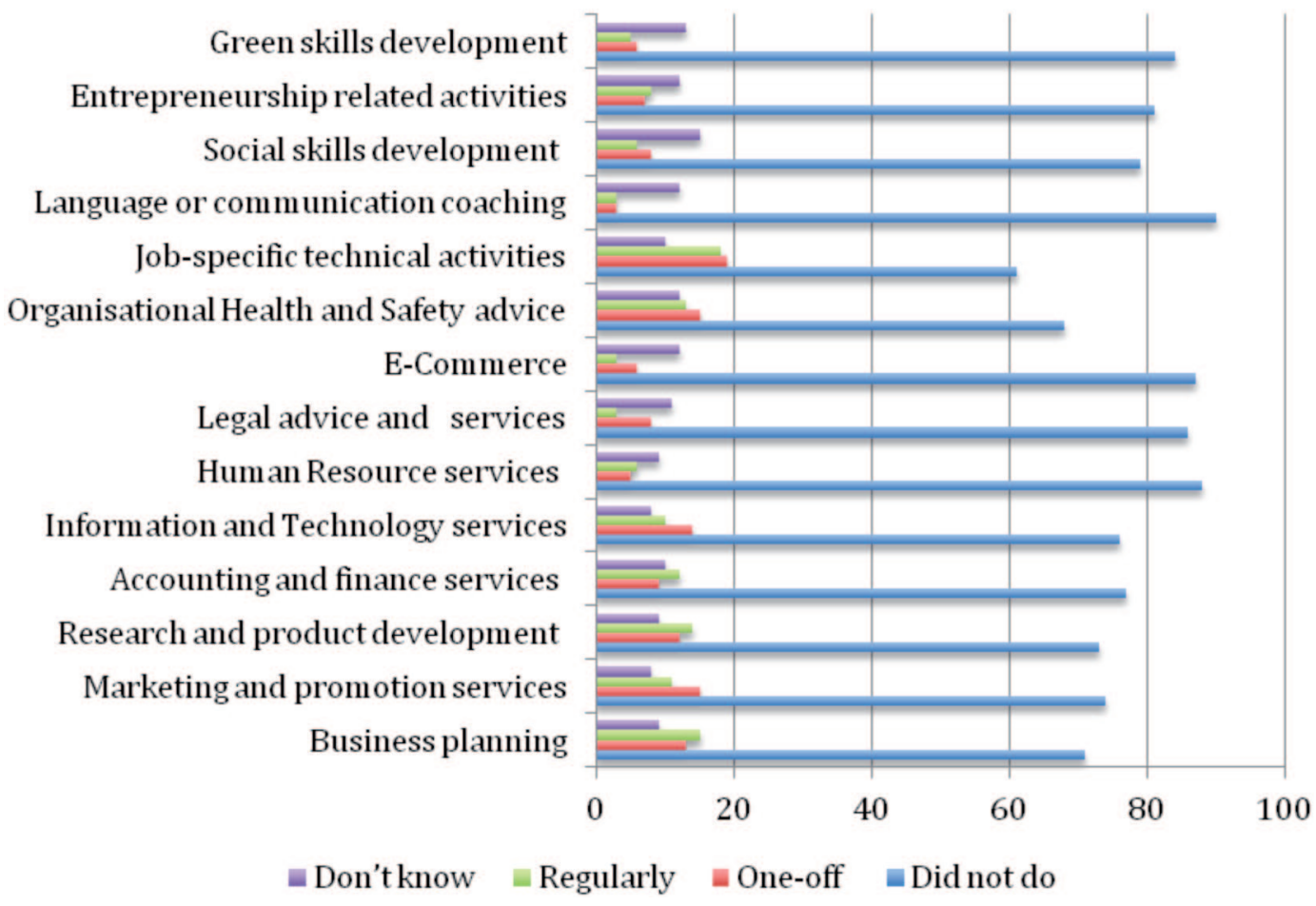

Business planning, marketing and promotion services, information and technology services, and research and development are the other areas which are of a relatively higher rate of interest to SMEs, although still only a small number of respondents stated that they carried out such KISA over the last 12 months.

The majority of respondent SMEs (62\%) rank clients the first in the order of importance in KISA during the past 12 months. Other important groups with high importance were listed as KOSGEB (50\%); suppliers (50\%); co-workers (48\%); university researchers and consultants (44\%) (Figure 14).

As seen in below figure, firms from the same industry cluster and firms from valuechain are relatively given little importance in KISA by the respondents. Government departments and industry associations are two groups with least importance attached by SMEs in their knowledge intensive skills activities.

27 respondents reported that their employees participated in KISA during the past 12 months. 11 respondents reported that only high-medium skilled employees were included. 
Figure 14. Importance of the groups in KISA of firms during the past 12 months

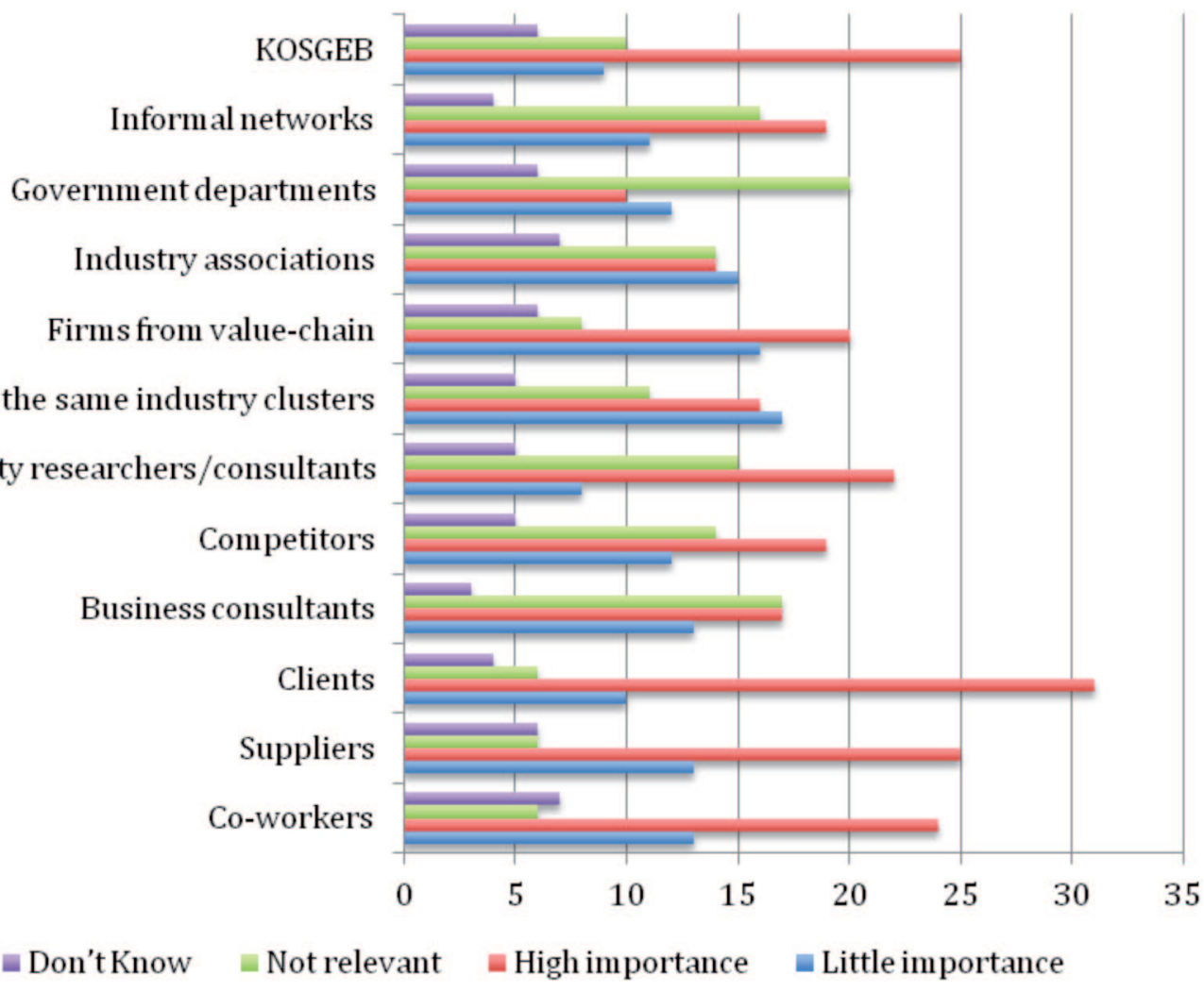

Figure 15. Outcomes produced for employees as a result of KISA

Firms from the same industry cluster

University researchers/consultants

\section{Mobility \\ Higher wages}

Employment progression / career..

Green skills

Entrepreneurial skills

Language/cultural skills

Social skills

Management skills

Technical/Advanced

Generic skills

Routine skills

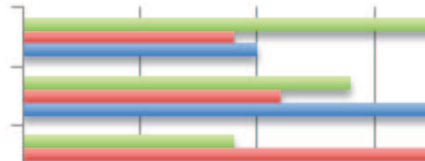

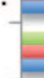

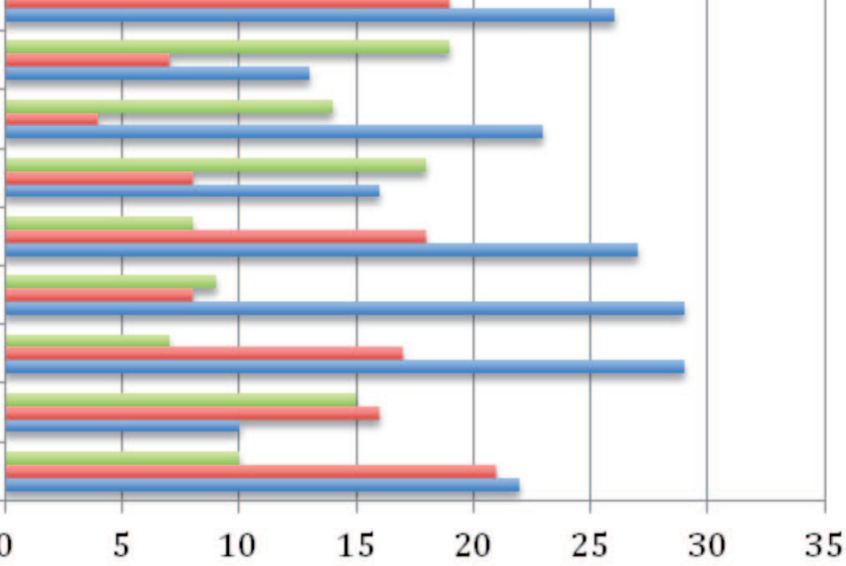

None $\quad$ For low skilled $\quad$ For High-medium skilled 
12 included both high-medium skilled and low skilled employees. As for the age groups of staff that participated in KISA, $71 \%$ were between $25-49$ years of age while $28 \%$ were below 25 years old.

The majority of outcomes are generated mainly for high-medium skilled staff than low-skilled workers. The main outcomes for high-medium skilled employees as a result of participating in KISA (in the short or long term) are management skills (e.g. business planning, human resources planning) (63\%); entrepreneurial skills (e.g. risk taking) (56\%); technical/advanced skills (such as problem solving) (55\%); and employment progression/ career advancement (48\%), as declared by responding SMEs. For high-medium skilled employees, mobility and generic skills were the least produced outcomes.

For low-skilled workers, KISA generated the main outcomes of routine skills (e.g. repetitive tasks) (40\%), generic skills (e.g. literacy, numeracy) (39\%); employment progression/career advancement (35\%), social skills (e.g. team work) (33\%); and technical/ advanced skills (32\%) (Figure 15). Entrepreneurial skills as an outcome are the least produced for low-skilled staff.

The main outcomes produced for the businesses from KISA included increased innovation (new/improved products or services or new/improved management processes), increased productivity and upgraded skill levels. Increased competitiveness was listed as a key outcome for the industry sector.

Outcomes of KISA for the local area, similar to that of VET, seem to be limited. The high number of "don't know" replies, particularly in outcomes related to green skills (mitigation of climate change/contributing to the greening of the economy) is remarkable. (Figure 16).

Figure 16. Outcomes produced for businesses, industry sector and local area as a result of KISA

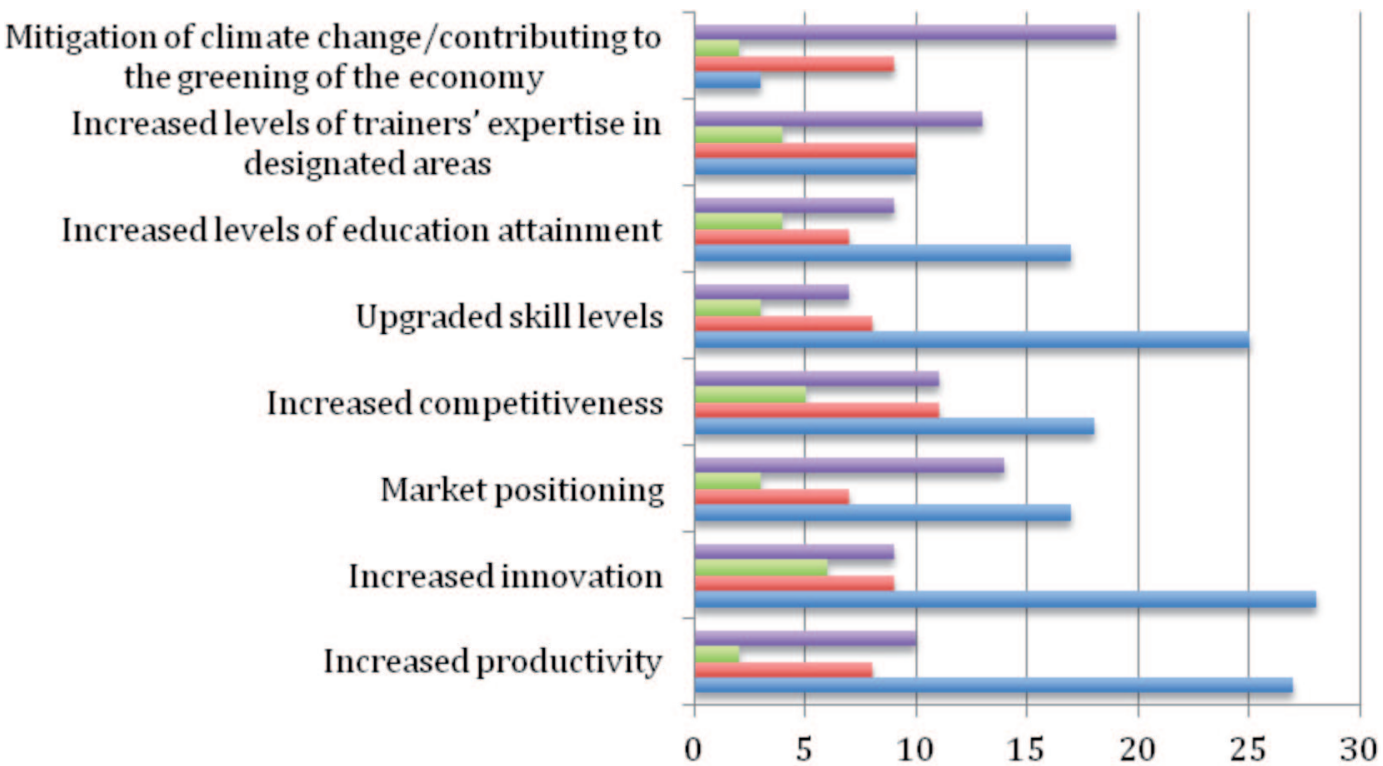

$\varpi$ Don't know $\equiv$ For local area $\quad$ For industry sector $\quad$ For business 
Compared to the VET courses, respondents consider that primarily following knowledge intensive service activities are better sources of learning for high-medium skilled staff:

- Business planning (including management and leadership services, consultancy and advice) (57\%)

- Marketing and promotion services (52\%)

- Research (including market research) and product development (46\%)

- Accounting and finance services (46\%)

- Entrepreneurship related activities (e.g. brainstorming about opening new markets or a new range of products and services) (43\%)

- For low-skilled employees, they primarily list the following knowledge intensive service activities as better sources of learning for staff than formal education and training courses:

- Job-specific technical activities (e.g. advice on utilisation of new plant or equipment) $(41 \%)$

- Organisational health and safety advice (39\%)

The majority of respondents replied "don't know" for green skills development (e.g. cooperation with other organisations to find ways to adjust production to minimise climate change impact) (64\%); e-commerce (e.g. online working with customers and suppliers, accessing web based information) (52\%) and legal advice and services (IP, patents, etc.) (52\%) (Figure 17).

Figure 17. Comparison of KISA with VET courses as sources of learning for staff

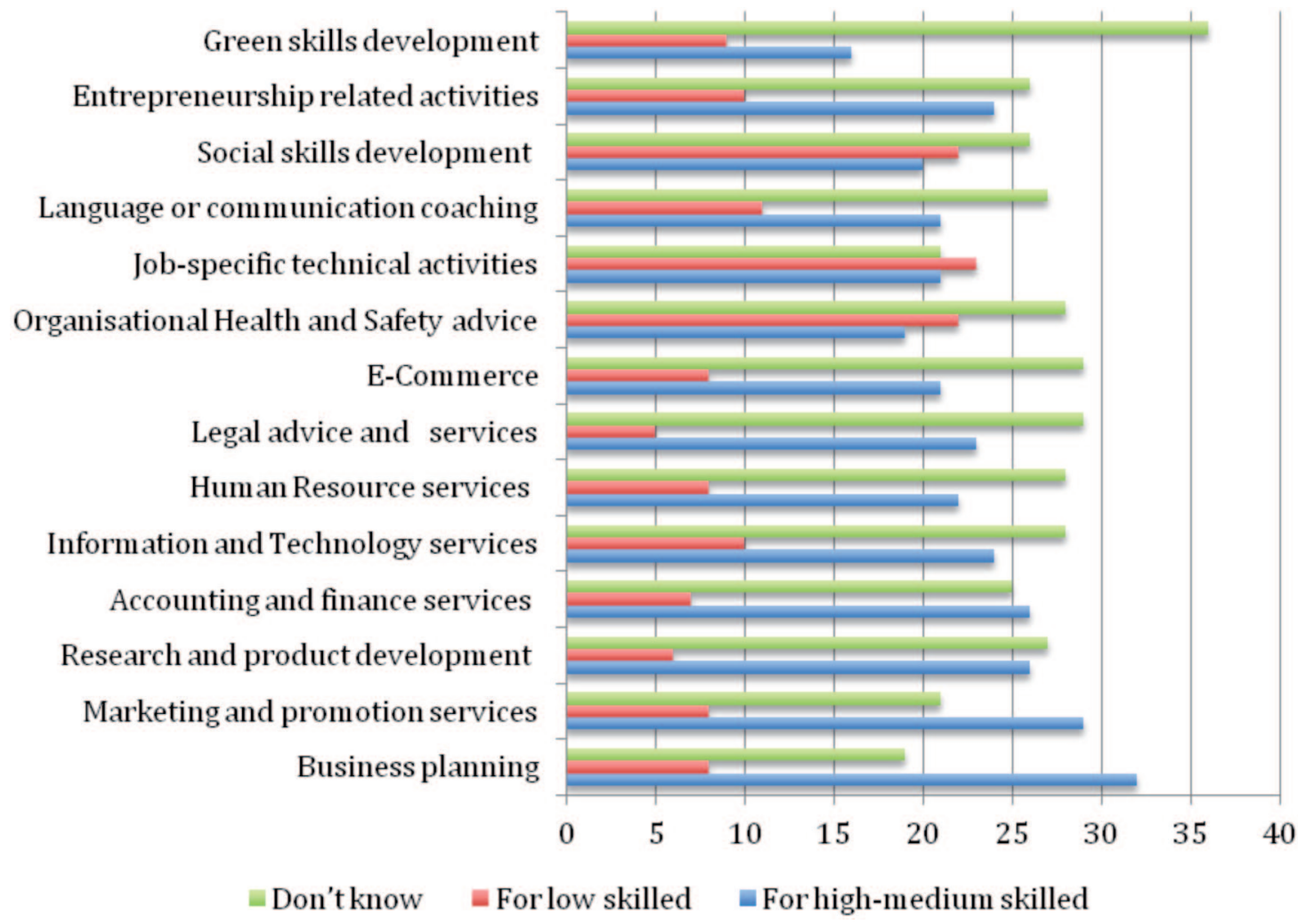




\subsubsection{Motivation and collaboration for training and skills development}

The main reasons for respondent SMEs to undertake training and skills development activities are listed as follows:

- For VET, in-house incentives are important; in particular, production needs $(62 \%)$ and the need to increase employee skill levels (54\%).

- For KISA, private incentives (mainly industry sector association services/activities [33\%]) and in-house incentives (in particular, production needs (29\%), service requirements (24\%) and needs to increase employee skill levels (24\%)) are the most important drivers.

Interestingly, the respondents, of which the majority are members of clusters, provided relatively low ratings to cluster related aspects (such as industry clusters services/activities; value-chain firms' activities; business networks activities, local networks activities and collective agreements) as main reasons for undertaking training and skills development activities (Figure 18). This can again be explained by the fact that the clusters are still at an early stage of development.

Figure 18. The reasons for respondent SMEs to undertake training and skills development activities (VET and/or KISA)

Need to increase employee skills level Job/position adjustments Adjustments to climate change impacts Adjustments to financial constraints New product / service development Service requirements Production needs Foundations activities Local networks activities Business networks activities Value-chain firms' activities Industry clusters services/activities Chambers of Commerce services/activities Industry sector association services/activities Collective agreements (trade unions) Country regulations Local (council / local government.. Regional (regional programmes) National (country specific government.. International (e.g. EU policies)

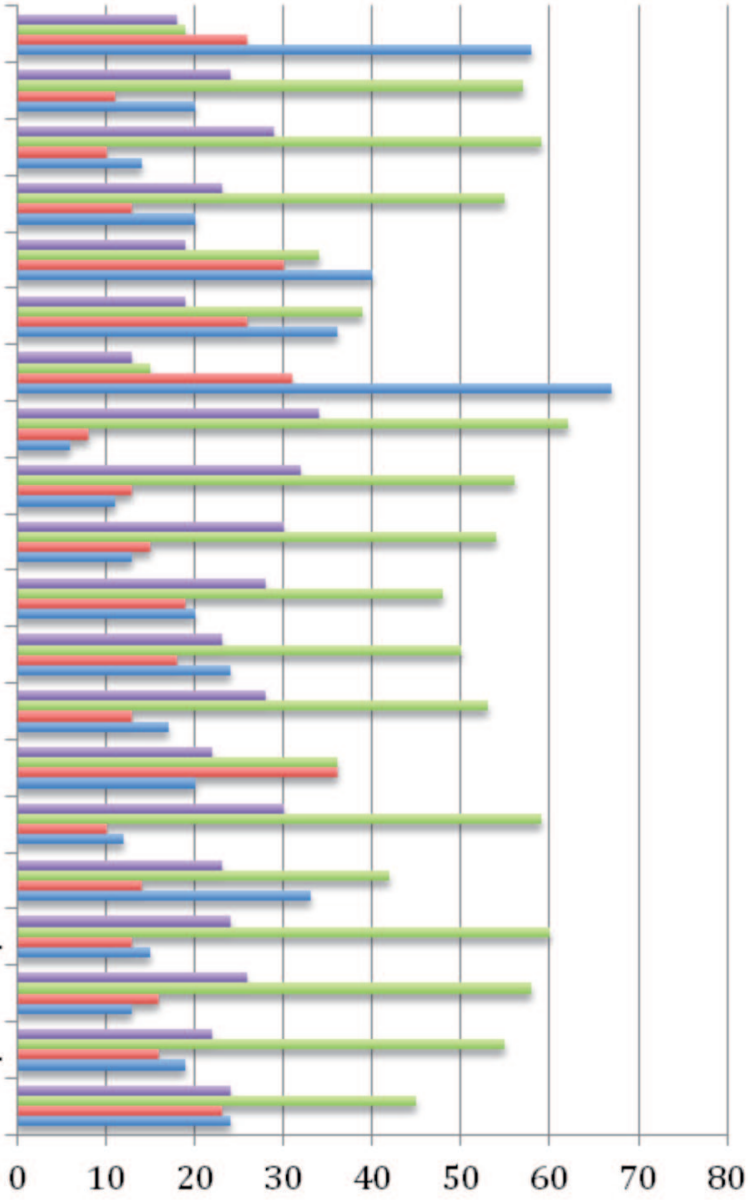

Don't Know $\quad$ Not Applicable $\quad$ KISA $\quad$ Industry training/VET courses 
Respondents consider private training providers, private consultants and paid advisors, and industry training organisations as the key organisations associated with VET.

For KISA, they mainly work with government bodies, followed by business organisations and universities (Figure 19). This somewhat contradicts with the finding that government departments are one of the groups with the least importance attached by SMEs in their knowledge intensive skills activities. Universities, despite being very active in OSTIM, were not given a high ranking for KISA.

Figure 19. The organisations with whom respondent SMEs associate for VET and KISA

Othereducation providers

Other parts of the same enterprise group

Local community organisation

Local councils

Private training providers

Private Consultants and paid advisors

Government departments

Firms from value-chain

Chambers of Commerce

Business organisations

Trade Unions

Universities

Further education colleges

Industry Training Organisations / Sector..

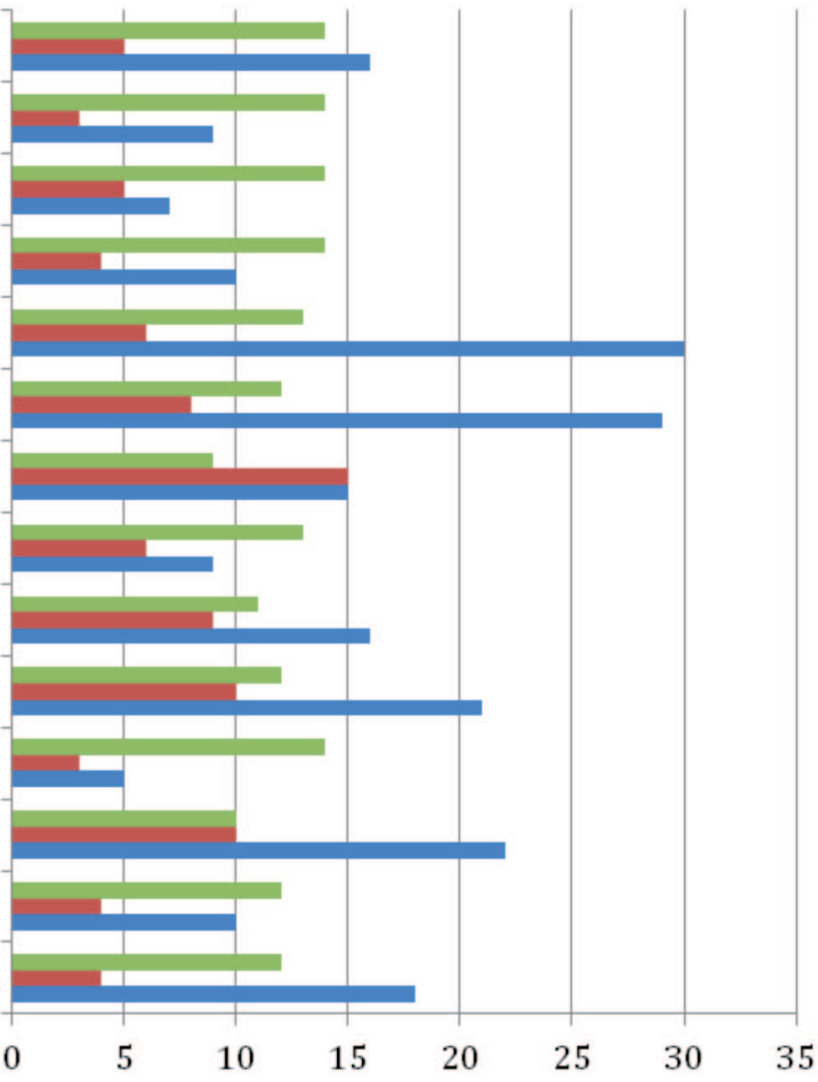

None $\quad$ KISA $\quad$ Industry training/VET activities

Trade unions are the least cited organisations both for KISA and VET.

When the respondents were requested to name the main organisations they work with on training and skills development, the majority listed KOSGEB, ODEM, Ankara Chamber of Industry and Gazi University as the main counterparts. (Figure 20). It is not surprising that KOSGEB and ODEM are rated the top two organisations by the respondents, due to their active support and interaction with the SMEs in the zone.

The fact that nine out of the 19 organisations listed are universities indicates the active role higher education institutes play in the zone. The list of universities does not only include regional universities but also those from other regions. 
Figure 20. The organisations named by respondent SMEs as counterparts for VET and KISA

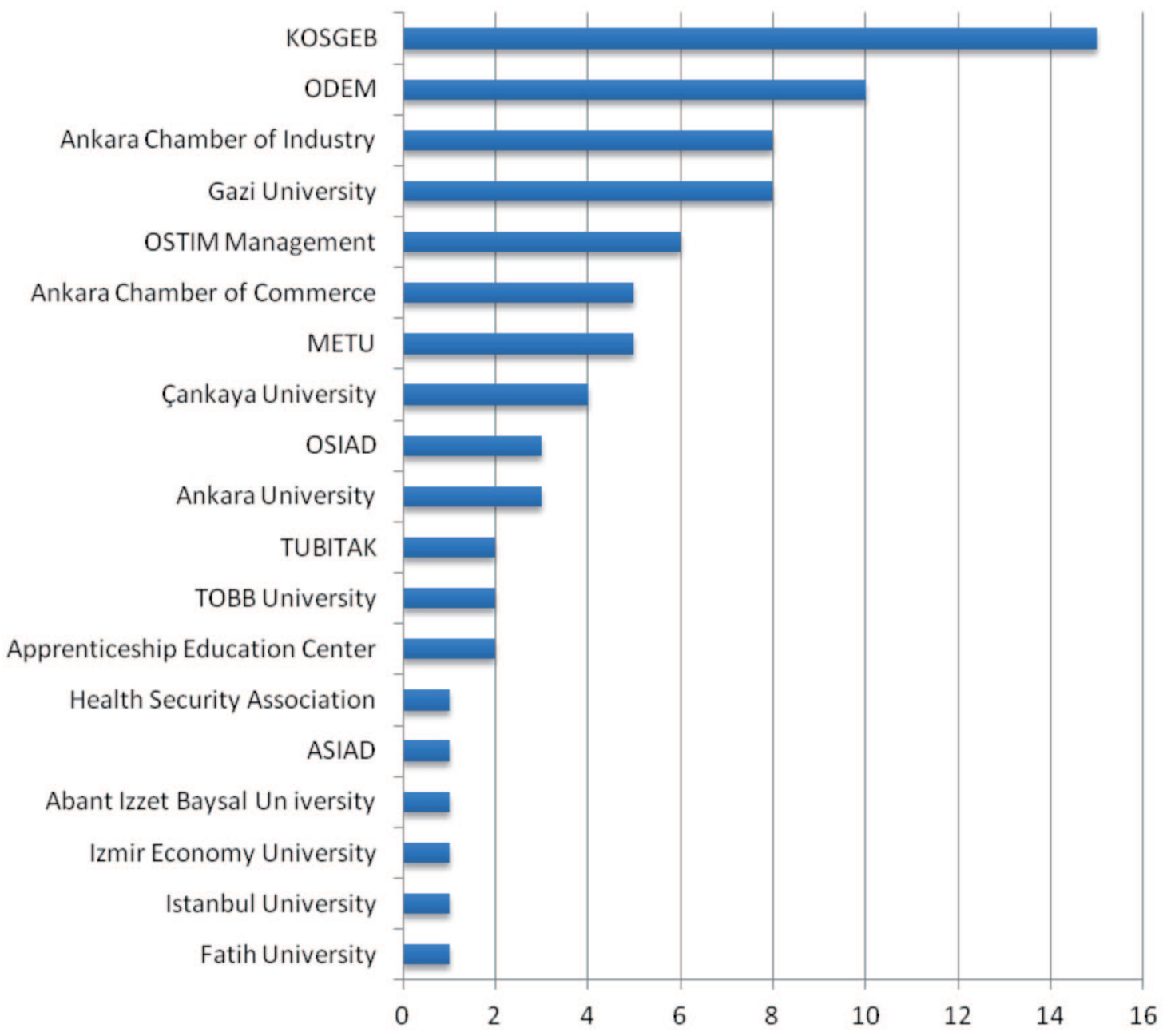

\subsubsection{The effect of institutionalisation of trainings on innovation, entrepreneurship and green skills}

Further analysis has been done to understand the effect of training investments on three key areas: innovation, entrepreneurship and green skills/investment.

$61 \%$ of 108 survey respondents declared that their businesses have formal training and career development plans for employees (e.g. plans for career advancement and promotion). $38 \%$ of SMEs that responded to the survey have an annual budget for training expenditure (e.g. formal/informal training; on/off the job; covering direct costs).

For correlation analysis, the "yes" and "no" values for firm training plan and budget were attributed to 1 and 0 , respectively. For the values that signify frequency of training (both for VET and KISA), regular and one-off trainings were counted in one single variable, which is 1. Answers other than these two ("none" and/or "don't know") were identified by 0 . Using this numbering system, Pearson correlations were calculated among variables (Table 3). 
Table 3. Pearson correlation coefficients

\begin{tabular}{|c|c|c|c|c|c|c|c|c|c|c|c|}
\hline & $\begin{array}{c}\text { Training } \\
\text { Plan }\end{array}$ & $\begin{array}{l}\text { Training } \\
\text { Budget }\end{array}$ & $\begin{array}{c}\text { PastVET_ } \\
\text { Entrepre- } \\
\text { neurship } \\
\text { Freq. }\end{array}$ & $\begin{array}{c}\text { PastVET_ } \\
\text { Green } \\
\text { Freq. }\end{array}$ & $\begin{array}{l}\text { Past- } \\
\text { KISA_- } \\
\text { Entrepre- } \\
\text { neurship } \\
\text { Freq. }\end{array}$ & $\begin{array}{c}\text { Past- } \\
\text { KISA_ } \\
\text { Green } \\
\text { Freq. }\end{array}$ & $\begin{array}{l}\text { Changes } \\
\text { Product }\end{array}$ & $\begin{array}{l}\text { Changes_ } \\
\text { Operation }\end{array}$ & $\begin{array}{c}\text { Changes_ } \\
\text { Mgmt }\end{array}$ & $\begin{array}{c}\text { Changes } \\
\text { Tech }\end{array}$ & $\begin{array}{c}\text { Changes_ } \\
\text { Green }\end{array}$ \\
\hline Training_Plan & 1.00 & 0.51 & -0.08 & -0.08 & -0.01 & -0.05 & 0.04 & 0.09 & 0.14 & 0.21 & 0.22 \\
\hline Training_Budget & 0.51 & 1.00 & 0.03 & -0.03 & 0.02 & -0.07 & 0.06 & 0.12 & 0.04 & 0.20 & 0.15 \\
\hline PastVET_Entrep_Frequency & -0.08 & 0.03 & 1.00 & 0.44 & 0.28 & 0.17 & -0.03 & -0.12 & -0.01 & 0.06 & -0.03 \\
\hline PastVET_Green_Frequency & -0.08 & -0.03 & 0.44 & 1.00 & 0.11 & 0.56 & -0.03 & -0.07 & -0.01 & -0.12 & 0.25 \\
\hline PastKISA_Entrep_Frequency & -0.01 & 0.02 & 0.28 & 0.11 & 1.00 & 0.31 & 0.09 & 0.18 & 0.16 & 0.01 & 0.11 \\
\hline PastKISA_Green_Frequency & -0.05 & -0.07 & 0.17 & 0.56 & 0.31 & 1.00 & 0.07 & -0.04 & 0.01 & -0.09 & 0.47 \\
\hline Changes_Product & 0.04 & 0.06 & -0.03 & -0.03 & 0.09 & 0.07 & 1.00 & 0.57 & 0.36 & 0.35 & 0.16 \\
\hline Changes_Operation & 0.09 & 0.12 & -0.12 & -0.07 & 0.18 & -0.04 & 0.57 & 1.00 & 0.40 & 0.26 & 0.17 \\
\hline Changes_Mgmt & 0.14 & 0.04 & -0.01 & -0.01 & 0.16 & 0.01 & 0.36 & 0.40 & 1.00 & 0.17 & -0.01 \\
\hline Changes_Tech & 0.21 & 0.20 & 0.06 & -0.12 & 0.01 & -0.09 & 0.35 & 0.26 & 0.17 & 1.00 & 0.06 \\
\hline Changes_Green & 0.22 & 0.15 & -0.03 & 0.25 & 0.11 & 0.47 & 0.16 & 0.17 & -0.01 & 0.06 & 1.00 \\
\hline
\end{tabular}

The results indicate that:

- The existence of a formal training plan and training budget positively affects all types of innovations as would be expected. Technological innovations and green innovations (a new product/service/operation due to climate change adaptation/ regulation) especially are highly related to the existence of a formal training plan and budget ( 0.21 and 0.22 for training plan, and 0.20 and 0.15 for training budget);

- VET and KISA on green skills and entrepreneurship do not seem to depend on the existence of a formal training plan and budget. The coefficients are very close to zero for both of them.

Furthermore, it is observed that both VET and KISA on green skills have a positive effect on green innovations. However, this effect is stronger in KISA than VET.

Also, KISA on entrepreneurship positively affects management innovations (changes to the way a firm does things such as a new or substantially changed accounting system or human resource management system (e.g. a new management process) and operation innovations (a new way of producing an existing product/service (e.g. a new operational process). These results are not observed in the case of formal training on entrepreneurship.

\subsubsection{Comparative analysis of the survey results for OSTIM clusters}

A further analysis of surveys at cluster level was conducted for OSTIM. As noted before, there are four clusters being developed in the zone. 59 SMEs surveyed are members of one of these clusters. The distribution of firms by cluster is given in Figure 21.

The first observation is that the levels of changes made by SMEs differ by cluster. As shown in Figure 22.

- The construction machinery cluster (C1) firms focus on incremental innovations, which mainly focus on technological and process changes. Radical innovations in this cluster are not widespread and they are limited to product and management changes. 
Figure 21. Distribution of firms by cluster

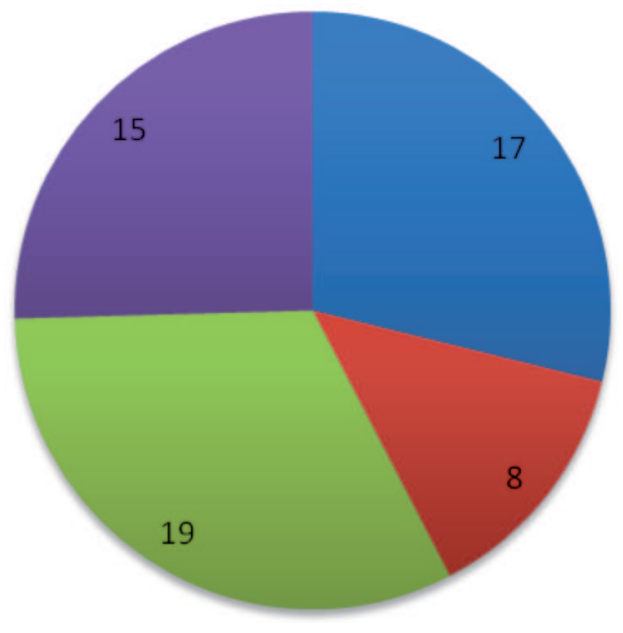

- Construction machinery

Medical industry

Defence and aviation

Renewable energy and environmental

technologies

Figure 22. Changes in the last 12 months

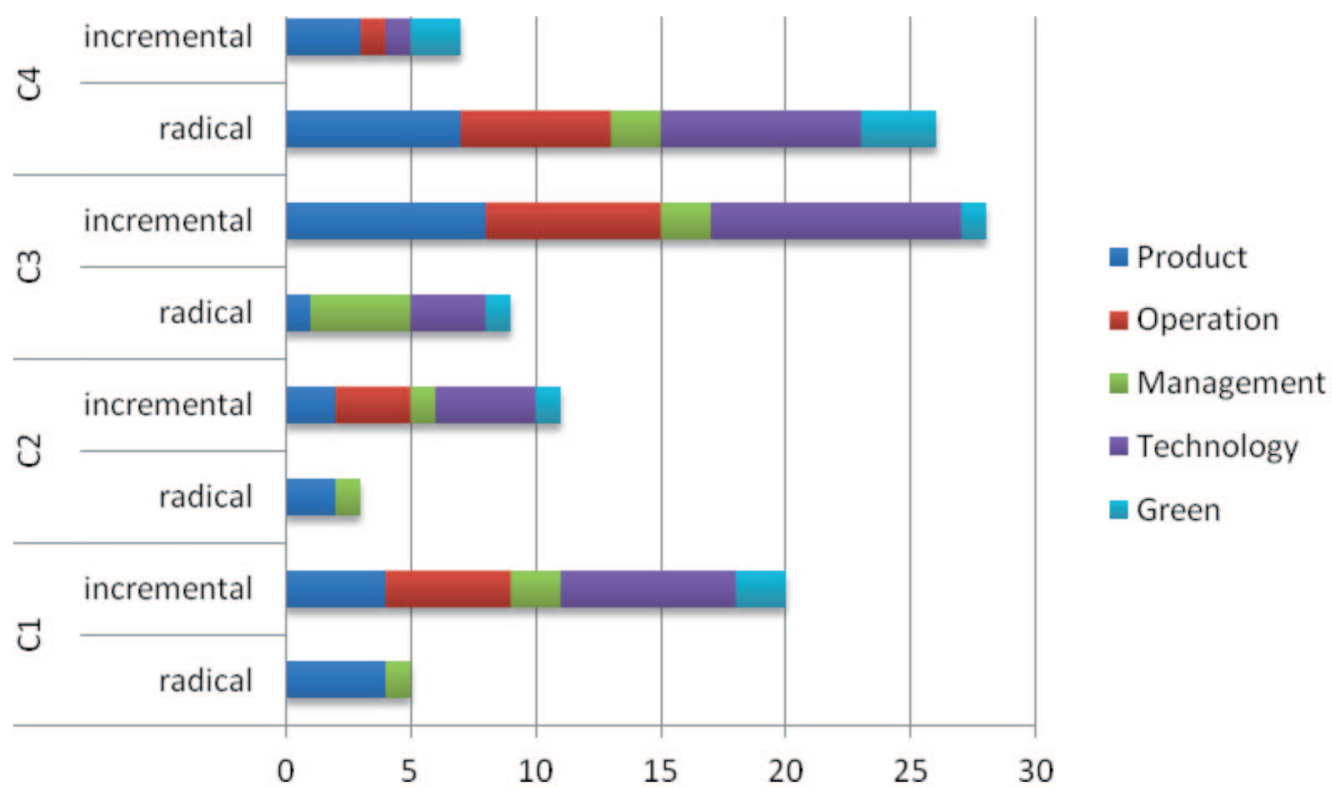

- The medical industry cluster (C2) seems to be the least innovating cluster among all four clusters in OSTIM (this may also be linked to the fact that only a limited number of firms in this cluster responded to the survey). Similar to the defence cluster firms, SMEs in this cluster mainly invest in incremental innovations (technology and process) and their limited radical innovation activities focus on product and management changes.

- The defence cluster (C3) is very active in conducting incremental innovations, particularly in the area of technological changes. In the radical innovations implemented in the cluster, the share of management changes is higher than the other types of innovation. 
- The members of the renewable energy and environmental technologies cluster (which is denoted by $\mathrm{C} 4$ ) reported 26 radical changes over the last 12 months, which is the highest amongst all. Moreover, the number of radical changes overpasses that of incremental changes in this cluster. In all other clusters, SMEs focus on incremental changes more than radical changes. The types of innovation in this cluster are mainly product, process and technological changes.

The institutionalisation of training activities also varies by cluster. $89 \%$ of firms in the defence and aviation cluster indicate that they have formal training plans. This represents the highest share of firms with formal plans among all four clusters (Table 4). The firms that allocate budgets for formal training activities are more frequently observed in the renewable energy cluster ( $89 \%$ of SMEs in this cluster declare that they have a training budget).

Table 4. Institutionalisation of training activities in clusters

\begin{tabular}{lcc}
\hline Cluster type & $\begin{array}{c}\text { Share of firms with } \\
\text { formal training plans }\end{array}$ & $\begin{array}{c}\text { Share of firms with } \\
\text { training budgets }\end{array}$ \\
\hline Construction and engineering machines & $59 \%$ & $40 \%$ \\
Medical industry & $63 \%$ & $40 \%$ \\
Defence and aviation & $89 \%$ & $59 \%$ \\
Renewable energy and environmental technologies & $60 \%$ & $89 \%$ \\
\hline
\end{tabular}

The changes observed in the organisations over the last 12 months are also different for each cluster as (Figure 23):

- The construction and engineering machines cluster (C1) firms declared that the situation has stayed mostly the same in terms of young employment, apprentices, training sources, and expenditures. Only $18 \%$ of SMEs in this cluster reported a decline in the number of employees over the last 12 months.

- For the medical industry cluster (C2) $63 \%$ of the respondents stated that the number of employees and the number of employees under 24 years of age increased over the last 12 months. However, there is a decline in training expenditure per employee for $13 \%$ of firms, which is the highest among all clusters. Nevertheless, there is also high number of not answered/“don’t know" responses.

- The SMEs in the defence (C3) and the renewable energy clusters (C4) achieved growth despite the crisis. Proportion of trained employees and expenditure also increased in more firms in these clusters than those in other clusters.

When comparing the VET received by the firms in each cluster by area (Figure 24) it is observed that organisational health \& safety and job-specific technical training were the areas with the highest rate of regular application by the respondent firms in all clusters except the medical industry cluster (C2). Likewise, respondents from the medical industry cluster cited no instance of social skills development and human resources trainings. Another interesting finding is that the defence and aviation cluster firms (C3) indicated that they did not receive any training on green skills development, social skills development and e-commerce. The high share of "did not do" replies in all areas in this cluster is also remarkable.

Another result from the analysis is that the construction and engineering machines cluster (C1) firms attach limited importance to the majority of the VET areas other than organisational health, safety, marketing and job-specific technical trainings. A consistent result from the analysis on this point is that $59 \%$ of the firms in this cluster declared that there have been VET activities they wanted to carry out but were unable to in the last year. 
Figure 23. Changes in the organisation in last 12 months per cluster

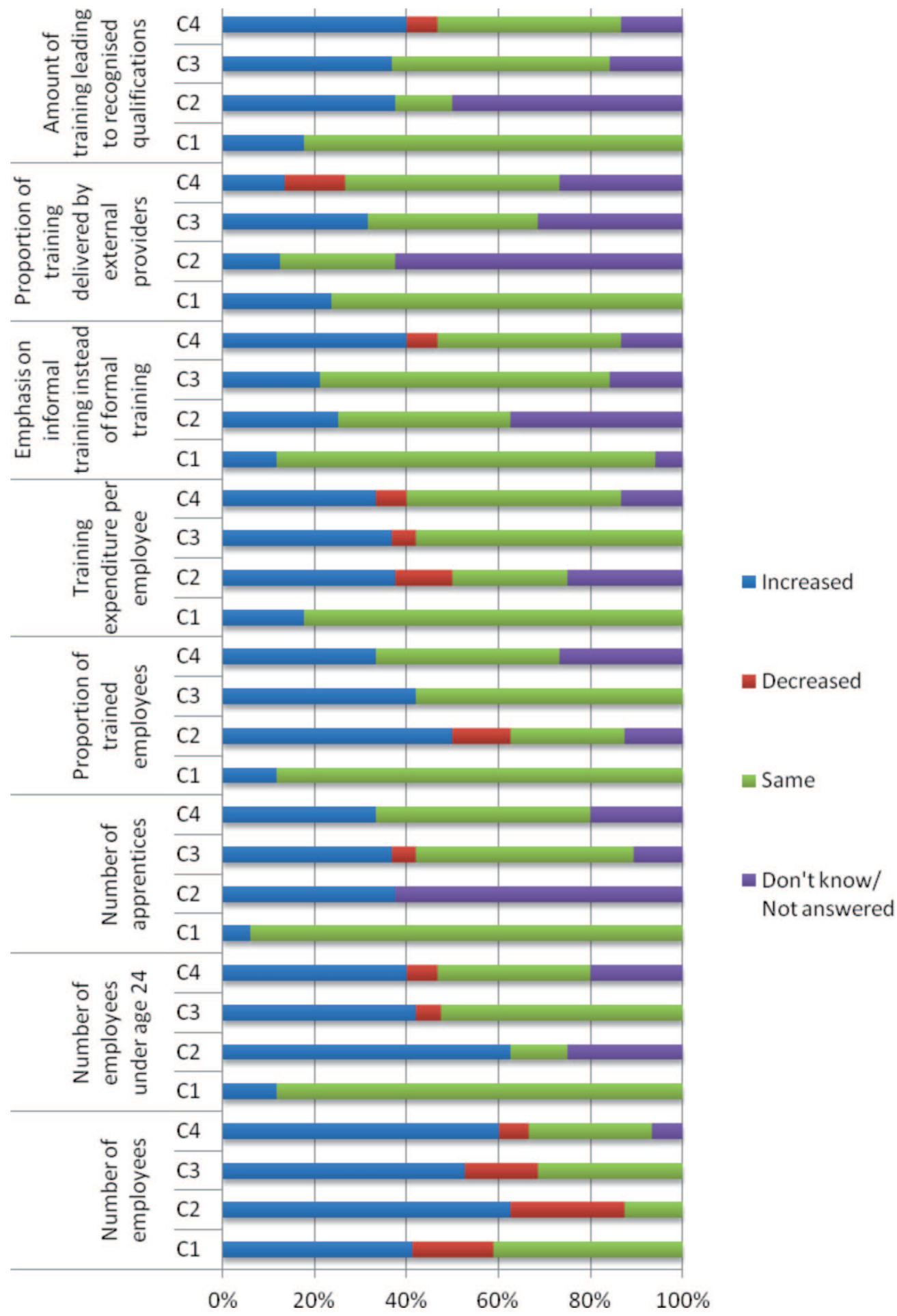


Figure 24. VET activities VET activities participated by SMEs over the past twelve months

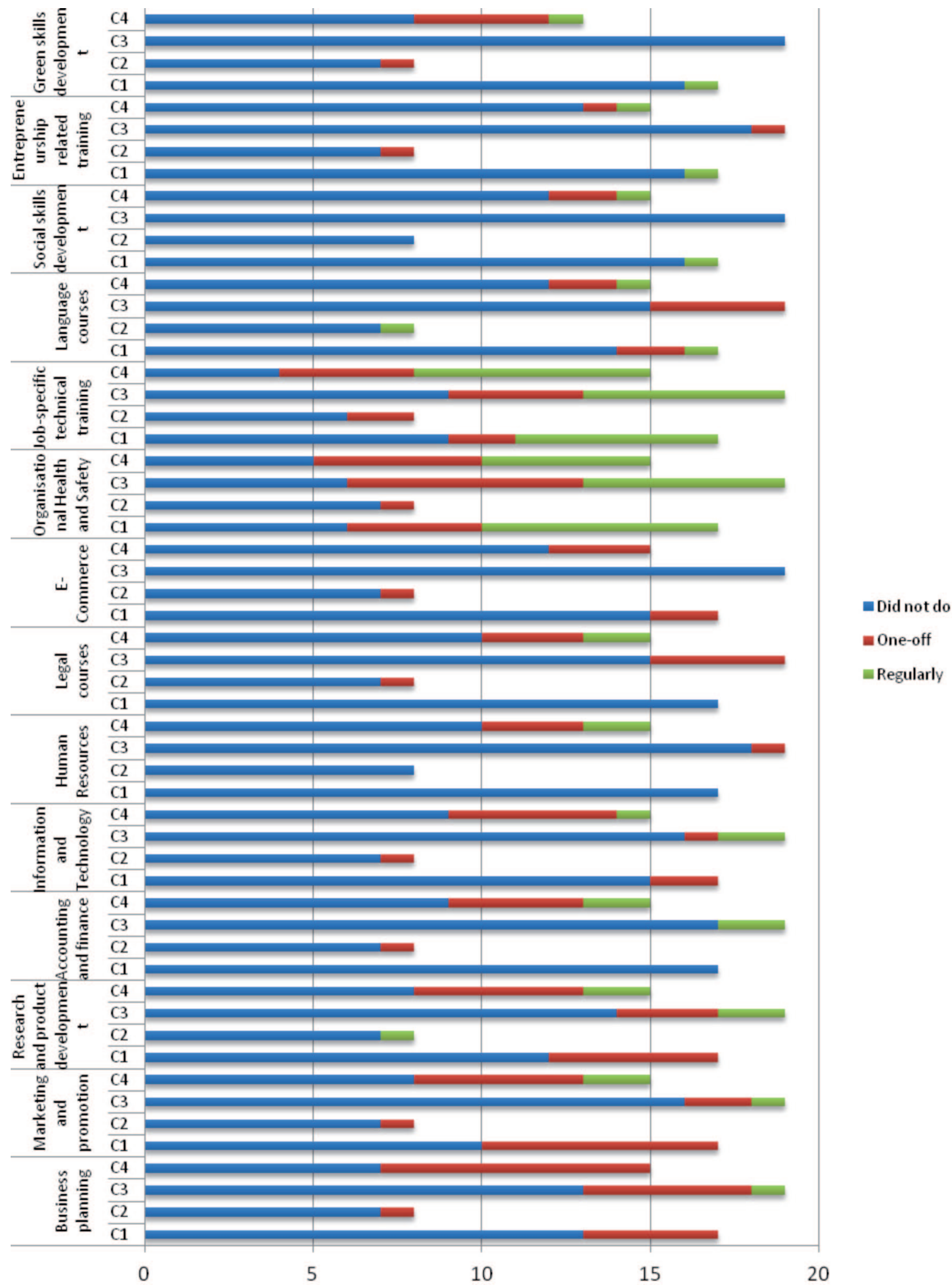


This percentage is the highest among all other clusters $(25 \%$ for medical industry cluster, $37 \%$ for defence and aviation cluster, $40 \%$ for renewable energy and environmental technologies cluster).

The differences between the clusters are slight when considering KISA activities of SMEs in clusters (Figure 25). The firms in the medical industry cluster (C2) perform more knowledge intensive skills activities than the others (especially in business planning, marketing and promotion, research and development, information and technology, job-specific technical training and entrepreneurship related areas).

The high share of "did not do" replies from the SME members of the defence and aviation cluster (C3) is remarkable, similar to the VET results of the same cluster.

The firms in the construction and engineering machines cluster (C1) marginally attach more importance to knowledge intensive skills activities than formal training activities. The clusters that focus more on KISA than VET are the renewable energy and environmental technologies cluster (C4) and the medical industry cluster (C2).

\subsubsection{A summary of key conclusions from the survey results}

The main conclusions from the analysis of the surveys conducted in OSTIM can be summarised as follows:

- SMEs in the zone, the majority of which are manufacturing firms operating as suppliers of high-medium tech producers, mainly implement incremental changes in their products, operations/processes and technologies. Likewise, they put emphasis mainly on the development of technical/advanced skills.

- A sufficient level of importance is not attached to Green changes by a large number of SMEs. Similar to green changes, the development of green skills is an area where the majority of SMEs do not choose to invest. This may be primarily because of the low levels of awareness of the need for alignment with the climate change adjustments, requirements or regulations.

- In general, the large number of "don't know"/“did not do" responses is a concern. The main explanation for this situation is the following: as indicated by the survey results - also observed during the site visits -, the majority of SMEs do not attach importance on training and skills development (as noted before, only $28 \%$ of SMEs declared that they received VET and 25\% stated that they participated in KISA over the last 12 months). Also, the majority neither have a department nor a staff responsible for human resources. This is also evident by the fact that human resources issues, including overseeing training and skills development for staff, are a minor part of the job role of the majority (66\%) of the respondents. Only $15 \%$ said that all of their roles were related to human resources and the rest stated it was a major part of their job roles. Thus, a high number of respondents with limited interest and role in training and skills development failed to provide an answer to a large number of questions and preferred to choose "don't know" replies.

- Since the clusters in OSTIM are still in the embryonic stage of development, positive outcomes and impacts of clusters in firm behaviour are not yet observed. For example, a relatively large number of SMEs state that they do not need to develop social skills of their employees. Also, the relatively high amount of "don't know"/“did not do" responses in relation to knowledge intensive services activities 
Figure 25. KISA activities participated by SMEs over the past twelve months

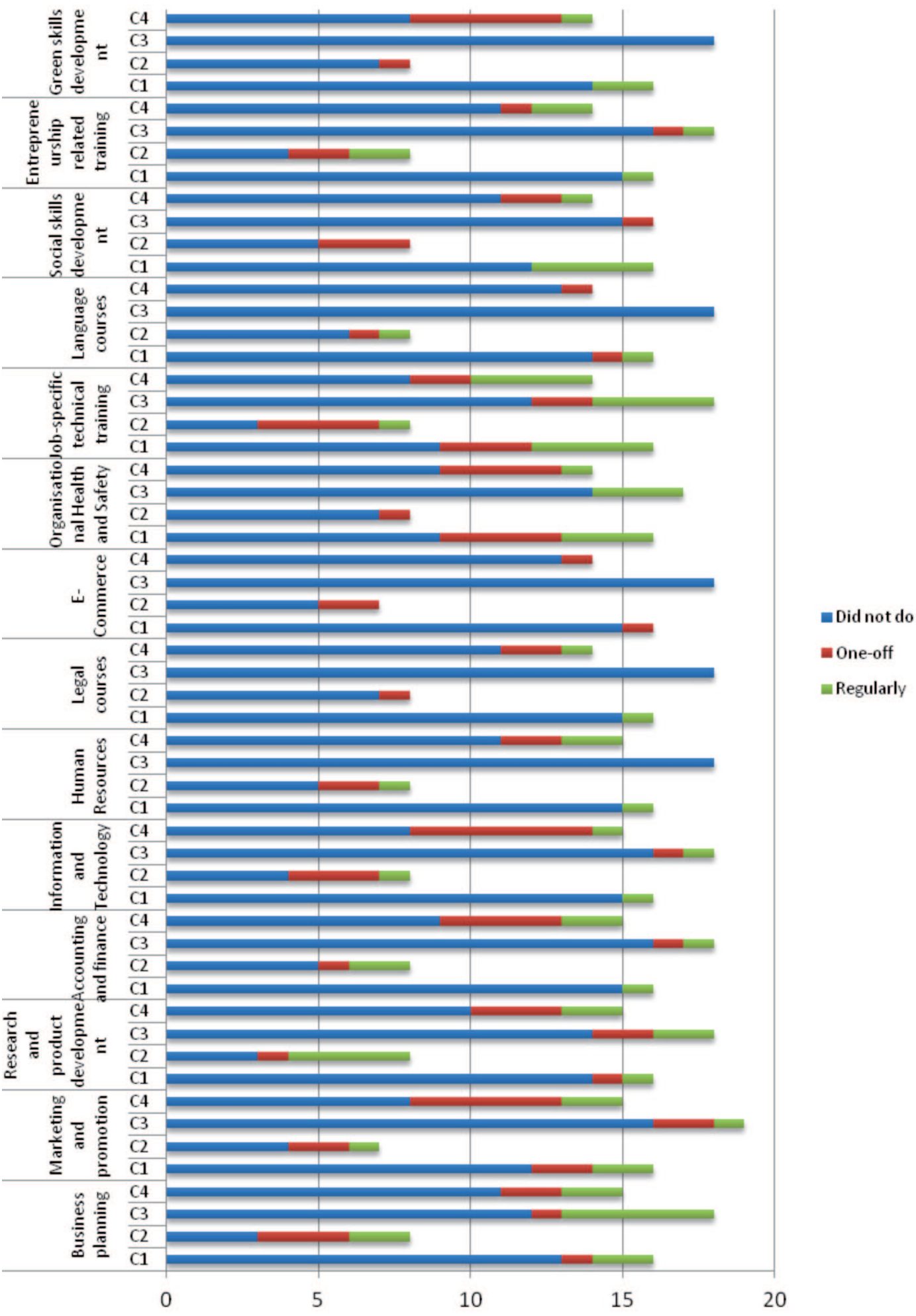


may indicate SMEs within the zone do not yet consider or use clusters as an important tool for SME development/innovation and skill development.

- Training (both VET and KISA) opportunities are not equally distributed among staff at firms. They mainly reach high-medium skilled employees rather than low skilled staff. Not surprisingly, low-skilled workers have difficulties in accessing training mainly since SMEs, according to the respondents, are not able to interrupt production. Also, the majority of employees receiving training are those between 25-49 years of age.

- The majority of SMEs cannot provide an assessment on the outcomes of trainings (both VET and KISA) for business, local area and industry sectors. Not being able to assess/observe these outcomes may have a negative effect on the level of interest in training activities.

- While SMEs state that the costs involved in trainings as well as the lack of public finance are the main reason for not carrying out trainings, a relatively large number of low-cost VET and KISA providers and public finance providers are accessible and active in the zone (perhaps more than in any other organised industrial zone in Turkey for the characteristics of OSTIM cited in Section 1).

- The benefit of investment in training and skills development on innovation activities of SMEs is confirmed by the correlation analysis: the existence of a formal training plan and training budget positively affects the innovation activities of SMEs. Investment in green skills development (particularly through KISA) has a positive impact on green innovations. Furthermore, KISA on entrepreneurship positively affects management innovations and operation innovations (which is not observed in the case of VET).

- The results of cluster level analysis revealed that - most probably due to their early stage of development - clusters in OSTIM show varying levels of innovation performance, and training and skills development investments. Similar to the results of aggregate analysis obtained from all respondents, cluster firms also attach greater importance to organisational health \& safety and job-specific technical training than any other training topic. The large amount of "did not do" replies is remarkable both in VET and KISA areas questioned in cluster firms, which again related with the fact of low levels of awareness on the importance of training and skills development among SMEs in general, as explained above.

\subsection{Main findings of the in-depth interviews}

In-depth interviews were conducted with five randomly selected SMEs from OSTIM. Two interviewees are active in renewable energy sector; and the others are from machinery, electronics and medical devices sectors. All five companies are members of OSTIM clusters. They are older than 10 years and are small (number of staff between10-49). Information about the companies interviewed is as follows:

- The renewable energy company working on hydrogen power was established 18 years ago. They employ 17 staff. The company designs, produces and sells systems and technologies to produce electrical energy from hydrogen.

- The solar energy company was established in 1994 as a supplier of spare parts, services and systems for the defence industry. In 2000, the company started to develop, produce and sell solar energy systems. They export their products to various countries in Asia and the Middle East. Today they are a full manufacturer of solar systems. 
- The company working in the electronics sector is 41 years old and employs 17 staff. They mainly design, produce and sell electronic cards. They work in the domestic market and cover a large number of regions in the country.

- The machinery manufacturer was established in 1987 and employs 20 staff. The main product line includes conveyors. The company designs, produces and sells their products. Their market range covers a wide range of countries in Europe, Asia and Middle East.

- The medical company is 40 years old. They employ 49 people. The main products of the company include sterilizers of various sorts. They design, manufacture, sell and provide technical services for their products. They operate over a broad geography from Europe to Africa.

\subsubsection{The impact of the crisis on training and skills development in firms}

The importance attached to training as well as the approaches considered important and therefore taken for skills development by the SMEs interviewed are different. These differences determine their different perspectives with regards to the impact of the crisis on their training and skills development activities.

- One of the renewable energy companies working on hydrogen power stated that they do not allocate any budget for trainings, and therefore the crisis did not affect their training activities. One of the shareholders of the company mentioned that they did not send their staff to external trainings but supported their masters' degree education. They consider the training provided by the producers/distributors of machinery they purchase as important training opportunities for their staff. They also send their staff to technical seminars/conferences.

- The financial crisis negatively affected the training and skills development activities of the other renewable energy firm: The company working on solar energy stated that they had to stop sending their staff to trainings due to the crisis. Until 2008 they regularly trained their employees on various topics such as ISO quality standards and foreign trade. The shareholder of the company stated that their annual turnover decreased remarkably because of the crisis and that they had to cut the training budget. On the other hand, they send their staff to free-of-charge trainings organised by KOSGEB. The management of the company observes a remarkable decline in motivation and in the staff's quality of work. They also stated that the customer relations and social skills of the staff were negatively affected because of the lack of training over the past two years.

- The firm working in the electronics sector stated that they do not receive training from external sources. According to the interviewee, the shareholders are experienced senior engineers who provide on-the-job trainings to their employees; thus they have not been affected negatively by the crisis in terms of training and skills development.

- The SME producing machinery said that they have not been able to send their staff on paid training courses for the last two years because of the crisis. As the revenue of the firm decreased due to lower sales volumes in the crisis period they had to cut the training budget. The interviewee explained that the impact of this cut on the company was dramatic: motivation and productivity of the staff decreased. The managers of the firms can also observe a decrease in the qualifications of the skilled employees. 
- The medical company stated that the crisis did not have a major impact on their training and skills development activities. They reduced the training budget but did not cut it completely. With the remaining budget they could continue with training and skills development activities.

\subsubsection{Training and skills development plans/structures in firms}

According to the results of the interviews, SMEs, in general, attach importance to technical trainings and look for opportunities to upgrade skills of employees in this field. They usually consider master degree programmes for high-skilled workers and free-of-charge trainings organised by local and regional non-profit organisations for low-tech staff. There is only one company among the interviewees which used to prepare annual training plans but abandoned this practice due to lack of resources.

- The SME working on hydrogen power stated that their plans focus on technical skills development of staff in their area of activity. For this purpose they encourage staff to attend master degree programmes. Other than that they do not plan or allocate budgets for trainings.

- The solar energy company explained that the managers of the company used to plan, at the beginning of each financial year, the annual trainings based on the needs of the staff until 2008. They used to allocate a budget for these trainings as well. However, they cannot prepare such plans and allocate resources due to crisis.

- To cope with the problem of not being able to train low-skilled workers, the firm selects and hires staff from among those who have attended apprenticeship courses organised by OSTIM management. They also send their low-skilled employees on these courses (which normally takes 6 months) once or twice a week for skills development. For the high-skilled staff, the company allows employees to attend master degree programme.

- The electronics company stated that they do not plan or allocate resources for trainings. In the case that an employee is required to be trained, it is provided in-house by experienced managers.

- The machinery company does not plan any training activities. When they are informed about a training organised by a public body/NGO they send their staff. Such trainings are usually of technical content. They also send their employees to free-of-charge trainings organised by OSTIM and recruit the students of apprenticeship courses as interns. The experienced staff/managers of the firm can provide in-house trainings to the other employees as well.

- The medical company stated that the majority of their staff were engineers who have certificates from accredited bodies. At the beginning of each year the managers of the managers check if there are any certificates which need to be updated. They send those engineers to the trainings of accredited organisations. These trainings are free-of-charge. They also send their staff to free trainings organised by the Ankara Chamber of Industry and Ankara Chamber of Commerce, and to the free trainings of OSTIM (on the topics such as EU harmonisation, project management, procurement techniques, marketing, etc). When they recruit new personnel, they send them to basic trainings such as ISO quality certificates, CE marking and marketing, etc. If they have to hire an engineer, they prefer the ones with a masters degree. They recruit the students of apprenticeship courses as interns who are provided with on-the-job trainings. 


\subsubsection{Impact of VET on skills in firms}

The SMEs interviewed cite similar impacts of VET on skills in their firms. They mainly list higher self-confidence, increased motivation and productivity, and improved social skills for staff. One company emphasises the positive impact of VET on the innovative behaviour of employees. The most cited impact on firms is explained as higher turnover and profit. For the local area, they express different views about the level of interaction between firms in OSTIM and therefore note both positive and no impact.

- The firm working on hydrogen power thinks that trainings help create a common culture and understanding between their staff. This leads to a more effective and productive working environment resulting in higher turnover and profit. For the employee, the increase in their technical knowledge leads to higher motivation and productivity. To make sure these positive impacts occur, the management of the company stimulates knowledge sharing among all staff. For the local area, the interviewees hold opinion that interaction between companies leads to dissemination of knowledge in the region, which has positive impacts on the capacities of regional firms.

- The solar energy company declared that trainings had major impact on the firm in terms of better relations with customers, higher turnover and increase in profitability. For the employees, improved social skills help establish better customer relations and lead to an increase in productivity. Impacts on the local area depend on the level and the quality of interaction between staff of different companies. According to the interviewee, when the interaction is high, the impact on the local area is positive.

- For the electronics company, the impact of trainings on the firm leads to higher confidence, better image of the company, and improved/stronger relations with customers because of the high quality staff. The interviewee stated that the major impact on staff was the higher self-confidence and increased ownership of the firm. It is not possible to identify any positive impacts on the local area, since, according to the interviewee, companies in the region do not interact and collaborate.

- According to the machinery company, the benefits of trainings for the firm are higher quality production and higher value added products, which means higher turnover of the company. For the employees, trainings help to enhance their productivity and work discipline. The interviewee stated that the impact on the local area was not known. They mentioned that the companies in the region tend not to share knowledge between them and prefer not to collaborate most of the time.

- The medical company listed the benefits for firms as the increase in quality and quantity of R\&D and innovation projects. They stated that training and skills development help their staff broaden their vision which results in more ideas and willingness to put these ideas into practice. They also observe that the employees develop higher self-confidence and increased entrepreneurial behaviours after trainings. In addition, trainings help the company develop a common understanding and culture among the staff in the company. The benefit for the local area was defined by the strengthened image of OSTIM as a region hosting successful companies. The interviewees did not know if it has any impact on the other firms in the local area.

\subsubsection{Impact of KISA on skills in firms}

Companies consider government R\&D support programmes as the key sources of KISA which help them develop their staff with the skills and competences required for 
product development and production improvements. One company highlights the impact of R\&D activities on the value chain developments. Again, impacts on the local area are not clear since the SMEs interviewed think that the level of interaction and collaboration between the firms falls below desired levels.

- The firm working on hydrogen power stated that the abilities they developed through their R\&D projects supported by government programmes had a positive impact on the productivity and product/production quality of the company. They also think that interactions with suppliers have a valuable impact on increased knowledge and expertise. The management of the company is of the opinion that KISA is important for the skills development of staff as they learn through interaction and experiencing. For the local area, since the level of interaction between companies is not at a desired level, it is not possible to judge the impact of KISA on the region, according to the interviewees.

- The solar energy company thinks that the high level of interaction they have with their customers abroad has helped them to develop better skills and capabilities in production and product development. The product and production quality has also improved. The R\&D projects they implement through government finance helped enhance project management and product development skills. All of these interactions and "learning by doing" has helped the staff to develop valuable skills. Their self-confidence and motivation has also increased. With improved skills and broader vision, the company has become aware of its capabilities. As a result, they increased $R \& D$ activities with local input in the $R \& D$ process, leading to a positive impact on the value chain. The material/process quality of local companies which supply input to the products developed by the firm increased, which led to an increase in sales and profitability of suppliers.

- The electronics company also consider their R\&D projects implemented through public support to be valuable tools for learning. They are of the opinion that this is the best way to equip their staff with new skills and capabilities. They do not observe any impact on the local area since the interaction between companies is below the desired level, as put forward by the company management.

- The machinery company states that KISA helps to increase product quality and productivity. It also increases the quality of work done by staff. The interviewees could not articulate the impact on the local area since, according to the company managers, the firms in the region do not share knowledge and information.

- According to the medical company, KISA helps them to continuously develop their skills and knowledge. Employees become better motivated and their work quality increases. The management of the firm regularly assesses the knowledge of staff by testing to see if they implement what they have learned. The interviewees think that companies with improved skills and knowledge are good for the image of the local area. However they do not know if there are any positive impacts on the skills ecosystem in OSTIM.

\subsubsection{Motivation and collaboration with other organisations}

The findings from the interviews under this heading confirmed the statements of interviewees on the low levels of collaboration and interaction between organisations in OSTIM. Taking into account that these firms are members of the clusters in OSTIM, it is possible to conclude that their statements support the relevant findings from the questionnaire survey on low levels of awareness and interest on cluster related skills. 
- The company working on hydrogen power explains that despite their previous efforts to interact and collaborate with other businesses, the companies they approached were not willing to interact. As a result, the company did not pursue such interactions.

- The solar energy company states that apart from the activities in their value chain, they do not collaborate with the local businesses.

- The electronics company says that they do not collaborate with other businesses similar to the other firms in the region.

- According to the machinery company, local businesses do not collaborate with each other.

- The medical company states that they do not collaborate with local businesses in their area and beyond for training and skills development. They say that they interact with various universities to exchange information and learn from their knowledge.

\subsubsection{New job profiles and trainings for climate change/climate change regulations}

Not surprisingly, companies operating in the renewable energy field express high needs for advanced green skills. The two other companies interviewed admit that they did not feel the need for green skills, similar to the majority of those covered by the questionnaire surveys. The fifth interviewee explains their efforts in energy and water savings and the need for skilled staff to reach higher saving targets.

- The renewable energy companies say that this issue is related to their core business and therefore they require a labour force skilled on the subject. As the level of technical knowledge they need increases with the advancement of technology in the field, they require technical staff with new qualifications. However, it is not always possible to find such people.

- As for the training, the solar company express that they would like to apply for the Ministry of Environment and Forestry's support schemes on decreasing carbon emissions, and therefore need trainings on how to apply for this support programme. In addition, they need to develop social skills in technical personnel. According to the managers of the company, technical staff should be able to explain the benefits of renewables and convince the customers on investing in renewable energy. The management team states that the technical staff also has a mission to raise awareness on the importance of renewables. Therefore they need to be able to speak in terms understood by an ordinary person who does not have information on renewable energy.

- The electronics company and the machinery company declare that they did not create new job profiles as a direct consequence of climate change or climate regulations. These firms did not request or provide specific training on these issues as well, since they did not feel the need so far.

- The medical company states that they received ISO 14000 quality certificate and took precautions for recycling. Now they are working on energy saving measures. So far, they have achieved a $70 \%$ saving on electrical energy and a $60 \%$ saving on water thanks to the efforts of engineers already employed by the company. Now they aim to increase savings to $90 \%$ and they need to hire a new engineer for this purpose. 


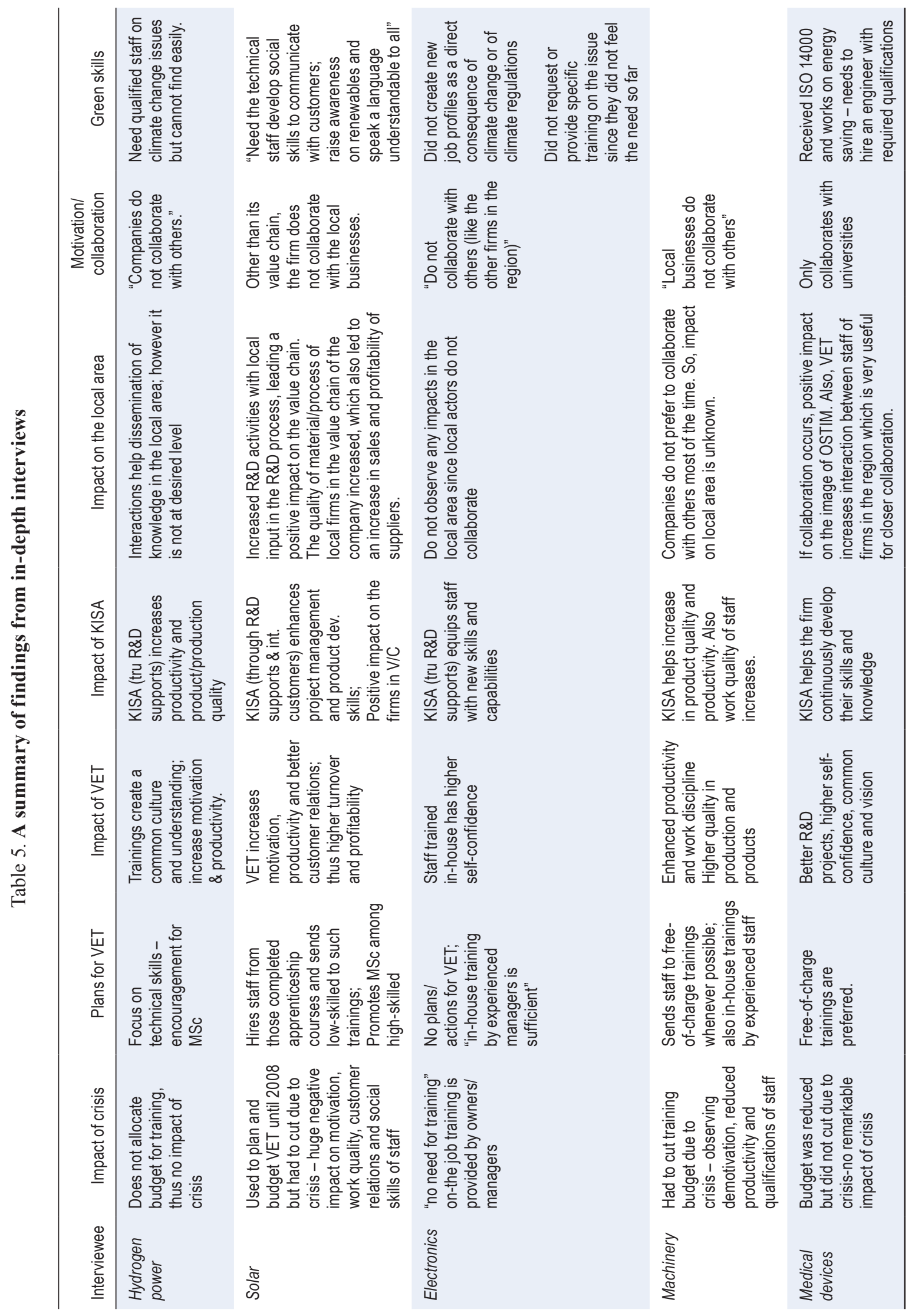




\subsection{Findings of the workshop: the regional skills and training ecosystem in OSTIM}

As explained before, one of the purposes of the study is to explore features of the regional training ecosystem supporting individual SMEs. The skills and training ecosystem in OSTIM is comprised from a variety of actors at governmental, regional, local and national levels, as shown in Figure 26.

Figure 26. The skills and training ecosystem in OSTIM

\section{Government bodies}

\section{Ministry of National Education}

KOSGEB

Export Promotion Centre

National Productivity Centre

Turkish Employment Agency

R\&D support bodies (Ministry of Industry

and Trade, TUBITAK, TTGV)

The Union of Chambers (TOBB)

\section{Local organisations}

OSTIM Management Unit

KOSGEB Ankara OSTIM Service Centre ODEM

Cluster management units

Apprenticeship School

Vocational Training Centre

Vocational High Schools

Technical and Industrial Education School

Vocational Training and Technology Centre

Branch of METU Technopark

\section{Regional organisations}

Ankara Regional Development Agency

Universities in Ankara

Ankara Chamber of Industry

Ankara Chamber of Commerce

Technology parks in Ankara

\section{OSTIM}

\section{SMES}

\section{National training providers}

Private training providers

MEKSA Foundation

TOSYOV Foundation

Universities in other regions

In order to investigate the characteristics and impact of ecosystem on the trainings and skills development needs of OSTIM SMEs, a workshop was organised. 40 participants attended the workshop from representatives of the private sector (SMEs and large companies), public organisations, NGOs, and training and education organisations.

The workshop focused on four themes:

- Training and skills development in SMEs

- Role of training networks

- $\quad$ Skills needs

- Outcomes of training and skills development

The issues discussed by the participants are summarised in the following sections. 


\subsubsection{Training and skills development in SMEs}

Under this theme, the participants discussed

- the challenges of training and skills development in SMEs in Ankara;

- whether or not training reaches low skilled, younger or older workers, intermediate staff and disadvantaged groups;

- if there are specific issues for SMEs that larger firms do not have to face.

The main results of the discussions on above issues are as follows:

- SMEs do not attach a sufficient level of importance to training and skills development. They do not include training in their strategies and hardly allocate any budget for trainings.

- The majority of SMEs are family-owned enterprises, which in general are not institutionalised. It depends on the vision and/or willingness of the owner of the company to invest in training. As put forward by a training organisation in OSTIM, most of the time employees from SMEs are applying and covering the cost of trainings individually since the SME owners prefer not to make this investment.

In addition, SME owners do not generally analyse the skills/training needs and do not give priority to the investment in human capital development. On the other hand, in larger firms, there are human resources departments which assess training needs, allocate annual budgets and motivate managers/staff (for example through performance measures) to participate in trainings.

- The main reasons for SMEs not investing in training were identified as follows:

- SMEs are not aware of the importance of training and skills development for their competitiveness and sustainable growth. Most of the time, SME owners think that investment in training means a waste of money. They never consider the real cost of continuing to employ staff without proper training/skills.

- SME owners fear that trained personnel would leave the company when their skill levels increase after training.

- SME owners claim that they do not have sufficient time to send managers/ staff to trainings, as every member of staff is very busy fulfilling a multitude of tasks. To cope with this problem, they prefer to send the staff to trainings out of working hours, however staff do not want to attend trainings after work.

- Since the quality of vocational school education is not sufficient in the country, SMEs have to invest more in training and skills development.

- Trainings do not reach micro enterprises as they do not have the capacity to follow up training opportunities and to benefit from public programmes that support training/skills development in SMEs. Participants of the workshop suggested that there should be an umbrella organisation in order to identify needs and coordinate trainings for micro enterprises.

- In general, low-skilled workers are not trained in SMEs. Often company owners attend training when they would like to take a training opportunity. This is also linked with the SME owners' fear that trained staff will be poached by rivals and resulting in losing their investment. 
One SME owner comments on this situation: "I, for example, own a forklift operator licence. As I am the owner of the company, I have to know everything since any employee may leave the company anytime, particularly if he/she is qualified."

- Training organisations complain about not having a large enough number of applications from SMEs when they announce trainings. In particular, training seminars organised free-of-charge to attendees by public/non-governmental organisations do not receive enough interest from the private sector.

One training organiser gave the example of a specific training organised for the unemployed where they gave pocket money to trainees to make training attractive to them. Even for this training - at the end of which the trainees also receive a certificate approved by the Ministry of National Education - they did not receive a large enough number of participants.

- According to the SME participants of the workshop, KISA is the most effective way to train managers and staff.

- SMEs mainly need on-the-job training on the topics specific to them. Such trainings are hard to organise and finance by SMEs. There are organisations organising such trainings; however, most of the time only a very limited number of companies show interest.

- The only trainings receiving sufficient interest from SMEs, are compulsory topics such as organisational health and safety. This is followed by trainings where participants are informed about public funding programmes and/or trained about applying to support programmes (such as the EC programmes).

This statement confirms the findings of the questionnaire surveys where it was observed that responding SMEs mainly attach importance to legally binding topics such as organisational health and safety.

\subsubsection{Role of training networks}

This theme covered the following topics of discussion:

- the role of public agencies, regional development organisations, local intermediaries, business organisations/chambers and training organisations on the functioning of the skills and training system in Ankara;

- interactions and projects around which the actors in the system collaborate;

- strategies that can be put in place to increase links between firms and training organisations in the region;

- the level of the policies and programmes effectiveness related to training and skills developments.

The main results of the discussions on this theme are as follows:

- OSTIM benefits from a large number of organisations engaged in training and skills development. The zone has various advantages, as it is located in the capital city of Turkey being close to the national bodies. The main government bodies promoting and/or financing training activities in SMEs are:

- Ministry of National Education,

- KOSGEB, 
- The Export Development Centre (IGEME) through the Undersecretary of Foreign Trade

- The Turkish Employment Agency (ISKUR)

- The Union of Chambers and Commodity Exchanges of Turkey (TOBB)

The key organisations coordinating/providing trainings to SMEs in OSTIM/Ankara regions include:

- Ankara Chamber of Industry

- Ankara Chamber of Commerce

- Regional Universities

There are also other national, regional and local organisations providing finance and/ or trainings to the private sector and in particular SMEs. At the local level, organisations such as ODEM, MEKSA and KOSGEB-OSTIM IGEM are quite active.

There are projects where bilateral co-operation takes place on trainings and skills development. These are mainly the projects implemented on topics such as vocational qualifications, employability skills, etc.

- Public organisations and NGOs responsible for trainings/skills development in SMEs need to collaborate and communicate effectively in the system. There is a need for enhancing the governance system at local, regional and national level in order to eliminate overlaps and fill the gaps in the system. In order to achieve this, there needs to be an oversight body for SME training/skills development which carefully orchestrates the co-operation of major players at national/regional/local levels.

- Continuous communication between the main actors in the system is important. For this purpose, regular meetings/workshops should be organised between the stakeholders.

- Collaboration with universities should be enhanced in order to both develop quality content and to make sure universities keep their curricula up-to-date according to the changing needs of SMEs.

- The most important action, which needs to be made jointly by the actors in the system, is to raise awareness on the investment in training/skills development in SMEs.

- The players in the system need to use more tools more effectively in order to identify the training needs of SMEs. They should improve understanding of SMEs by visiting them often, and by developing and using methods to understand the real needs. The regional development agencies should play a key role in needs analysis.

- The training organisations should be able to customise training contents according to the needs of the SMEs.

- It is important that SMEs co-finance trainings funded by the public organisations. Free-of-charge trainings are proved to be ineffective, as SMEs do not take them seriously.

- Trainings should also be provided to the staff of the organisations providing SME services, including the public bodies implementing SME support programmes. 
- The quality of some of the training organisations needs to be increased in order to provide high-quality trainings to SMEs. The training of trainers is an important issue in maintaining the quality of training services provided to SMEs at high level. In addition, an accreditation system is required in order to make certain that qualified organisations provide training/skills development services to SMEs.

- According to the law, companies employing more than 200 people have to have a training department. The government can lower this number in order for more SMEs to create training departments and formally invest in skills development.

\subsubsection{Skills needs}

This theme covered the following topics of discussion:

- the most pressing skills needs in Ankara and whether or not employees in SMEs and local talent are able to provide these skills;

- the ways in which these skills can be developed and made ready for local firms to utilize them;

- whether or not available skills are being utilised;

- actions that can be taken by public agencies, intermediaries and by business and training organisations so that the level of skills needs is reached.

The main results of the discussions around this theme are as follows:

- Skills related to effective management and organisation; marketing, promotion, sales, customer relations and brand development are important for SMEs. Trainings should be applied and be job-relevant to respond the needs.

- A notable action on the identification of training needs is taken by ISKUR. ISKUR organises training needs analysis activities and identifies the requirements for vocational education.

- It is important to identify skills needs and be specific about the requirements for vocational education. Also, accurate definitions of occupations should be prepared in order to be able to clarify the skills needs.

- The low levels of quality and quantity of intermediate staff are a major issue in Turkey. It is crucial to invest in vocational schools and enhance their attractiveness to the youth.

- Delegation of authority is a major problem in SMEs. SME owners do not authorise the employees they hire to whether they work as a member of the management team or as high-medium skilled employees. This can also be a problem in utilising the skills developed as a result of training: since SME owners do not delegate the authority, trained/skilled staff, who would like to use their newly developed capabilities, become demotivated, and as a result, training investments are wasted.

\subsubsection{Outcomes of training and skills development}

Under this theme, the participants discussed whether:

- there are clear skills shortages; 
- they have changed in the context of national/global challenges (including recession/ economic crisis);

- training and skills development foster innovation activity and business growth;

- the level of training and skills of local talent is a factor in firm establishment/ start-up.

The main results of the discussions on the above issues are as follows:

- There is a shortage of qualified managers in SMEs. It is also difficult to find highskilled employees.

- SMEs lack capabilities particularly to increase their market share, and find new markets and customers. They need qualified staff who are able to help them in these areas. However, SME owners do not allocate resources in hiring such staff and developing such skills in their enterprises. Awareness should be raised and SME owners should be educated on these requirements.

- National and global challenges negatively affect training investments in firms. Many SMEs not only cut training expenses in the first place but can also dismiss skilled/trained staff in the case of financial/economic crisis.

- Effective training programmes enhance innovative capabilities in SMEs leading to higher innovation investment and activity in enterprises.

- SMEs should be informed that training and skills development activities do not pay off in the short run. These activities also have positive side effects which are very important for SMEs and which cannot be easily recognised. Therefore, they should be encouraged to continuously invest in trainings and use the skills developed in daily operations.

- Co-operation between the organisations in the ecosystem is required to stimulate entrepreneurship among the skilled workforce. New entrepreneurs do not only need trainings but also mentoring. 



\section{CONCLUSIONS AND RECOMMENDATIONS}

The findings of the field research conducted for the study highlighted a number of key conclusions on training and skills development among OSTIM SMEs:

- SMEs attach limited importance on training and skills development. The SME owners/managers only value technical trainings in the field of activity of the firm.

- Although there are a large number of organisations providing opportunities in this area, trainings do not reach the majority of SMEs.

- The large number of bodies providing training and skills development opportunities suggests fragmentation in the system. Particularly, horizontal (mainly among the actors at local level) and vertical (between the actors at local, regional and national levels) co-ordination needs are evident.

- The low levels of co-ordination between the players of the ecosystem make it difficult for SMEs to indentify the opportunities for trainings: For example, as noted before, SMEs which state that they could not carry out training in the past 12 months although they wanted to listed the high costs associated with trainings and the lack of public finance as the most important reasons, although there are various public supports where SMEs can finance their training expenditures (See, for example, KOSGEB support schemes explained in Annex 1).

- SMEs, in general, do not consider green skills as an important area of investment.

- Trainings/skills development are usually aimed at high-skilled employees, resulting in limited opportunities for low-skilled workers on training and skills development.

- On average, training has little impact on job mobility, despite employer fear about trained staff being poached by rivals and thus losing their investment.

- Institutionalisation of training activities in SMEs positively affects innovations of all types, in particular technological innovations and green innovations. On the other hand, the existence of a training plan and training budget do not positively affect investment in green skills and entrepreneurship trainings in OSTIM SMEs.

- Knowledge intensive service activities are considered more important by SMEs and the other stakeholders of the ecosystem, and have a stronger impact on SME skills than formal training.

- Clusters in OSTIM are not yet effective in promoting skills development among their members through increased interaction and co-operation.

In light of these conclusions and from the other findings, it is possible to list the following recommendations under two main groups: 


\section{Investing in training and skills development in SMEs}

- Raise awareness among SMEs on the need for training and skills development through various means, for example by:

- $\quad$ giving right messages on wrong perceptions, such as "Training has little impact on job mobility, despite employer fear about trained staff being poached by rivals and so losing their investment" and "It is much more expensive not to train the people";

- identifying and disseminating success stories of SMEs from different sectors which continuously invests in training and skills development;

- particularly targeting cultural change among SME owners/managers.

- Design and implement policy measures

- $\quad$ to stimulate training and skills development for low-skilled workers;

- $\quad$ specific to micro enterprises' needs on training and skills development;

- to encourage institutionalisation of SMEs;

- to provide on-the-job coaching/mentoring to micro and small enterprises;

- to stimulate development of green skills, and innovation, entrepreneurship and social skills in SMEs;

- to encourage inter-firm collaboration and collaboration between SMEs and other actors in the system for training and skills development (also through effective cluster development programmes);

- Pay attention to developing a balanced policy mix on trainings and skills development. For this purpose, focus on a segmentation of target groups to successfully address their needs in the area.

\section{Improving the ecosystem}

- Improve governance by assigning an oversight body for SME training \& skills development which carefully orchestrates co-operation among major players at national/regional/sectoral levels - KOSGEB can play this role effectively.

- Develop a balanced, effective and complementary set of training and skills development programmes by evaluating existing measures (in terms of their complementarity, effectiveness, efficiency, impact, relevance, coherence and sustainability), and by eliminating overlaps and multiplicities.

- Make sure that the main stakeholders in the system communicate and interact regularly and effectively (through meetings/workshops, etc). Regional level coordination can be performed by the regional development agencies.

- Develop and implement tools to monitor and measure the impact of training and skills development at different levels.

- Modernise VET education and develop mechanisms to ensure that vocational schools and universities collaborate with SMEs in order to keep their curricula relevant and current to the changing needs of companies.

- Conduct a skills gap analysis to identify critical work-force skills, analyse shortfalls, and develop strategies resolving these shortfalls. 
- Provide regular trainings to the staff of the organisations providing SME services, including the public bodies implementing SME support programmes.

- Develop an accreditation system for the organisations providing trainings to SMEs. Also help them to continuously upgrade their services and improve their skills and capabilities through training-the-trainers schemes. 



\section{REFERENCES}

OECD (2010) SMEs, Entrepreneurship and Innovation, OECD, Paris.

OECD (2009) Learning for Jobs, Initial report, OECD, Paris.

OECD (2006) Innovation and Knowledge-Intensive Service Activities, OECD, Paris.

OECD (2003), "Knowledge Intensive Service Activities in the Software Industry", draft synthesis report of TIP Innovation Case Studies on KISA: Software Module, Directorate for Science, Technology and Industry/Science and Technology Policy/ Innovation and Technology Policy, Volume 11, OECD, Paris.

Martinez-Fernandez, M. C. (2006), "An Introduction to KISA", in Martinez-Fernandez and Martinez-Solano (eds.) Knowledge Intensive Service Activities (KISA) in Software Innovation, International Journal of Services Technology and Management, Volume 7(2), pp. 109-114.

\section{Websites}

SME Development and Support Organisation, http://www.kosgeb.gov.tr/

OSTIM Organised Industrial Zone, http://www.ostim.org.tr/

OSTIM Medical Industry Cluster, http://www.ostimmedikal.com/

OSTIM Renewable Energy \& Environmental Technologies Cluster, http://www.ostimenerjik.com

OSTIM Construction \& Engineering Machines Cluster, http://www.ostim.cankaya.edu.tr/ OSTIM Defence and Aviation Cluster http://www.ostimsavunma.org/ 



\section{ANNEX A}

\section{BRIEF INFORMATION ABOUT SME DEVELOPMENT AND SUPPORT ORGANISATION (KOSGEB)}

KOSGEB was established by the government in 1990 to increase the value added and productivity of SMEs, to enhance their competitiveness in national and international markets. Reporting to the Ministry of Industry and Trade, KOSGEB plays a leadership role in supporting SMEs in all stages of their development.

KOSGEB implements its support schemes through its service units established throughout Turkey. There are 73 Enterprise Development Centres, 26 Technology Development Centres, 33 virtual incubators and 101 Synergy Centres established by KOSGEB. KOSGEB also participates in six consortia of the Enterprise Europe Network (EEN) and acts as the leader in five of them (EEN is coordinated by the Ministry of Industry and Trade, there are seven EEN consortia established in Turkey. KOSGEB also undertakes general coordination and acts as a contact point for the Ministry for the Turkish consortia).

The main support programmes of KOSGEB are as follows:

- SME Project Support Programme, which finances projects targeting companyspecific problems. Main project fields supported include production, management and organisation, marketing, foreign trade, human resources, accounting and finance, and information management.

- Thematic Project Support Programme aiming to support projects implemented to address regional and sectoral needs of SMEs. The thematic areas identified are selected from the priority fields identified in the policy documents.

- The Programme to Support SME Collaboration is aimed at bringing together SMEs in order to develop and implement "common solutions for common problems". Within this framework, problems faced by SMEs in the areas such as procurement, marketing, capacity usage, competitiveness and finance are addressed.

- R\&D, Innovation and Industrial Applications Support Programme is designed to promote R\&D and innovation activities of SMEs, and to support technology entrepreneurs.

- General Support Programme aims to improve competitiveness of SMEs by stimulating quality improvements, business development activities and efficient production.

- Entrepreneurship Support Programme promotes the dissemination of entrepreneurship culture and development of new entrepreneurs by stimulating the creation of business incubators. 
- Emerging Companies Market SME Support Programme was designed for SMEs to obtain permanent financial resources from stock markets. Under this programme, KOSGEB supports the expenses of SMEs related to market advisor consultancy service, independent audit, Capital Market Board registration, Istanbul Stock Exchange Emerging Companies Market and intermediary institution. 
ANNEX B

\section{TECHNICAL AND VOCATIONAL EDUCATION SYSTEM, AND GENERAL STRUCTURE OF HIGHER EDUCATION IN TURKEY}

Figure B.1 Technical and vocational education system in Turkey

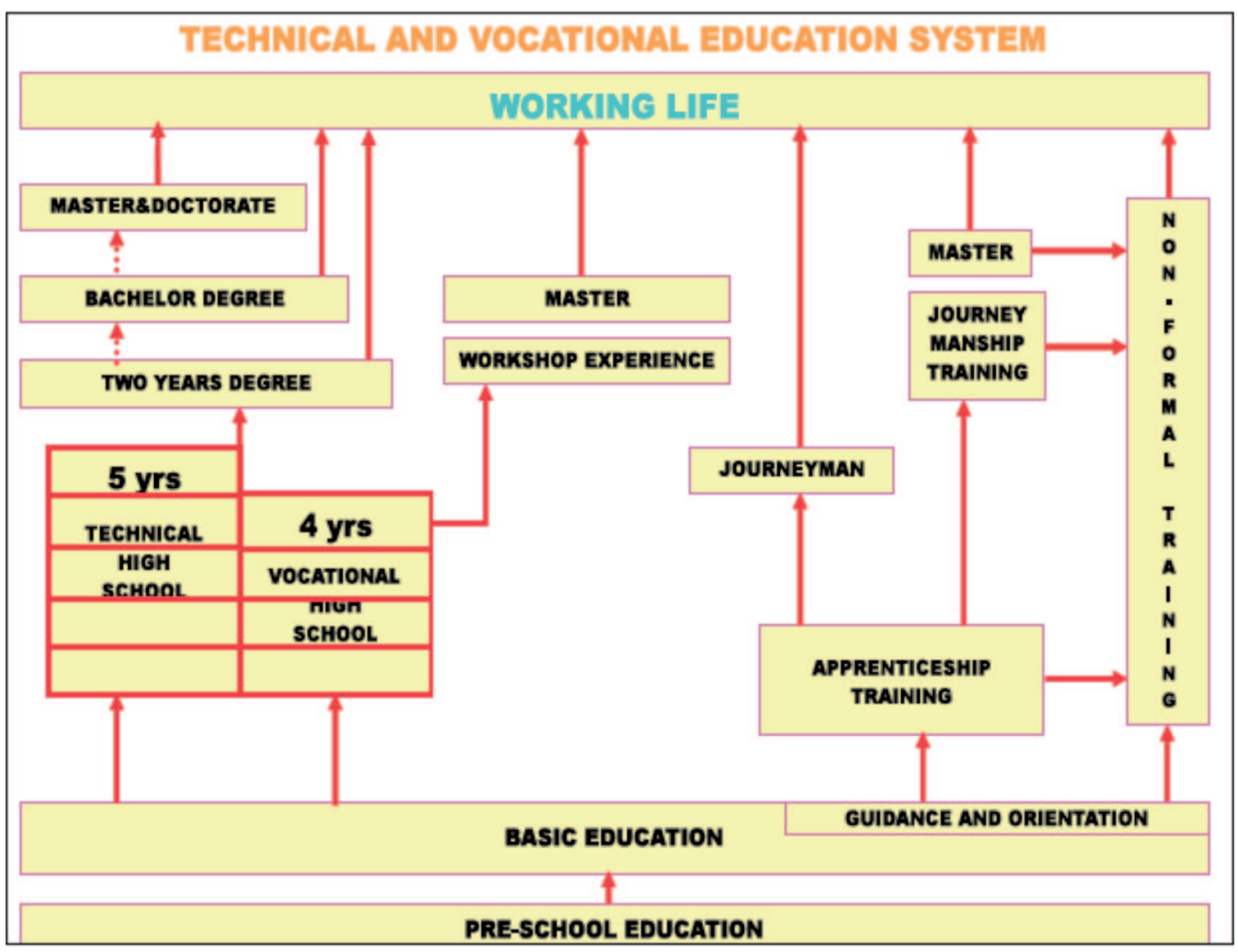

Source: Prof. Dr. Sabahattin BALCI (2009), Turkish Tertiary Education System, Turkey-UK Partnership Seminar, Ankara. 
Figure B.2 General structure of higher education in Turkey

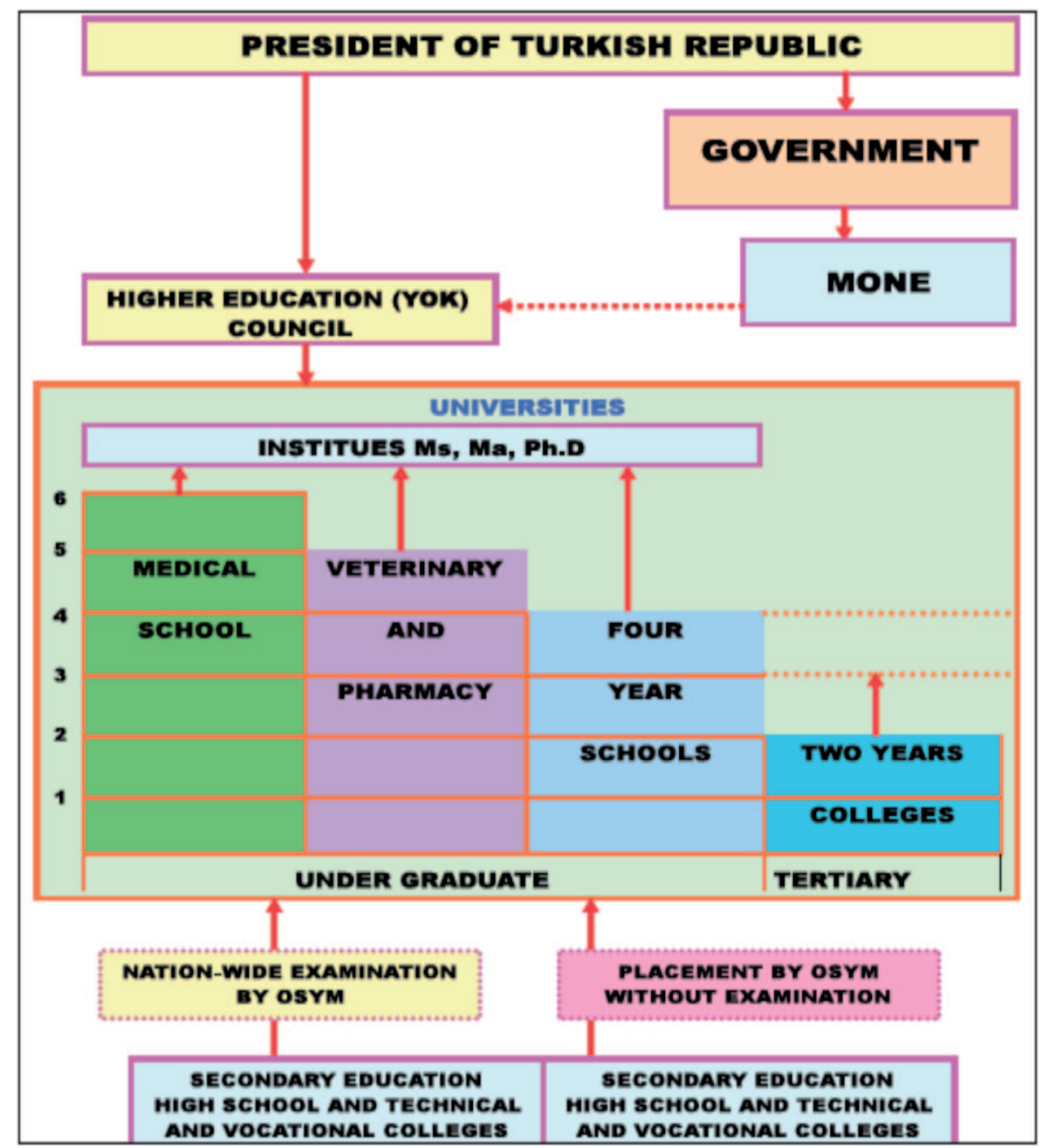

Source: Prof. Dr. Sabahattin BALCI (2009), Turkish Tertiary Education System, Turkey-UK Partnership Seminar, Ankara. 


\section{ANNEX C}

\section{PARTICIPANTS OF ECOSYSTEM WORKSHOP}

CFE/LEED, OECD

Ankara Chamber of Industry

TUSAS/TAI Corp.

EMGE Co.

\section{KOSGEB}

Turkish Employment Agency

OSTIM Management

Turkish Union of Chambers and Commodities Exchanges

Ankara Development Agency

Digitech Ltd.

Cankaya University

MEKSA Foundation

BMD Solar Ltd.

OSTIM-ODEM

Gokser Makina Ltd.

Ministry of Industry and Trade

KOSGEB-OSTIM Centre

Ministry of National Education 


\section{ANNEX D}

\section{QUESTIONNAIRE}

This survey is part of a study conducted by the Organisation for Economic Co-Operation and Development (OECD) in collaboration with [country agency]

The project looks at training and skills development in Small and Medium-sized Enterprises (SMEs).

Your assistance in completing the survey will therefore be very valuable for identifying those factors related to skills development hindering competitiveness and innovation in SMEs.

This survey should be completed by someone in your business responsible for Human Resources and/or training. If this is not you please forward it to the appropriate person. The survey consists of 25 mostly multiple choice questions and will take approximately 20 minutes to complete.

The survey is divided into four sections: - the first section asks for some details about your business and employees. Section two asks about your business's use of industry and skills development training / vocational education and training (VET) activities. Section three asks about other ways of building your employees' skills, knowledge and competencies beyond training. Section four refers to your business collaborative activities and reasons for training and skills development.

Your privacy is important to us. All information is kept confidential. 


\section{SECTION 1 - ABOUT YOUR BUSINESS and EMPLOYEES}

S.1. In which country is your business located?

$\begin{array}{lc} & \text { [SINGLE RESPONSE] } \\ \text { Belgium } & \square \\ \text { New Zealand } & \square \\ \text { Poland } & \square \\ \text { Turkey } & \square \\ \text { UK } & \square \\ \text { Canada } & \square \\ & \square\end{array}$

Q.1. To what extent you would say your job role is responsible for human resource issues, including overseeing training and skills development for staff? Is it..

[SINGLE RESPONSE]

All of your role

A major part of your role

口

A minor part of your role

Q.2. Are your products or services primarily sold...

[SINGLE RESPONSE]

Locally / Regionally

Nationally

Internationally

Don't know

Q.3. How long has your business been in operation?

[SINGLE RESPONSE]

less than 1 year

$1-4$ years

5-9 years

10 years or more

Q.4. What is the main sector your business operates in?

Q.4.1. And more specifically, which one of the following economic sectors does your business operate in?

[SINGLE RESPONSE]

A - Agriculture, hunting and forestry

01 - Agriculture, hunting and related service activities

02 - Forestry, logging and related service activities

B - Fishing

05 - Fishing, aquaculture and service activities incidental to fishing

$\mathrm{C}-\overline{\text { Mining and quarrying }}$

$\underline{10}$ - Mining of coal and lignite; extraction of peat

11 - Extraction of crude petroleum and natural gas; service activities incidental to oil and gas extraction, excluding surveying

12 - Mining of uranium and thorium ores

13 - Mining of metal ores

14 - Other mining and quarrying

D - Manufacturing

15 - Manufacture of food products and beverages

16 - Manufacture of tobacco products

$\underline{17}$ - Manufacture of textiles

$\underline{18}$ - Manufacture of wearing apparel; dressing and dyeing of fur

19 - Tanning and dressing of leather; manufacture of luggage, handbags, saddler, harness and footwear

$\underline{20}$ - Manufacture of wood and of products of wood and cork, except furniture; manufacture of articles of straw and plaiting materials 
21 - Manufacture of paper and paper products

$\underline{22}$ - Publishing, printing and reproduction of recorded media

23 - Manufacture of coke, refined petroleum products and nuclear fuel

24 - Manufacture of chemicals and chemical products

25 - Manufacture of rubber and plastics products

26 - Manufacture of other non-metallic mineral products

$\underline{27}$ - Manufacture of basic metals

28 - Manufacture of fabricated metal products, except machinery and equipment

$\underline{29}$ - Manufacture of machinery and equipment n.e.c. ${ }^{1}$

$\underline{30}$ - Manufacture of office, accounting and computing machinery

31 - Manufacture of electrical machinery and apparatus n.e.c.

32 - Manufacture of radio, television and communication equipment and apparatus

$\underline{33}$ - Manufacture of medical, precision and optical instruments, watches and clocks

34 - Manufacture of motor vehicles, trailers and semi-trailers

$\underline{35}$ - Manufacture of other transport equipment

$\underline{36}$ - Manufacture of furniture; manufacturing n.e.c.

$\underline{37}$ - Recycling

E - Electricity, gas and water supply

$\underline{40}$ - Electricity, gas, steam and hot water supply

$\underline{41}$ - Collection, purification and distribution of water

F - Construction

45 - Construction

G - Wholesale and retail trade; repair of motor vehicles, motorcycles and personal and household goods $\underline{50}$ - Sale, maintenance and repair of motor vehicles and motorcycles; retail sale of automotive fuel

$\underline{51}$ - Wholesale trade and commission trade, except of motor vehicles and motorcycles

$\underline{52}$ - Retail trade, except of motor vehicles and motorcycles; repair of personal and household goods

$\underline{H}$ - Hotels and restaurants

$\underline{55}$ - Hotels and restaurants

I - Transport, storage and communications

$\underline{60}$ - Land transport; transport via pipelines

$\overline{61}$ - Water transport

$\underline{62}$ - Air transport

$\underline{63}$ - Supporting and auxiliary transport activities; activities of travel agencies

64 - Post and telecommunications

J - Financial intermediation

$\underline{65}$ - Financial intermediation, except insurance and pension funding

$\underline{66}$ - Insurance and pension funding, except compulsory social security

$\overline{67}$ - Activities auxiliary to financial intermediation

$\underline{\mathrm{K}}$ - $\overline{\text { Real estate, renting and business activities }}$

70 - Real estate activities

$\overline{71}$ - Renting of machinery and equipment without operator and of personal and household goods

$\overline{72}$ - Computer and related activities

73 - Research and development

74 - Other business activities

$\underline{\mathrm{L}}$ - Public administration and defence; compulsory social security

$\underline{75}$ - Public administration and defence; compulsory social security

M - Education

80 - Education

N - Health and social work

$\underline{85}$ - Health and social work

O - Other community, social and personal service activities

90 - Sewage and refuse disposal, sanitation and similar activities

$\overline{91}$ - Activities of membership organisations n.e.c. ${ }^{1}$

$\underline{92}$ - Recreational, cultural and sporting activities

93 - Other service activities

$\underline{P}$ - Activities of private households as employers and undifferentiated production activities of private households

95 - Activities of private households as employers of domestic staff

96 - Undifferentiated goods-producing activities of private households for own use

$\overline{97}$ - Undifferentiated service-producing activities of private households for own use

Q - Extraterritorial organisations and bodies

99 - Extraterritorial organisations and bodies 
Q.5. How many employees does your business have? (approximately)

[SINGLE RESPONSE PER LINE]

Employed...

Don't

know

Q.5.1. In total

And of these, how many are...

Full time

Part time

Casual or temporary

Q.5.2. How many of your employees are apprentices/trainees? (approximately)

Number [SINGLE RESPONSE]

employees

Q.6. How many of your staff are in each of the following occupations (approximately)?

[SINGLE RESPONSE PER LINE]

Managers and senior officials

Professional occupations ${ }^{2}$

Associate professional and technical occupations ${ }^{3}$

Skillsed trades occupations ${ }^{4}$

Personal service occupations ${ }^{5}$

Sales and customer service occupations ${ }^{6}$

Process, plant and machine operatives ${ }^{7}$

Elementary occupations ${ }^{8}$

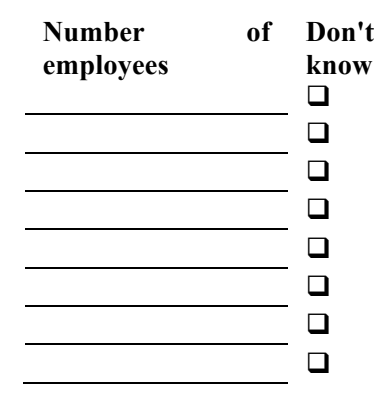

2 e.g. accountant, chemist, architect, engineer, economist

3 e.g. associate technician, building associate

4 e.g. electrician, carpenter, welder, sheet metal worker, instrument mechanic

5 e.g. child-care worker, home care aides

6 e.g. shop assistant, sales assistant

7 e.g. process workers, van/fork-lift truck drivers, food processing machine operator

8 e.g. labourers, cleaners, packers, security guards 
Q.7. How many of your staff are in the following age groups (approximately)?

[SINGLE RESPONSE PER LINE]

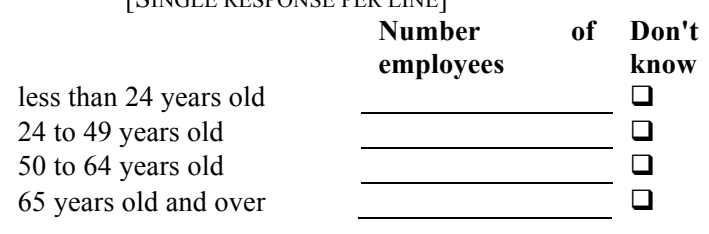

Q.8. Has your business made changes in the past 12 months in terms of introducing:

[SINGLE RESPONSE PER LINE]

\begin{tabular}{|c|c|c|}
\hline A new product/service (or a substantially changed product/service)? & $\begin{array}{l}\text { Yes } \\
\square\end{array}$ & $\begin{array}{l}\text { No } \\
\square\end{array}$ \\
\hline $\begin{array}{l}\text { A new way of producing an existing product/service (e.g. a new operational } \\
\text { process)? }\end{array}$ & $\square$ & $\square$ \\
\hline $\begin{array}{l}\text { Changes to the way your firm does things such as a new or substantially changed } \\
\text { accounting system or human resource management system (e.g. a new management } \\
\text { process)? }\end{array}$ & $\square$ & $\square$ \\
\hline A new technology or equipment & $\square$ & $\square$ \\
\hline A new product/service/operation due to climate change adaptation/regulation & $\square$ & $\square$ \\
\hline
\end{tabular}

Q.9. Would you consider these changes to be "incremental" (series of gradual or small changes over time) or "radical" (a onetime big change)?

[SINGLE RESPONSE PER LINE]

A new product/service (or a substantially changed product/service)?

Incremental Radical

A new way of producing an existing product/service (e.g. a new operational process)?

Changes to the way your firm does things such as a new or substantially changed accounting system or human resource management system (e.g. a new management process)?

A new technology or equipment

A new product/service/operation due to climate change adaptation/regulation

$\begin{array}{ll}\text { Incremental } & \text { Radical } \\ \square & \square \\ \square & \square \\ \square & \square \\ \square & \square \\ \square & \square\end{array}$


Q.10. Training plans

[SINGLE RESPONSE PER LINE]

Training plans

$\begin{array}{llll} & \text { Not } & \text { Don’t } & \\ \text { Yes No } & \text { Applicable } & \text { Know } & \text { RULE }\end{array}$

Q.10.1. Does your business have formal training ${ }^{9}$ and career development plans for employees (e.g. plans for career advancement and promotion)?

Q.10.2. Does your business have an annual budget for training expenditure (e.g. formal/informal training; on/off the job; covering direct costs)?

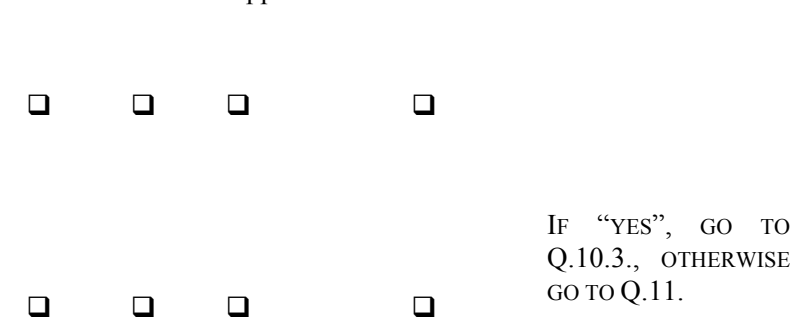
Q.10.3. What percentage of your total salary budget is this, for the current financial year?

Q.11. Over the last 12 months, have the following increased, stayed about the same or decreased at this business?

[SINGLE RESPONSE PER LINE]

$\begin{array}{llll}\text { Increase } & \begin{array}{l}\text { Stayed } \\ \text { the } \\ \text { same }\end{array} & \text { Decreased } & \begin{array}{l}\text { Don't know } \\ \text { /Not } \\ \text { Relevant }\end{array}\end{array}$

The number of staff employed at your

establishment in total

The number of young people aged under 24

recruited to their first job

The number of apprentices and new trainees

recruited by your establishment

The proportion of employees provided with training

Expenditure on training per employee

The emphasis placed on informal learning instead of formal learning

The proportion of your total training delivered by external providers

The amount of formal training, leading to recognised qualifications, that your business supports

$\square$
$\square$
0
0
0
0
0
$\square$

$9 \quad$ Formal Training refers to learning that occurs in an organised and structured environment (e.g. in an education or training institution or on the job) and is explicitly designated as learning (in terms of objectives, time or resources). Formal learning is intentional from the learner's point of view. It typically leads to validation and certification.

Informal Training refers to learning resulting from daily activities related to work, family or leisure. It is not organised or structured in terms of objectives, time or learning support. Informal learning is in most cases unintentional from the learner's perspective (CEDEFOP, 2008). 
Q.12. Where do you think additional training is needed in your business(ongoing need or newly needed) over the next 12 months?

Definition: Value-chain is a linked set of activities within a supply chain, involving a number of businesses performing different activities of the process which actively add value to the end product.

[SINGLE RESPONSE PER LINE]

Skills

Generic- general IT user skills, oral communication, written communication, numeracy and literacy, office admin skills;

Routine - repetitive, more basic, low knowledge intensive skills;

Technical/Advanced - skills required for problem solving; design, operation, rethinking and maintenance of machinery or technological structures; IT professional skills;

Management - skills for business planning, regulations and quality control, human resources planning (recruitment, training and skills development) and allocation of resources;

Social - motivation and appreciation of people's characteristics for individual and team working purposes, customer handling; appreciation of networks and value-chain partners;

Language and cultural - ability to communicate in more than one language, appreciation of cultural characteristics of different ethnic groups;

Entrepreneurial - specific skills for start-ups such as risk, strategic thinking, self-confidence, the ability to make the best of personal networks and the ability of dealing with challenges and requirements of different nature.

Green - specific skills required to adjust your products, services or operations due to climate change adjustments, requirements or regulations

$\begin{array}{llll}\begin{array}{l}\text { High } \\ \text { need }\end{array} & \begin{array}{l}\text { Some } \\ \text { need }\end{array} & \text { No need } & \begin{array}{c}\text { Don't } \\ \text { know }\end{array} \\ \square & \square & \square & \square \\ \square & \square & \square & \square \\ \square & \square & \square & \square \\ \square & \square & \square & \square \\ \square & \square & \square & \square \\ \square & \square & \square & \square \\ \square & \square & \square & \square \\ \square & \square & \square & \square\end{array}$




\section{SECTION 2 - YOUR FIRM'S INDUSTRY TRAINING / VOCATIONAL EDUCATION AND TRAINING (VET) ACTIVITIES}

Questions in this section refer to any industry and skills development training your business has supported or provided even if only to one employee during the past 12 months. The section also asks your opinion regarding the outcomes of the training and skills development.

Q.13. Did any of your employees participate in training in any of the following areas during the past 12 months?

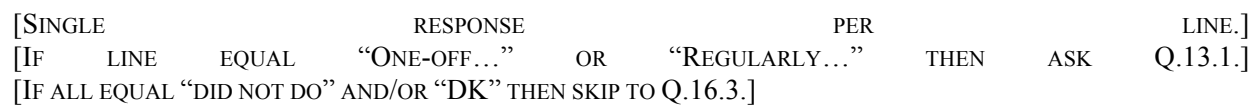

One-off

(specific Regularly Don't

Industry training / VET

Did not do need)

Business planning (including management and leadership training)

Marketing and promotion

Research (including market research) and product development

Accounting and finance

Information and Technology

Human Resources

Legal courses (IP, patents, etc.)

E-Commerce

Organisational Health and Safety

Job-specific technical training

Language courses

Social skills development

Entrepreneurship related training

Green skills development

Other (please specify)

$\begin{array}{ll}\square & \square \\ \square & \square \\ \square & \square \\ \square & \square \\ \square & \square \\ \square & \square \\ \square & \square \\ \square & \square \\ \square & \square \\ \square & \square \\ \square & \square \\ \square & \square \\ \square & \square \\ \square & \square \\ \square & \square\end{array}$

(Weekly/monthly) know

Q.13.1. Which of this trainingwaslegally required?

\begin{tabular}{|c|c|}
\hline \multicolumn{2}{|c|}{$\begin{array}{l}\text { [SINGLE RESPONSE } \\
\text { [ONLY ASK LINE IF EOUALS “ONE-OFF...” OR "REGULARLY ...” IN O.13.] }\end{array}$} \\
\hline \multicolumn{2}{|c|}{ [ONLY ASK LINE IF EQUALS “ONE-OFF...” OR “REGULARLY...” IN Q.13.] } \\
\hline training / VET & Legal requirement? \\
\hline lanning (including management and leadership training) & $\square$ \\
\hline and promotion & $\square$ \\
\hline cluding market research) and product development & $\bar{\square}$ \\
\hline and finance & 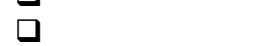 \\
\hline and Technology & $\square$ \\
\hline ources & $\square$ \\
\hline es (IP, patents, etc.) & $\square$ \\
\hline & $\vec{\square}$ \\
\hline nal Health and Safety & $\square$ \\
\hline technical training & $\vec{\square}$ \\
\hline urses & $\vec{\square}$ \\
\hline evelopment & $\square$ \\
\hline Irship related training & $\bar{\square}$ \\
\hline development & $\square$ \\
\hline specify) & $\square$ \\
\hline
\end{tabular}

Industry training / VET

Business planning (including management and leadership training)

Marketing and promotion

Research (including market research) and product development

Accounting and finance

Information and Technology

Human Resources

Legal courses (IP, patents, etc.)

E-Commerce

Organisational Health and Safety

Job-specific technical training

Language courses

Social skills development

Entrepreneurship related training

Green skills development

Other (please specify) 
Q.14. How was the training provided?

Mark as many as apply.

Note: To continue survey, please ensure you also answer the "Other" question.

[SINGLE RESPONSE PER LINE.]

\begin{tabular}{|c|c|c|c|}
\hline $\begin{array}{l}\text { Provision of vocational \& educational training (VET) } \\
\text { programmes\& courses } \\
\text { On-the-Job (during working hours) }\end{array}$ & $\begin{array}{l}\text { All the } \\
\text { time } \\
\square\end{array}$ & $\begin{array}{l}\text { Most of } \\
\text { the time } \\
\square\end{array}$ & $\begin{array}{l}\text { Never } \\
\square\end{array}$ \\
\hline $\begin{array}{l}\text { Off-the-job (training away from the individual's immediate work } \\
\text { position, whether on your premises or elsewhere) }\end{array}$ & $\square$ & $\square$ & $\square$ \\
\hline Within the firm (in-house) & $\square$ & $\square$ & $\square$ \\
\hline Outside the firm (e.g. at an external training provider) & $\square$ & $\square$ & $\square$ \\
\hline By accredited trainers & $\square$ & $\square$ & $\square$ \\
\hline Providing formal (nationally recognised) qualifications & $\square$ & $\square$ & $\square$ \\
\hline Other (please specify) & $\square$ & $\square$ & $\square$ \\
\hline
\end{tabular}

Q.15. What percentage of all your employees participated in training during the past 12 months (approximately)?

High-skillsed occupations: professionals, associate professionals, technical occupations.

Medium-skillsed: administrative, secretarial, skillsed trades, personal services, sales and customer services.

Low-skillsed: routine process, plant and machine operators, elementary occupations such as garbage collectors, food processing workers.

[SINGLE RESPONSE PER LINE.]

Employees in training

Don't

Q.15.1. And of these, what percentage were...

High-medium skillsed

Low skillsed

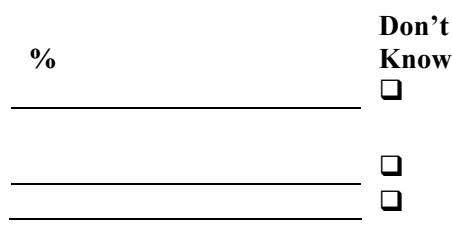

Q.15.2. And of those employees in training, what is the breakdown by age? (approximately)?

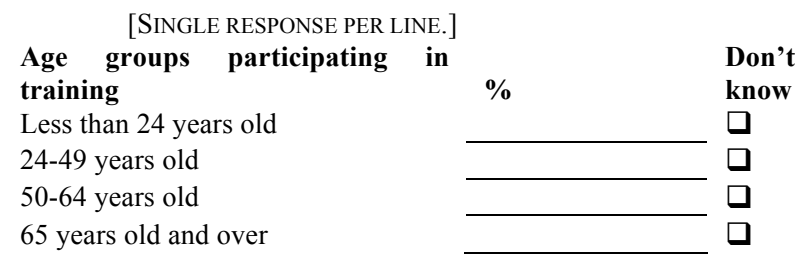


Q.16. In your opinion...

Q.16.1. Did your employees get any of the following outcomes from the training? Please differentiate between high-medium and low skillsed.

[MULTIPLE RESPONSE PER LINE, EXCEPT FOR “NONE”.]

For High-

Outcomes for Employees

medium skillsed For low skillsed None

Improved Skills

Routine skills (basic/repetitive tasks, e.g. packing)

Generic skills (e.g. literacy, numeracy)

Technical/Advanced (problem solving)

Management skills (e.g. business planning, HR

planning)

Social skills (e.g. team work)

Language/cultural skills

Entrepreneurial skills (e.g. risk taking)

Green skills (e.g. adjusting to climate change)

Other outcomes

Employment progression / career advancement

Higher wages

Change job (higher mobility within firm / industry

sector)

Other (please specify)

Q.16.2. Please indicate if you think the training undertaken by your business has led to the following outcomes.

Please differentiate between outcomes for the firm, for the industry sector and for the local area, if known.

[MULTIPLE RESPONSE PER LINE, EXCEPT FOR “DON'T KNOW”.]

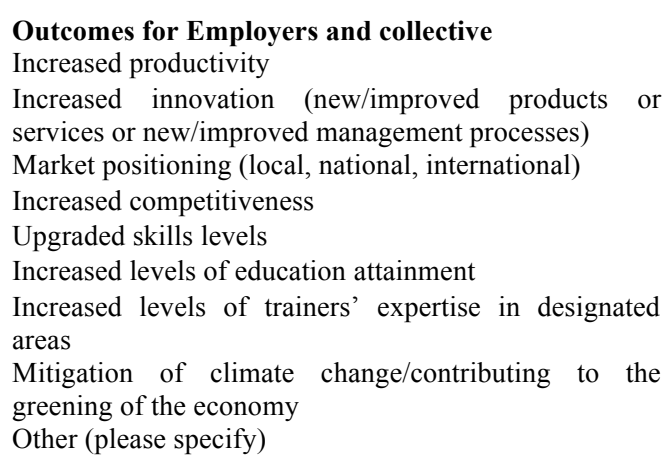

For

For industry For local area Don't business sector (e.g. radius of $20 \mathrm{~km})$ know $\begin{array}{llll}\square & \square & 0 & 0\end{array}$

$\begin{array}{lll}\text { or } & \square & \square\end{array}$

$\begin{array}{lll}\square & a & \square \\ \square & a & \square \\ \square & \square & \square \\ \square & \square & \square \\ \square & \square & \square \\ \square & \square & \square \\ \square & \square & \square \\ \square & \square & \square\end{array}$

Q.17. Where there any training activities that you would have liked to have carried out but did not in the last 12 months?

[SINGLE

RESPONSE.]

[IF “No", SKIP TO SECTION 3]

Don't

Where there any training activities that you would have liked to have carried out

Yes No Know

but did not in the last 12 months? 
Q.17.1. What were the reason(s) that you did not carry out this training?

Please differentiate between medium-high and low skillsed employees (mark as many as apply).

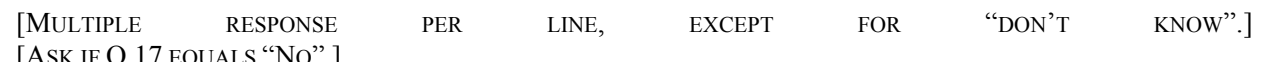

[ASK IF Q.17 EQUALS “No”.]

\section{Barriers to training}

High costs/too expensive

People recruited with skills needed (initial training sufficient)

Lack of public financing

Impossible to interrupt production/no time

Difficult to assess enterprise needs

Staff not willing to participate in training

Training is too difficult to implement

Risk of poaching after training

Too difficult to identify suitable training providers

Too difficult to access training (location; availability at a suitable time)

Other barriers (please specify)

\section{For High-medium} skillsed
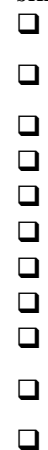

\section{For low skillsed Don't Know}

For low skillsed Don

口 $\square$

口

$\square$

$\square$

$\square$

$\square$

$\square$

口 $\square$
口

a 


\section{SECTION 3 - BUILDING YOUR EMPLOYEES' SKILLS THROUGH OTHER WAYS}

In the previous section you were asked about formal education and training at your firm. This section explores other activities ${ }^{10}$ that may increase the skills, knowledge or competencies of your employees in significant ways. For example, employees may learn significant amounts through interactions with co-workers, suppliers, clients or consultants. Alternatively, projects internal to a firm to improve work processes (such as quality control and product development) might result in staff learning and development. In these situations, the skills, competencies or knowledge gained are not part of recognised education and training programmes that were explored in Section 2.

Q.18. In addition to any training activities that were mentioned previously, did your business carried out, in the past 12 months, any of the following activities which significantly increased the skills, competencies or knowledge of your employees? (Mark as many as apply)

\begin{tabular}{|c|c|c|c|c|c|c|c|}
\hline [SINGLE & & RESPONSE & & PER & & & LINE.] \\
\hline LINE & EQUAL & "ONE-OFF..." & OR & "REGULARLY..." & THEN & ASK & Q.19.] \\
\hline
\end{tabular}

\section{Activities}

Business planning (including management and leadership services, consultancy and advice)

Marketing and promotion services

Research (including market research) and product development

Accounting and finance services

Information and Technology services

Human Resource services

Legal advice and services (IP, patents, etc.)

E-Commerce (e.g. on-line work with clients and suppliers; access to web-based information)

Organisational Health and Safety advice

Job-specific technical activities (e.g. advice on utilisation of new plant or equipment)

Language or communication coaching

Social skills development

Entrepreneurship related activities (e.g. brainstorming about opening new markets or new range of products and services)

Green skills development (e.g.co-operation with other organisations to find ways to adjust production to minimise climate change)

Other (please specify)

$\begin{array}{llll}\text { Did not do } & \begin{array}{l}\text { One-off } \\ \text { (specific } \\ \text { need) }\end{array} & \begin{array}{l}\text { Regularly } \\ \text { (Weekly } \\ \text { monthly) }\end{array} & \begin{array}{l}\text { Don't } \\ \text { know }\end{array} \\ \square & \square & \square & \square \\ \square & \square & \square & \square \\ \square & \square & \square & \square \\ \square & \square & \square & \square \\ \square & \square & \square & \square \\ \square & \square & \square & \square \\ \square & \square & \square & \square \\ \square & \square & \square & \square \\ \square & \square & \square & \square \\ \square & \square & \square & \square \\ \square & \square & \square & \square \\ \square & \square & \square & \square \\ \square & \square & \square & \square \\ \square & \square & \square & \square \\ \square & \square & \square & \square\end{array}$

10 These activities can be defined as informal learning resulting from daily activities related to work that are not organised in terms of objectives, time or learning support (CEDEFOP, 2004). 
Q.19. Please indicate the importance of the following groups in the other activities your business did during the past 12 months?

[SINGLE RESPONSE PER LINE.]

Participants in alternative interacting activities Co-workers

Suppliers

Clients

Business consultants

Competitors

University researchers/consultants

Firms from the same industry clusters

Firms from value-chain*

Industry associations

Government departments

Informal networks

Other (please specify)

$\begin{array}{llll}\begin{array}{l}\text { Little } \\ \text { importance }\end{array} & \begin{array}{l}\text { High } \\ \text { importance }\end{array} & \begin{array}{l}\text { Not } \\ \text { relevant } \\ \square\end{array} & \begin{array}{l}\text { Don't } \\ \text { Know }\end{array} \\ \square & \square & \square & \square \\ \square & \square & \square & \square \\ \square & \square & \square & \square \\ \square & \square & \square & \square \\ \square & \square & \square & \square \\ \square & \square & \square & \square \\ \square & \square & \square & \square \\ \square & \square & \square & \square \\ \square & \square & \square & \square \\ \square & \square & \square & \square \\ \square & \square & \square & \square \\ \square & \square & \square & \square\end{array}$

Q.20. What percentage of all your employees participated in these types of activities during the past 12 months (approximately)?

High-skillsed occupations: professionals, associate professionals, technical occupations. Medium-skillsed: administrative, secretarial, skillsed trades, personal services, sales and customer services.

Low-skillsed: routine process, plant and machine operators, elementary occupations such as garbage collectors, food processing workers.

[SINGLE RESPONSE PER LINE.]

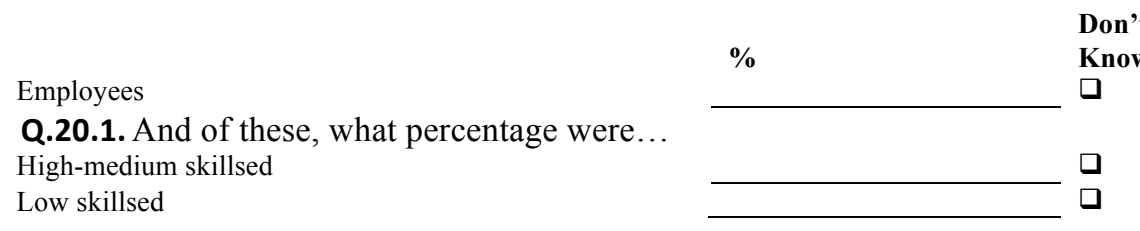

Q.20.2. And of those employees who participated in skills development activities, what is the breakdown by age? (approximately)

[SINGLE RESPONSE PER LINE.]
$\begin{aligned} & \text { Age groups participating in } \\ & \text { training }\end{aligned}$
Less than 24 years old
24-49 years old
50-64 years old
65 years old and over


Q.21. In your opinion, did your employees get any of the following outcomes from participating in these activities (in the short or long term)? Please differentiate between high-medium and low skillsed employees.

[MULTIPLE RESPONSE PER LINE, EXCEPT FOR “NONE”.]

$\begin{array}{llll}\text { Outcomes for Employees } & \begin{array}{l}\text { For } \\ \text { medium skillsed }\end{array} & \text { For low skillsed } & \text { None } \\ \text { Improved Skills } & & \square & \square \\ \text { Routine skills (basic/repetitive tasks, e.g. packing) } & \square & \square & \square \\ \text { Generic skills (e.g. literacy, numeracy) } & \square & \square & \square \\ \text { Technical/Advanced (problem solving) } & \square & \square & \square \\ \text { Management skills (e.g. business planning, HR } & \square & \square & \square \\ \text { planning) } & \square & \square & \square \\ \text { Social skills (e.g. team work) } & \square & \square & \square \\ \text { Language/cultural skills } & \square & \square & \square \\ \text { Entrepreneurial skills (e.g. risk taking) } & \square & \square \\ \text { Green skills (e.g. adjusting to climate change) } & & \square & \square \\ \text { Other outcomes } & \square & \square & \square \\ \text { Employment progression / career advancement } & \square & \square & \square \\ \text { Higher wages } & \square & \square & \square \\ \text { sector) job (higher mobility within firm / industry } & \square & \square & \square \\ \text { Other (please specify) } & \square & \square\end{array}$

Q.22. What do you think were the outcomes of using these activities for your business, the industry sector and the local area?

[MULTIPLE RESPONSE PER LINE, EXCEPT FOR “DON'T KNOW”.]

\section{Outcomes for Employers and collective}

Increased productivity

Increased innovation (new/improved products or services or new/improved management processes)

Market positioning (local, national, international)

Increased competitiveness

Upgraded skills levels

Increased levels of education attainment

Increased levels of trainers' expertise in designated areas

Mitigation of climate change/contributing to the greening of the economy

Other (please specify)
For

For industry For local area Don't

business sector (e.g. radius of $20 \mathrm{~km})$ know

$\begin{array}{llll}\square & \square & \square\end{array}$

口 $\quad \square \quad \square$

$\begin{array}{llll}\square & \square & \square & \square\end{array}$

口

$\square$

口 $\quad$ 口

口 $\quad$ 口 $\quad$ 口 
Q.23. Do you consider any of the activities below to be better sources of learning for staff than formal education and training courses? Please differentiate between high-medium and low skillsed employees.

[MULTIPLE RESPONSE PER LINE, EXCEPT FOR “DON'T KNOW”.]

\author{
Activities \\ Business planning (including management and leadership services, \\ consultancy and advice) \\ Marketing and promotion services \\ Research (including market research) and product development \\ Accounting and finance services \\ Information and Technology services \\ Human Resource services \\ Legal advice and services (IP, patents, etc.) \\ E-Commerce (e.g. on-line work with clients and suppliers; access to \\ web-based information) \\ Organisational Health and Safety advice \\ Job-specific technical activities (e.g. advice on utilisation of new plant \\ or equipment) \\ Language or communication coaching \\ Social skills development \\ Entrepreneurship related activities (e.g. brainstorming about opening \\ new markets or new range of products and services) \\ Green skills development (e.g. co-operation with other organisations to \\ find ways to adjust production to minimise climate change impact) \\ Other (please specify)
}

$\begin{array}{lll}\begin{array}{l}\text { Better for staff who are... } \\ \text { High- } \\ \text { medium } \\ \text { skillsed }\end{array} & \begin{array}{l}\text { Low } \\ \text { skillsed }\end{array} & \begin{array}{l}\text { Don't } \\ \text { know }\end{array} \\ \square & \square & \square \\ \square & \square & \square \\ \square & \square & \square \\ \square & \square & \square \\ \square & \square & \square \\ \square & \square & \square \\ \square & \square & \square \\ \square & \square & \square \\ \square & \square & \square \\ \square & \square & \square \\ \square & \square & \square \\ \square & \square & \square \\ \square & \square & \square \\ \square & \square & \square \\ \square & \square & \square\end{array}$




\section{SECTION 4 - MOTIVATION AND COLLABORATION FOR TRAINING AND SKILLS DEVELOPMENT}

Q.24. What are the reasons for your business to undertake training and skills development activities (industry vocational \& educational training (VET) and/or other activities)? Please specify for "industry training" and "other activities".

[MULTIPLE RESPONSE PER LINE.]

\begin{tabular}{|c|c|c|c|c|}
\hline $\begin{array}{l}\text { Reasons for Training / skills development } \\
\text { activities }\end{array}$ & $\begin{array}{l}\text { Industry } \\
\text { training } \\
\text { /VET courses }\end{array}$ & $\begin{array}{l}\text { Other } \\
\text { activities that } \\
\text { develop skills } \\
\text { and } \\
\text { competencies }\end{array}$ & $\begin{array}{l}\text { Not } \\
\text { Applicable }\end{array}$ & $\begin{array}{l}\text { Don't } \\
\text { Know }\end{array}$ \\
\hline \multicolumn{5}{|l|}{ Public Incentives/Government programmes } \\
\hline International (e.g. EU policies) & $\square$ & $\square$ & & $\square$ \\
\hline $\begin{array}{l}\text { National (country specific government } \\
\text { programmes) }\end{array}$ & $\square$ & $\square$ & & $\square$ \\
\hline Regional (regional programmes) & $\square$ & $\square$ & & $\square$ \\
\hline $\begin{array}{l}\text { Local (council / local government } \\
\text { programmes) }\end{array}$ & $\square$ & $\square$ & & $\square$ \\
\hline $\begin{array}{l}\text { Country regulations (e.g. training levies, } \\
\text { training requirements) }\end{array}$ & $\square$ & $\square$ & & $\square$ \\
\hline \multicolumn{5}{|l|}{$\begin{array}{l}\text { Private Incentives } \\
\text { facilitation/promotion/information } \\
\text { training) }\end{array}$} \\
\hline Collective agreements (trade unions) & $\square$ & $\square$ & & $\square$ \\
\hline Industry sector association services/activities & $\square$ & 口 & & $\square$ \\
\hline Chambers of Commerce services/activities & $\square$ & $\square$ & & $\square$ \\
\hline Industry clusters services/activities & $\overline{0}$ & $\bar{a}$ & & 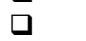 \\
\hline Value-chain firms' activities ${ }^{11}$ & $\overline{0}$ & 口 & & $\square$ \\
\hline Business networks activities & $\square$ & $\square$ & & $\square$ \\
\hline Local networks activities & $\square$ & $\square$ & & $\square$ \\
\hline Foundations activities & 口 & 口 & & 口 \\
\hline \multicolumn{5}{|l|}{ In-house incentives } \\
\hline Production needs & $\square$ & $\square$ & & $\square$ \\
\hline Service requirements & $\square$ & $\square$ & & $\square$ \\
\hline New product / service development & $\bar{\square}$ & $\bar{a}$ & & $\bar{\square}$ \\
\hline Adjustments to financial constraints & $\square$ & $\square$ & & $\square$ \\
\hline Adjustments to climate change impacts & $\overline{0}$ & $\square$ & & $\bar{\square}$ \\
\hline Job/position adjustments & $\square$ & $\square$ & & $\square$ \\
\hline Need to increase employee skills level & 口 & $\bar{\square}$ & & $\square$ \\
\hline Other (please specify) & $\bar{\square}$ & $\vec{\square}$ & & $\bar{\square}$ \\
\hline
\end{tabular}

11 Value-chain: a linked set of activities within a supply chain, involving a number of businesses performing different activities of the process which actively add value to the end product. 
Q.25. This question will help to understand which key training and skills development organisations operate in your area of activity. Could you please cite the organisations with whom your firm/business associate with for training and skills development activities (industry training, vocational \& educational training (VET) and/or other interactive activities)?

[MULTIPLE RESPONSE PER LINE.]

\begin{tabular}{|c|c|c|c|}
\hline Group & Name of organisation/s & $\begin{array}{l}\text { Industry } \\
\text { training/VET } \\
\text { activities }\end{array}$ & $\begin{array}{l}\text { Other } \\
\text { interactive } \\
\text { activities }\end{array}$ \\
\hline $\begin{array}{l}\text { Industry Training Organisations / } \\
\text { Sector Skills Councils }\end{array}$ & & $\square$ & $\square$ \\
\hline Further education colleges & & $\square$ & $\square$ \\
\hline Universities & & $\square$ & $\square$ \\
\hline Trade Unions & & $\square$ & $\square$ \\
\hline Business organisations & & $\square$ & $\square$ \\
\hline Chambers of Commerce & & $\square$ & $\square$ \\
\hline $\begin{array}{l}\text { Firms from value-chain } \\
\text { (suppliers, clients) }\end{array}$ & & $\square$ & 口 \\
\hline Government departments & & $\square$ & $\square$ \\
\hline $\begin{array}{l}\text { Private Consultants and paid } \\
\text { advisors }\end{array}$ & & $\square$ & $\square$ \\
\hline Private training providers & & $\square$ & $\square$ \\
\hline Local councils & & $\square$ & $\square$ \\
\hline Local community organisation & & $\square$ & $\square$ \\
\hline $\begin{array}{l}\text { Other parts of the same } \\
\text { enterprise group (i.e. head office } \\
\text { in a different location) }\end{array}$ & & $\square$ & $\square$ \\
\hline $\begin{array}{l}\text { Other education providers } \\
\text { (please specify...) }\end{array}$ & & $\square$ & $\square$ \\
\hline
\end{tabular}





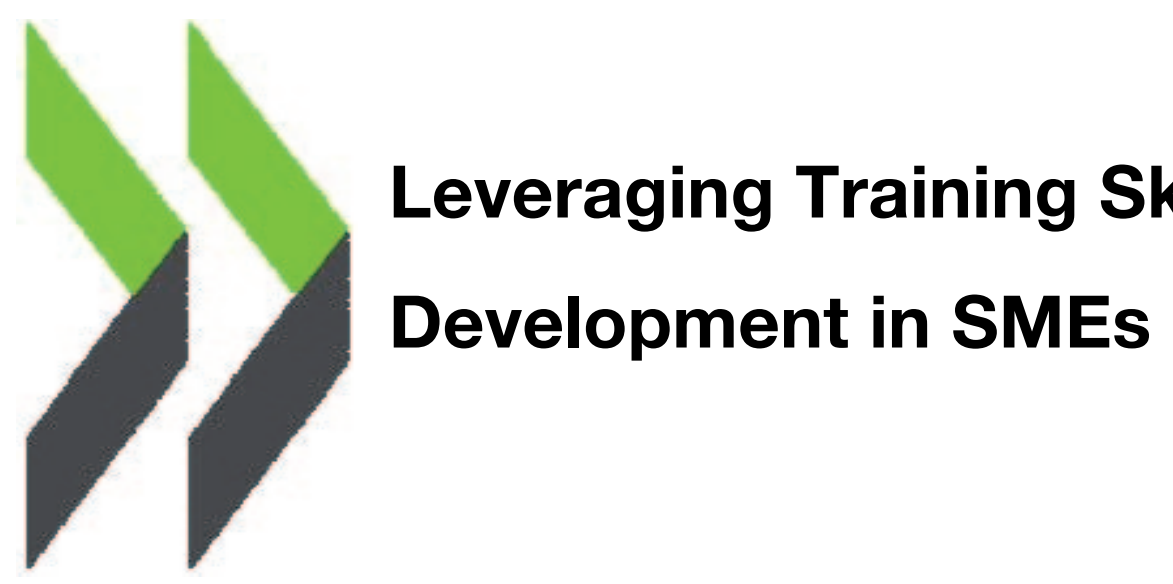

The leveraging training and skills development in SMEs project is an international effort to look at policy issues related to the:

- Low access to training in SMEs

- Barriers encountered by SMEs to training

- Formal and informal ways SMEs access knowledge that is relevant for their

- business operations.

The project examines how formal and alternative ways of training and skills development relate to specific outputs for the firm and employees, for the industry and for the local area where they are located. In particular the role of skills and training ecosystems at the local level is analysed.

Participant countries: New Zealand, United Kingdom, Poland, Belgium (Flanders) \& Turkey. The project is supported by: the European Commission, DG Employment, Social Affairs and Equal Opportunities.
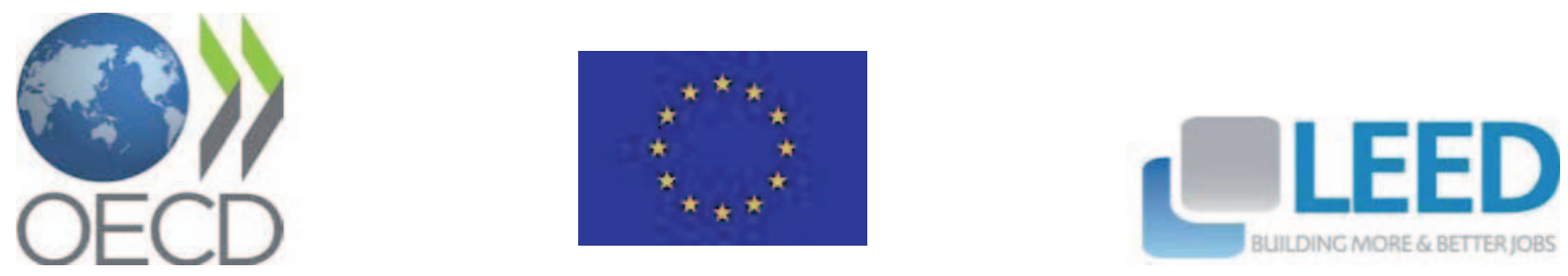